\title{
Die Verschriftlichung des Kriegsalltages. Die Akten der während des Hussitenkrieges in Znaim und Iglau stationierten österreichischen Söldner
}

\author{
Writing Everyday War: The Papers of the Austrian Mercenaries \\ Garrisoned in Znojmo and Jihlava during the Hussite War
}

Petr Elbel / elbel@phil.muni.cz

Ústav pomocných věd historických a archivnictví, Filozofická fakulta, Masarykova univerzita, Brno, CZ

\begin{abstract}
The present paper uses two case studies to scrutinize the many different documents emanating from the administrative needs of late medieval mercenaries and their employers. The analyzed documents come from the Moravian towns of Jihlava and Znojmo, both of which Duke Albert of Austria held in pledge during the Hussite War. The corpus consists mostly of receipts issued by the mercenaries confirming received pay, and documents, which pertain to transactions concerning compensations for damages. The sources are first classified and analyzed from the point of view of medieval diplomatics. Secondly, the study tries to reconstruct the overall expenditure for the Austrian garrisons in Jihlava and Znojmo. Thirdly, the paper discusses fruitful areas for further research based on the presented sources.
\end{abstract}

\section{Keywords}

Mercenaries; Hussite War; Jihlava; Znojmo; Duke Albert V of Austria

\footnotetext{
Der vorliegende Aufsatz entstand im Rahmen des von der Grantová agentura České republiky/Czech Science Foundation geförderten Forschungsprojektes GX19-28415X "From Performativity to Institutionalization: Handling Conflict in the Late Middle Ages (Strategies, Agents, Communication)." Der Autor dankt Dr. Alexandra Kaar (Prag - Wien) für sprachliche Korrekturen sowie Mag. Thomas Just, MAS und MMag. Kathrin Kininger (Österreichisches Staatsarchiv, Wien) für die freundliche Unterstützung.
} 


\section{Einleitung}

Im späten Mittelalter kam es zu einer allmählichen Verschriftlichung der Kriegsführung und des gesamten Kriegsalltages. Zu Beginn dieses Prozesses war Krieg grundsätzlich von mündlicher und symbolischer Kommunikation geprägt; an dessen Ende stark formalisiert und von unzähligen Erzeugnissen der pragmatischen Schriftlichkeit gerahmt. Der Grund für diese Verschriftlichung dürfte vor allem im wachsenden Einsatz professioneller Söldnertruppen gelegen haben, die das gesamte Kriegsgeschäft nicht nur stark kapitalisierten, sondern eben auch verschriftlichten und bürokratisierten. Beides hing offensichtlich eng zusammen, da das Vordringen kaufmännischer Mentalitäten zwangsläufig auch Bedarf nach einer nachvollziehbaren und geordneten Rechnungsführung generierte.

Im vorliegenden Beitrag werde ich Erzeugnisse der pragmatischen Schriftlichkeit analysieren, die im Zusammenhang mit dem spätmittelalterlichen Söldnerwesen entstanden sind. In den vergangenen Jahrzehnten mangelte es nicht an Publikationen zu diesem Thema. ${ }^{1}$ Im Unterschied zur Mehrzahl dieser Autoren, die die vorhandenen Quellen hauptsächlich unter militärhistorischen, sozial- und wirtschaftsgeschichtlichen Perspektiven auswerteten, werde ich die untersuchten Schriftstücke, welche sich in einer Grauzone zwischen Urkunden, Akten und Amtsbüchern bewegen, vor allem unter diplomatischen Gesichtspunkten betrachten. Dabei werde ich zwei klar umgrenzte Quellenkomplexe besprechen, die aus der Tätigkeit der vorwiegend österreichischen Söldner hervorgegangen sind, welche Herzog Albrecht V. während des Hussitenkrieges in Iglau und Znaim einsetzte.

Einleitend muss kurz angemerkt werden, dass die beiden genannten landesherrlichen Städte gemeinsam mit Brünn und Olmütz zu den hauptsächlichen Stützen der katholischen Partei in Mähren zählten und noch während der kurzen dortigen Regierung König Sigismunds (1419-1423/1424), konkret im Sommer 1421, gemeinsam mit der böhmischen Stadt Budweis und zwei kleineren mährischen Städten an Sigismunds künftigen Schwiegersohn Albrecht verpfändet wurden, um die Kosten von dessen Teilnahme an den ersten Hussitenkreuzzügen in Höhe von nicht weniger als 200.000 ungarischen Gulden zu besichern. ${ }^{2}$ Im Herbst 1421 wurden auf dieselben Städte noch Heimsteuer

1 Für das Söldnerwesen in und rund um Böhmen im 15. Jahrhundert siehe vor allem die Editionen und Arbeiten Uwe Tresps, die teilweise in Zusammenarbeit mit anderen Historikern entstanden: Heimann, Heinz-Dieter - Tresp, Uwe (Hg.): Thüringische und böhmische Söldner in der Soester Fehde. Quellen zum landesherrlichen Militärwesen im 15. Jahrhundert aus thüringischen und sächsischen Archiven. Potsdam 2002; Šimůnek, Robert - Tresp, Uwe: Beiträge zur Praxis des spätmittelalterlichen böhmischen Söldnerwesens. Das Söldnerwesen der Herren von Rosenberg um die Mitte des 15. Jahrhunderts. Die Söldnerwerbungen Herzog Ludwigs des Reichen von Bayern-Landshut in Böhmen (1459-1462) - mit Prosopographie. Táborský archiv 10, 2000-2001, S. 73-174; Tresp, Uwe: Ein Beispiel für Anwerbung, Kosten und Rechtspraxis böhmischer Söldnerheere in der Mitte des 15. Jahrhunderts. Die böhmischen Söldner Herzog Wilhelms III. von Sachsen. Mediaevalia Historica Bohemica 8, 2001, S. 169-201; ders.: Söldner aus Böhmen im Dienst deutscher Fürsten. Kriegsgeschäft und Heeresorganisation im 15. Jahrhundert. Krieg in der Geschichte 19. Paderborn - München - Wien - Zürich 2004.

2 Die Verpfändung von Budweis, Iglau, Znaim, Jamnitz/Jemnice und Pohrlitz/Pohořelice wurde im Rahmen des zwischen Sigismund und Albrecht am 7. Juli 1421 in Theben/Devín geschlossenen Bündnisvertrages, der in Haus-, Hof- und Staatsarchiv (= HHStA) Wien, Codex 13 weiß, „Österreichisches Diplo- 
und Widerlegung für Sigismunds Tochter Elisabeth in Höhe von jeweils 100.000 Gulden hinzugeschlagen. ${ }^{3}$ Albrecht übernahm die verpfändeten Städte erst um die Jahreswende 1421/1422. ${ }^{4}$ Im Oktober 1423 bekam er zusammen mit seiner Gemahlin von Sigismund die gesamte Markgrafschaft Mähren geschenkt, was als eine Art Kompensation für die nur ungenügend besicherten Heimsteuer betrachtet werden kann. ${ }^{5}$ Im Februar 1424 übernahm Albrecht dann tatsächlich die Herrschaft in Mähren. ${ }^{6}$ Die schon früher verpfändeten Städte, Znaim und Iglau eingeschlossen, blieben jedoch bis zu Albrechts Tod formal aus Mähren ausgegliedert und sein Pfand in seiner Eigenschaft als Herzog von Österreich. ${ }^{7}$

Die hier bearbeiteten Quellen zu Herzog Albrechts Söldnern in Iglau entstanden in den Jahren 1422 und 1423, d. h. noch vor dessen Regierungsantritt als Markgraf von Mähren; jene aus Znaim stammen aus den Jahren 1429-1431. Da sich der rechtliche Charakter der Herrschaft Albrechts in den beiden Städten Anfang 1424 kaum änderte (es handelte sich jeweils um Pfandherrschaften des Herzogs von Österreich, obwohl dieser ab 1424 auch das übrige Land als Landesfürst regierte), unterschied sich die Administration der Söldnertruppen in beiden Städten nur wenig. Vor allem unterstand sie nach wie vor der österreichischen herzoglichen Kammer und deren Leiter, dem österreichischen Hubmeister. ${ }^{8}$

matar 1353-1441“, fol. 109r-112r, überliefert ist, vereinbart. Siehe dazu Rudolf, Karl: Die Markgrafschaft Mähren und Herzog Albrecht V. von Österreich. Salzburg 1973 (ungedruckte Diss.), S. 80-85; Elbel, Petr - Bárta, Stanislav - Ziegler, Wolfram: Die Heirat zwischen Elisabeth von Luxemburg und Herzog Albrecht V. von Österreich. Rechtliche, finanzielle und machtpolitische Zusammenhänge (mit einem Quellenanhang). In: Kras, Paweł - Nodl, Martin (Hg.): Manželství v pozdním středověku: rituály a obyčeje. Colloquia mediaevalia Pragensia 14. Praha 2014, S. 79-152, hier S. 103-105.

3 Siehe den Heiratsvertrag vom 28. September 1421, neue Edition bei Elbel, P. u.a.: Die Heirat, S. 142-145, Nr. 5; siehe dazu ebd., S. 111-116.

4 Siehe das Mandat Sigismunds an den Stadtrat von Znaim vom 8. Dezember 1421, Iglau, in dem der König der Stadt gebietet, seinem Schwiegersohn zu huldigen, so wie es die Iglauer gerade getan hätten - siehe Elbel, Petr (Bearb.): Die Regesten Kaiser Sigismunds (1410-1437) nach Archiven und Bibliotheken geordnet. Hg. von Karel Hruza. 1. Die Urkunden und Briefe aus den Archiven Mährens und Tschechisch-Schlesiens. Wien - Köln - Weimar 2012, S. 143-144, Nr. 84. Die Znaimer huldigten Albrecht Anfang 1422, als die Stadt eine große Huldigungsgesandtschaft nach Wien abordnete. Dazu siehe Elbel, Petr: Pobyty vyslancu a posli̊ města Znojma na dvoře krále Zikmunda a rakouského vévody Albrechta V. ve svètle znojemských městských úctů z let 1421-1422. Př́spěvek k dvorské každodennosti [Die Aufenthalte von Gesandten und Boten der Stadt Znaim am Hof König Sigismunds und Herzog Albrechts V. von Österreich im Licht der Znaimer Stadtrechnungen der Jahre 1421-1422. Ein Beitrag zur höfischen Alltagsgeschichte]. In: Dvořáčková-Malá, Dana - Zelenka, Jan (Hg.): Dvory a rezidence ve středověku III. Všední a sváteční život na středověkých dvorech. Mediaevalia Historica Bohemica, Supplementum 3. Praha 2009, S. 475-502, hier S. 489 und 498.

5 Siehe die Schenkungsurkunde vom 1. Oktober 1423, Ofen/Buda, Edition bei Bretholz, Bertold: Die Übergabe Mährens an Herzog Albrecht V. von Österreich im Jahre 1423 (Beiträge zur Geschichte der Hussitenkriege in Mähren). Archiv für österreichische Geschichte 80, 1893, S. 249-349, hier S. 346-349, Nr. XVI; siehe dazu Elbel, P. u.a.: Die Heirat, S. 130-133.

6 Die Trebitscher Fortsetzung der Kosmas'schen Chronik datiert die Herrschaftsübernahme Albrechts in Mähren zum 4. Februar 1424 - siehe Meinert, Johann Georg: Die Tribauer Handschrift. Archiv für Geographie, Historie, Staats- und Kriegskunst 10, 1819, S. 65-66, 90-92, 100-103, hier S. 92.

7 Die oben zitierte Schenkungsurkunde vom 1. Oktober 1423 (siehe Anm. 5) nimmt die verpfändeten Städte ausdrücklich aus dem geschenkten Land aus.

8 In diesem Zusammenhang stellt sich die Frage, ob die übrigen mährischen Städte ab 1424 ebenfalls zur österreichischen Kammer ressortierten, oder ob dort einer der mährischen Amtsträger Herzog Albrechts 
Beide Quellenkomplexe sind schon lange bekannt, aber nur teilweise publiziert und ausgewertet. Das Iglauer Quellenkorpus besteht aus insgesamt 28 Urkunden: neben je einem herzoglichen Schadlosbrief und einem Mandat blieben 26 Quittungen der Iglauer Hauptleute und einzelner Söldner erhalten. ${ }^{9}$ Diese Urkunden wurden bereits durch Joseph Beck und Johann Loserth teils im Volltext, teils auszugsweise ediert. ${ }^{10}$ Eine kurze historische Analyse lieferte František Hoffmann in seiner Monografie über die Geschichte Iglaus während der Hussitischen Revolution. ${ }^{11}$

Das Znaimer Quellenkorpus ist bisher nur teilweise zugänglich. Es handelt sich um ein bis dato unveröffentlichtes Register mit Forderungen der Söldner vom November $1429,{ }^{12}$ und 33 Quittungen, fünf verschlossene Briefe und etliche Zettel der Hauptleute und Söldner, ${ }^{13}$ die größtenteils in den Quellen zur Geschichte der Stadt Wien in Regestenform publiziert wurden. ${ }^{14}$

Wie bereits angedeutet werde ich auf den folgenden Seiten versuchen, die beiden Quellenkorpora vor allem diplomatisch einzuordnen. Am Ende des Aufsatzes kann ich nur eine vorläufige historische Auswertung dieser Quellen bieten, welche vor allem auf finanzgeschichtliche Aspekte eingeht; weitere Möglichkeiten der historischen Auswertung können lediglich angedeutet werden. ${ }^{15}$

für die Entlohnung der Söldner zuständig war. Man könnte z. B. an den mährischen Unterkämmerer denken, der nachweislich die dem Landesherrn gebührenden Abgaben in der Markgrafschaft einhob. Diese Frage lässt sich hier jedoch nicht beantworten, auch weil aus den übrigen mährischen Städten offenbar keine vergleichbaren Quellen überliefert sind.

9 HHStA Wien, Allgemeine Urkundenreihe (= AUR), 1422 IV 22 (ein Schadlosbrief mit 25 beigelegten Quittungen); 1423 I 25 (eine weitere Quittung); 1423 IV 27 (ein Mandat Herzog Albrechts).

10 Beck, Joseph Ritter von - Loserth, Johann: Urkundliche Beiträge zur Geschichte der hussitischen Bewegung und der Hussitenkriege mit besonderer Berücksichtigung Mährens und der mährisch-hussitischen Söldner. Notizenblatt des Vereines für die Geschichte Mährens und Schlesiens 1896, Heft 7-8, S. 115-120; Heft 11-12, S. 177-181; Zeitschrift des Vereines für die Geschichte Mährens und Schlesiens 1, 1897, Heft 2, S. 56-73. Einige dieser Urkunden wurden später auch in Regestenform publiziert - siehe Lampel, Josef (Hg.): Quellen zur Geschichte der Stadt Wien. I. Abteilung. Regesten aus In- und ausländischen Archiven mit Ausnahme des Archives der Stadt Wien. 7. Regesten aus dem Haus-, Hof- und Staatsarchive zu Wien. Wien 1923 (= QGStW I/7), S. 3-12, Nr. 14363, 14374-14375, 14377-14380, 14382-14385, 14387, 14389, 14401. Weiter unten werden lediglich die Originalurkunden und die Edition, nicht aber die Regesten zitiert. Eine Konkordanz mit den QGStW siehe in der Tabelle 1 im Anhang.

11 Hoffmann, František: Jihlava v husitské revoluci [Iglau in der Hussitischen Revolution]. Havlíčkův Brod 1961, S. 153-161. Hoffmann interessierte sich hauptsächlich für die Stärke der herzoglichen, aber auch der städtischen Söldnertruppen und die mit den Söldnern verbundenen finanziellen Aufwendungen.

12 HHStA Wien, AUR, 1429 XI 09. Es handelt sich um ein schmales, längliches Heft mit 18 (bzw. 17 nummerierten) Folien. Kurz, Franz: Österreich unter K. Albrecht dem Zweyten. 2. Wien 1835, S. 339-344, Beilage XXV, hier S. 339-341, druckte lediglich kurze Passagen daraus.

13 HHStA Wien, AUR, jeweils sub dato (einige Quittungen und Briefe und sämtliche Zettel werden jedoch als Beilagen zu anderen Schriftstücken, d. h. also nicht unter ihrem jeweils eigenen Datum aufbewahrt).

14 QGStW I/7, S. 42-54, Nr. 14531-14536, 14541-14548, 14552, 14554-14556, 14559-14563, 14565-14568, 14573-14574. Ein Brief, zwei Quittungen und ein Zettel wurden auch bei Kurz, F.: Österreich unter K. Albrecht, 2, S. 339-344, Beilage XXV, hier S. 341-344, abgedruckt. Vier Briefe und drei Quittungen sind bis dato unediert. Während die Quellen aus Iglau bereits summarisch ausgewertet wurden (Hoffmann, F.: Jihlava, S. 153-161), wurde der viel umfangreichere Quellenkorpus aus Znaim von der Forschung kaum berücksichtigt.

15 In diesem Zusammenhang plane ich eine weitere Publikation. 


\section{Beschreibung und diplomatische Analyse der Quellen}

\subsection{Das Iglauer Quellenkorpus}

Beginnen wir mit der diplomatischen Einordnung der Iglauer Urkunden. Wie bereits angedeutet, wird das Iglauer Quellenkorpus von einem Schadlosbrief eröffnet, den Herzog Albrecht am 22. April 1422 für jene Söldner ausstellte, die yecz zu der Igla in unserm dienst und sold sind, es sein Deutsch oder Behem. ${ }^{16}$ Von der äußeren Form her handelt es sich um litterae patentes auf Pergament mit verso aufgedrücktem herzoglichen Sekretsiegel. Die Urkunde wurde später eindeutig kassiert.

Als Schadlosbriefe werden im Zusammenhang mit dem spätmittelalterlichen Söldnerwesen unterschiedliche Arten von Schriftstücken bezeichnet, darunter oft auch Stücke, die man eher als Werbe- oder Bestellbriefe ansprechen sollte, da sie primär die Rahmenbedingungen definieren bzw. das Dienstverhältnis konstituieren, wobei sie $\mathrm{u}$. a. auch die Verpflichtung des Kriegsherrn beinhalten, den Angeworbenen erlittene Schäden zu ersetzen. In unserem Fall handelt es sich jedoch um einen reinen Schadlosbrief, der erst einige Zeit nach der Stationierung der österreichischen Garnison in Iglau die Abwicklung des Schadenersatzes genauer regelte. ${ }^{17}$ Die Urkunde legt fest, dass jene Schäden, die die Söldner unter Albrechts Hauptmann im herzoglichen Dienst erlitten (was si in unserm dienste von den veinden redleicher und ritterleicher schëden nemen nach unsers haubtmanns geschêft, wissen und willen) und die dem Herzog ordnungsgemäß durch den Hauptmann gemeldet wurden (die uns derselb unser haubtman wissentleich gemachen mag an geverde), nach Anerkennung durch die herzoglichen Räte unverzüglich ersetzt werden sollten (daz wir si darumb furderleich auzrichten und beczalen sullen und wellen nach unserr rèt rat und erkantnusse ungevearleich).

An den Schadlosbrief knüpfen mit einem längeren - mehr als ein halbes Jahr - zeitlichen Abstand die 26 Quittungen an, die zwischen dem 21. Dezember 1422 und dem 21. November 1423 ausgestellt wurden. Von ihrer äußeren Form her handelt es sich fast ausschließlich um litterae patentes auf Papier mit verso oder recto aufgedrückten Siegeln; nur in einem Fall haben wir es mit einer Pergamenturkunde mit anhängenden Siegeln zu tun.

Inhaltlich lassen sich unter den Quittungen zwei Gruppen unterscheiden. Die erste Gruppe bilden Quittungen über ausbezahlten Sold, die eigentlich unabhängig von dem oben zitierten Schadlosbrief sind. ${ }^{18}$ Diese insgesamt zwölf Urkunden wurden - bis auf eine Ausnahme - durch den jeweiligen Iglauer Hauptmann - Matthias von Rohr, Düring von Hallwyl und schließlich Wilhelm Waldner - ausgestellt, welcher den Sold für

16 HHStA Wien, AUR, 1422 IV 22; siehe Beck, J. - Loserth, J.: Urkundliche Beiträge, 1897, S. 72, Nachtrag Nr. 8.

17 Das genaue Datum der Einlage einer österreichischen Besatzung nach Iglau bleibt unbekannt, sie dürfte jedoch bald nach der Übernahme der verpfändeten Stadt durch Albrecht um die Jahreswende 1421/1422 erfolgt sein.

18 Wahrscheinlich gab es auch noch einen Werbe- bzw. Bestellbrief des Hauptmanns von Iglau, in welchem die Höhe des Soldes geregelt wurde. 
alle oder die meisten der in Iglau stationierenden Söldner übernommen haben dürfte. Interessanterweise datieren diese Quittungen alle in Iglau. Sie sind unabhängig von der Person des Hauptmanns nach einem einheitlichen Formular konzipiert und wurden durch eine sehr charakteristische Schreiberhand mundiert. Möglicherweise handelte es sich um den Stadtschreiber oder einen seiner Hilfsschreiber, was jedoch noch im Iglauer Archiv überprüft werden müsste. ${ }^{19}$ Andernfalls könnte es sich um einen Schreiber des Hauptmanns handeln, was allerdings bedeuten würde, dass die Hauptleute ihren Schreiber jeweils an ihren Amtsnachfolger „weiterreichten“.20

Das Formular dieser Quittungen ist durchgängig wie folgt aufgebaut: der Hauptmann führt in der Narratio an, er habe für das laufende halbe Quartal (i. e. ein Achteljahr bzw. sechseinhalb Wochen) eine bestimmte Anzahl von Reitern und/oder Fußsoldaten in Iglau unter Sold, wobei jedem Reiter für diesen Zeitraum 5 Gulden und jedem Fußsoldaten 2 Pfund, 3 Schilling und 15 Pfennig (i. e. 3 Gulden, 1 Schilling und 15 Pfennig) zuständen. ${ }^{21}$ Daraus ergäbe sich eine bestimmte Gesamtsumme an Sold. In der anschließenden Dispositio bekennt der Hauptmann, der Herzog habe ihm diese Summe ausbezahlt, weshalb der Hauptmann ihn für quitt und los erklärt.

Von diesem Schema wird nur geringfügig abgewichen, vor allem in einer Quittung Dürings von Halwyll vom 21. Februar 1423, in der neben dem Sold für 200 Reiter für das laufende halbe Quartal auch die zusätzliche Besoldung einer Truppe Jörgs von Teuffenbach 14 Tage vor diesem Zeitraum quittiert wird (so ist auch hie innbegriffen, das der Tewffenpacher mit zwainczick pherden vierczechen tag gediennt hat, ee dann sich die halb quatember hat angefangen... .). ${ }^{22}$ Der mutmaßliche Grund für diese Unregelmäßigkeit wird unten noch näher behandelt.

Sonst aber schließen die Quittungen der Hauptleute fast nahtlos aneinander an, wobei es in der Regel separate Quittungen für Berittene und Fußsoldaten gibt. Letztere werden meist als Südtiroler (von der Etsch) bezeichnet. Die Anzahl der Söldner schwankt bzw. geht mit der Zeit zurück. Anfang 1423 waren in Iglau 213 Reiter und 60 Fußsoldaten von der Etsch stationiert, ${ }^{23}$ im Februar 200 Reiter und 100 Fußsoldaten, ${ }^{24}$ im April

19 Die für diesen Zweck erforderlichen Recherchen im Staatlichen Bezirksarchiv Iglau konnten leider im Zuge der Vorbereitung dieses Aufsatzes nicht durchgeführt werden.

20 Darauf, dass dieser Schreiber eher zum Gefolge des Hauptmanns als zur städtischen Kanzlei gehörte, deutet die Tatsache hin, dass derselbe Schreiber am 26. September 1423 in Wien eine Urkunde für den ehemaligen Iglauer Hauptmann Düring von Halwyll ausfertigte. Dies spricht eher gegen einen Angehörigen der städtischen Kanzlei. HHStA Wien, AUR, 1422 IV 22, siehe Beck, J. - Loserth, J.: Urkundliche Beiträge, 1896, S. 180, Nr. 31. Vor und nach der besagten Urkunde, d. h. am 22. August bzw. am 7. Oktober, fertigte er für Dürings Nachfolger Wilhelm Waldner in Iglau Quittungen aus - HHStA Wien, AUR, 1422 IV 22, siehe Beck, J. - Loserth, J.: Urkundliche Beiträge, 1896, S. 180, Nr. 30; S. 181, Nr. 32.

21 Die Umrechnung der Wiener Pfennige (1 Pfund = 8 Schilling = 240 Pfennige/Denare) in ungarische Gulden folgt dem in den Jahren 1423-1435 üblichen Wechselkurs: 1 Gulden $=6$ Schilling.

22 HHStA Wien, AUR, 1422 IV 22; siehe Beck, J. - Loserth, J.: Urkundliche Beiträge, 1896, S. 118-119, Nr. 13.

23 Zwei Quittungen Matthias' von Rohr vom 7. Januar 1423 in HHStA Wien, AUR, 1422 IV 22; siehe Beck, J. - Loserth, J.: Urkundliche Beiträge, 1896, S. 117, Nr. 9 und 10.

24 Zwei Quittungen Dürings von Hallwyl vom 21. Februar 1423 in HHStA Wien, AUR, 1422 IV 22; siehe Beck, J. - Loserth, J.: Urkundliche Beiträge, 1896, S. 118-119, Nr. 13; S. 119, Nr. 14. 
212 Reiter und 100 Fußsoldaten. ${ }^{25}$ Im Mai waren es immer noch 200 Reiter, aber nur noch 50 Fußsoldaten. ${ }^{26}$ In den Sommermonaten sank die Anzahl der Reiter auf 177 bzw. $171,{ }^{27}$ im Herbst auf nur mehr 102. ${ }^{28}$ Quittungen über die Besoldung von Fußsoldaten gibt es seit Mai 1423 nicht mehr, was natürlich nicht unbedingt heißt, dass es in Iglau keine solchen mehr gab.

Einen Sonderfall bildet die Quittung Jörgs von Teuffenbach, Jörg Pairhofers und Andre Lugasters vom 21. Dezember 1422 für den Sold ihrer Rotte von 130 Reitern, die ab Datum der Urkunde bis zum 4. Februar 1423 in den böhmischen oder mährischen Schlössern Herzog Albrechts dienen sollten (als wir uns mitsambt unsern gesellen, die wir bë̈ uns in unsrer rot haben, gegen dem hochgeboren fürsten, herczog Albrechten, herczogen ze Osterreich etc., unserm genädigen herren, verfangen haben, in seinen geslossen ze Bechem oder ze Merchern ze halden hundert und dreisczickk werleicher ze rossen auf ain halbe quatember, die sich wirt enden des phincztags nach Unsrer Frawn tag der liechtmess schierist künftig) ${ }^{29}$ František Hoffmann war der Auffassung, dass es sich bei den drei Genannten um die Vorgänger Matthias' von Rohr in der Iglauer Hauptmannschaft gehandelt hätte. ${ }^{30}$ Das ist jedoch wenig wahrscheinlich, da die Abrechnungsperiode der drei Söldnerführer größtenteils mit der des Matthias von Rohr übereinstimmt. Es scheint vielmehr, dass Anfang 1423 in Iglau 213 Reiter unter dem Kommando des Hauptmannes und daneben noch zusätzlich eine 130 Mann starke Rotte unter dem Kommando Teuffenbachers, Pairhofers und Lugasters oder zumindest ein Teil dieser Rotte stationiert waren, von welcher aber im Frühling nur noch 20 Reiter unter Teuffenbacher in Iglau verblieben, welche dann direkt dem Kommando des Hauptmanns unterstellt wurden, der in seiner Quittung auch über ihren Sold abrechnete; diese Abrechnung erstreckte sich auch auf die 14 Tage vor Matthias von Rohrs laufender Abrechnungsperiode (was auch dessen untypische Quittung vom 21. Februar 1423 erklären würde).

25 Zwei Quittungen Dürings von Hallwyl vom 8. April 1423 in HHStA Wien, AUR, 1422 IV 22; siehe Beck, J. - Loserth, J.: Urkundliche Beiträge, 1896, S. 177, Nr. 19 und 20.

26 Eine Quittung Dürings von Hallwyl (gemeinsam für Reiter und Fußsoldaten) vom 23. Mai 1423 in HHStA Wien, AUR, 1422 IV 22; siehe Beck, J. - Loserth, J.: Urkundliche Beiträge, 1896, S. 178, Nr. 24.

27 Eine Quittung Wilhelm Waldners vom 8. Juli und eine andere vom 22. August 1423 in HHStA Wien, AUR, 1422 IV 22; siehe Beck, J. - Loserth, J.: Urkundliche Beiträge, 1896, S. 179, Nr. 27; S. 180, Nr. 30.

28 Eine Quittung Wilhelm Waldners vom 7. Oktober 1423 in HHStA Wien, AUR, 1422 IV 22; siehe Beck, J. - Loserth, J.: Urkundliche Beiträge, 1896, S. 181, Nr. 32. Die rasante Abnahme der Zahl der Söldner Anfang Oktober dürfte mit einem Scharmützel zwischen der Iglauer Besatzung und dem Feldheer Jan Žižkas vor der Stadtmauer zusammenhängen, bei dem Duzende Söldner zu Tode gekommen sein sollen - siehe Hoffmann, F.: Jihlava, S. 172-173.

29 HHStA Wien, AUR, 1422 IV 22; siehe Beck, J. - Loserth, J.: Urkundliche Beiträge, 1896, S. 118-119, Nr. 13.

30 Hoffmann, F.: Jihlava, S. 160: „Mezi jihlavskými hejtmany byli přední Albrechtovi velitelé. V r. 1422 a 1423 se jich vystř́dalo několik. Po G. Tewffenpacherovi, J. Pairhoferovi a A. Lugasterovi, kteří měli v Jihlavě společně rotu jízdných, byl v Jihlavě po 3 měsíce následujícího roku Mathias z Roru..." [PE: Unter den Iglauer Hauptleuten begegnen wir vornehmen Feldherren Herzog Albrechts. In den Jahren 1422 und 1423 lösten sich einige ab. Nach G. Tewffenpacher, J. Pairhofer und A. Lugaster, die in Iglau gemeinsam eine Rotte zu Ross kommandierten, folgte für die ersten drei Monate des Folgejahres Matthias von Rohr...]. 
Die zweite Gruppe bilden Quittungen über Schadenersatz. Diese Stücke wurden durch einzelne Söldner bzw. kleinere oder auch größere Söldnergruppen meist in Wien, einmal auch in Eggenburg ausgestellt. Aus dem Ausstellungsort geht hervor, dass die Söldner ihre erlittenen Schäden am Herzogshof anzeigten und dort über die Höhe des Schadenersatzes verhandelten, was in den Urkunden ggf. auch direkt angeführt wird (z. B. ...als ich das des obgenanten meins gnedigen herren reten aigentleich erczelt han... $\left.{ }^{31}\right)$. Dass die herzoglichen Räte bei der Festlegung der Schadenersatzhöhe eine entscheidende Rolle spielten, ergibt sich auch aus dem oben besprochenen Schadlosbrief vom 22. April 1422.

Das Formular der Schadenersatzquittungen ist ebenfalls sehr gleichförmig. Variabel ist die Anzahl der Aussteller, die zwischen einer und neun Personen schwankt, in einem Sonderfall jedoch sogar 28 Personen umfasst. ${ }^{32}$ In der Narratio sind die Schäden, die die Aussteller im Sold und Dienst Herzog Albrechts in Iglau erlitten hatten, manchmal nur allgemein erwähnt, manchmal aber näher beschrieben (z. B. ...als ich in des hochgeboren fürsten herczog Albrechts [...] dienst, die czeit und ich sein soldnér gewesen bin, mitsambt andern seinen dienern zu der Igla von den Hussen gevangen worden bin und wann ich von derselben vênknüss wegen schéden genomen hab... $\left.{ }^{33}\right)$. Dann wird angeführt, dass der Herzog dem Aussteller die Schäden vollkommen ersetzt habe, wobei nur in einem Fall an dieser Stelle auch die Höhe des Schadenersatzes angegeben wird. ${ }^{34}$ Erst danach folgt die kurze Dispositio, in welcher der Aussteller den Herzog für quitt und los erklärt und sich dabei meist ausdrücklich verpflichtet, den Herzog und dessen Länder nie wieder aufgrund der genannten Schäden zu behelligen. ${ }^{35}$ Sehr variabel ist die Corroboratio, in welcher entweder das Siegel des Ausstellers, oder aber das Siegel eines bzw. mehrerer zugezogener Siegler angekündigt wird (die Corroboratio ist im Anschluss oft mit einer Schadlosformel versehen). Das Eschatokol bildet eine meist leicht gekürzte Datierung.

Da die Höhe des anerkannten Schadenersatzes im eigentlichen Urkundentext zumeist fehlt, wurde sie in der Regel entweder durch den Urkundenschreiber oder durch eine

31 Siehe die Quittung Ulrich Močihubs von Kralovice vom 30. Januar 1423, Wien, in HHStA Wien, AUR, 1422 IV 22; Beck, J. - Loserth, J.: Urkundliche Beiträge, 1896, S. 118, Nr. 12.

32 In einem Fall ist der Aussteller zwar lediglich ein einzelner Söldner, Jörg Teuffenbacher, der jedoch auch im Namen seines Bruders Mert urkundet. Siehe die Quittung vom 28. März 1423, Wien, in HHStA Wien, AUR, 1422 IV 22; Beck, J. - Loserth, J.: Urkundliche Beiträge, 1896, S. 177, Nr. 18.

33 So die Quittung Ulrich Močihubs von Kralovice vom 30. Januar 1423, Wien, in HHStA Wien, AUR, 1422 IV 22; Beck, J. - Loserth, J.: Urkundliche Beiträge, 1896, S. 118, Nr. 12.

34 Dies ist nur in der Quittung Niklas Werdenbergers vom 25. Januar 1423, Wien, der Fall - HHStA Wien, AUR, 1422 I 25; Beck, J. - Loserth, J.: Urkundliche Beiträge, 1896, S. 117-118, Nr. 11: ... daz mich der obgenant mein genediger herr herczog Albrecht von derselben scheden wegen genczleich benugig gemacht und mir dafur ausgericht hat zehen guldein... In den restlichen aus Iglau erhaltenen Quittungen wird die Höhe des Schadenersatzes an dieser Stelle nicht angegeben.

35 Die kürzere Form findet sich in der gerade zitierten Quittung Niklas Werdenbergers - siehe ebd.: ... und sag in von der obgeschriben scheden wegen genczleich ledig und los. Die längere Form findet sich etwa in der Quittung Ulrich Močihubs von Kralovice vom 30. Januar 1423 - siehe in HHStA Wien, AUR, 1422 IV 22; Beck, J. - Loserth, J.: Urkundliche Beiträge, 1896, S. 118, Nr. 12: ... und gelob wissentleich mit dem brief, daz ich von der obgeschriben veanknüs und schęden, sold und zerung wegen hincz demselben meinem gnédigen herren, seinen landen und lëuten furbas dhainerlay zůsprüch noch vordrung haben sol noch wil in dhainerweis an geverd. 
andere Hand unter dem Textspiegel nachgetragen. ${ }^{36}$ Stellten mehrere Söldner gemeinsam die Urkunde aus, findet sich unter dem Urkundentext oft eine Liste von Namen und Teilbeträgen, die am Ende aufaddiert werden. ${ }^{37}$ Meist sind diese Nachträge objektiv, ausnahmsweise jedoch auch subjektiv stilisiert, wobei am ehesten an den Hubmeister Berthold von Mangen zu denken ist (z. B. darauf hab ich im ausgericht CL gulden ${ }^{38}$ ). Der Schadenersatz wurde zumeist in bar, manchmal jedoch auch teilweise in Form von Pferden ausbezahlt. Einmal wurden solche Pferde in Stillfried gekauft, wie in dem entsprechenden Nachtrag detailliert festgehalten wird (darauf ist in ausgericht worden LXI guld. LX den. und XIIII pferd, sind ze Stillfrid kaufft worden umb CLXXX t. XLII den. mitsampt dem, daz darauf gegangen ist ${ }^{39}$ ).

An denselben Berthold von Mangen als Verwalter der landesherrlichen Finanzen erging am 27. April 1423 ein herzogliches Mandat mit der Aufforderung, dem Iglauer Hauptmann Düring von Hallwyl 100 Gulden aus den Kammereinkünften auszubezahlen. ${ }^{40}$ Dabei ging es offensichtlich weder um Sold für Dürings Söldner, noch um Schadenersatzzahlungen, sondern vielmehr um die reguläre oder aber außerordentliche Entlohnung des Hauptmannes, die in den oben besprochenen Quittungen keine Erwähnung findet. ${ }^{41}$

Mit Düring von Hallwyl ist schließlich noch eine weitere Quittung verbunden, die zusammen mit den anderen Iglauer Dokumenten im Haus-, Hof- und Staatsarchiv überliefert ist, jedoch offenbar nicht mehr unmittelbar mit der Bezahlung der österreichischen Söldner in Iglau zusammenhängt. Düring bestätigte mit dieser am 26. September 1423

36 Auf der einzigen Pergamenturkunde, der Quittung Ulrich Močihubs von Kralovice vom 30. Januar 1423 HHStA Wien, AUR, 1422 IV 22; Beck, J. - Loserth, J.: Urkundliche Beiträge, 1896, S. 118, Nr. 12, findet sich diese Notiz auf der Plica (im Wortlaut: LXX gulden). Auf den Papierurkunden findet sie sich mittig unter dem Text. Auf der Quittung Hans' Wilswols vom 10. März 1423 in HHStA Wien, AUR, 1422 IV 22; Beck, J. - Loserth, J.: Urkundliche Beiträge, 1896, S. 119, Nr. 15, lesen wir an dieser Stelle: Dem hat man ausgericht LX gulden.

37 Auf der gemeinsamen Quittung fünf anderer Söldner vom selben Tag, dem 10. März 1423, in HHStA Wien, AUR, 1422 IV 22; Beck, J. - Loserth, J.: Urkundliche Beiträge, 1896, S. 119-120, Nr. 16, findet sich z. B. mittig unter dem Text:

Wolfgangen Kurnbach III guld.

Kaspar Schreyer X tal. den.

Vlreich Puchler XVII tal. den.

Niclas Grossenmugler XVI guld.

Hannsen Villacher $X$ guld.

Summa XLVIII tal. VI $\beta$.

38 Diese Notiz findet sich auf einer Quittung Dietmar Kunigspergers vom 8. November 1423 in HHStA Wien, AUR, 1422 IV 22; Beck, J. - Loserth, J.: Urkundliche Beiträge, 1896, S. 181, Nr. 33.

39 Es handelt sich um die gemeinsame Quittung von 28 Söldnern vom 25. Mai 1423, Wien, in HHStA Wien, AUR, 1422 IV 22; Beck, J. - Loserth, J.: Urkundliche Beiträge, 1896, S. 178-179, Nr. 25.

40 HHStA Wien, AUR, 1423 IV 27; Beck, J. - Loserth, J.: Urkundliche Beiträge, 1896, S. 177-178, Nr. 21. Die äußere Form des Mandats entspricht vollkommen dem Usus der herzoglichen Kanzlei Albrechts V. Es handelt sich um einen offenen Brief mit verso aufgedrücktem Sekretsiegel. Der Kanzleivermerk d(ominus) $d(u x)$ in consilio findet sich recto, rechts unter dem Text.

41 In den Quittungen Dürings und der anderen Hauptleute wird jeweils die Anzahl der Söldner mit dem Sold des einzelnen Reiters bzw. Fußsoldaten multipliziert. Der Sold des Hauptmanns bleibt unberücksichtigt, muss also gesondert ausbezahlt worden sein. 
in Wien ausgestellten Quittung, dass der herzogliche Hubmeister Berthold von Mangen ihm 82 Pfund 5 Schilling und 3 Pfennig ausbezahlt hatte, die Herzog Albrecht ihm gewährt hatte, um sich aus dem Einlager in Wien zu befreien, in welches Düring nach seiner Rückkehr aus Iglau am 8. Juli 1423 geraten war. ${ }^{42}$ Das Datum seiner Rückkehr entspricht dem Amtsantritt Wilhelm Waldners als Iglauer Hauptmann. ${ }^{43}$ Der Grund für Dürings Einlager wird in der Quittung nicht angegeben.

\subsection{Das Znaimer Quellenkorpus}

Von den Iglauer Quittungen kommen wir jetzt nach Znaim in die Jahre 1429-1431. Die Quellenlage ist hier viel komplexer, als einige Jahre früher in Iglau. Neben urkundlichen Quittungen, die jenen aus Iglau ähneln, gibt es hier nämlich noch etliche Briefe und Zettel, die näheres Licht auf die Schadenersatzverhandlungen werfen, und vor allem eine zusätzliche zentrale Quelle: ein Register, in welchem ausständiger Sold und erlittene Schäden der in Znaim stationierten Söldner verzeichnet wurden. ${ }^{44}$

Aus diplomatischer Sicht handelt es sich bei diesem Register um ein Amtsbuch, oder eher um eine Urkunde in Buchform, die mit einer Corroboratio und dem aufgedrückten Signet Herzog Albrechts unterhalb des Textes schließt. ${ }^{45}$ Im Unterschied zur üblichen Form herzoglicher Urkunden enthält dieses Dokument keine Intitulatio, ist objektiv stilisiert und beginnt mit einer für Akten oder Amtsbücher typischen Überschrift inklusive Betreff und Datierung: Hie ist vermerkt ain aufschreiben der soldnẹr cze Cznö̈m, was man ydem von aller vergangen zeit von sold wegen unts auf Unser Frawn tag assumpcionis schuldig ist und auch was man in von aller vergangen czeit von scheden wegen unts auf hewtigen tag schuldig ist. Das benant aufschreiben ist beschehen an mittichen vor sand Merten tag anno etc. Domini vicesimo nono. ${ }^{46}$

Wie in der eben zitierten Überschrift angeführt, enthält das Register eine Auflistung der in Znaim stationierenden Söldner und ihrer Forderungen Herzog Albrecht gegenüber, wobei der Herzog sich am Ende verpflichtet, alle Forderungen bis zur kommenden Fastnacht (i. e. 28. Februar 1430) zu begleichen. ${ }^{47}$ Diese Verpflichtungserklärung ist zwar

42 HHStA Wien, AUR, 1422 IV 22; Beck, J. - Loserth, J.: Urkundliche Beiträge, 1896, S. 180, Nr. 31: das mich der hochgeboren fürst herczog Albrecht [...] hat geschaft mich ze ledigen aus der herberg in des Smerbecken haws ze Wienn, darin ich gelegen pin und geczert hab, von dem suntag vor Margarete, als ich von der Ygla her aus geriten bin, uncz auf den suntag nach Mathey apostoli [...], daruber mich ausgericht hat der erber Berichtold von Mangen, hubmeister in Österreich...

43 Siehe die Quittung Wilhelm Waldners vom 8. Juli 1423, Iglau, in HHStA Wien, AUR, 1422 IV 22; Beck, J. - Loserth, J.: Urkundliche Beiträge, 1896, S. 179, Nr. 27.

44 HHStA Wien, AUR, 1429 XI 09; kurze Auszüge davon gedruckt bei Kurz, F.: Österreich, 2. S. 339-344, Beilage XXV, hier S. 339-341.

45 Die Corroboratio lautet: Des czu urkund mit des egenanten herczog Albrechts, herczogen ze Osterreich, aufgedrucktem sekret - HHStA Wien, AUR, 1429 XI 09, fol. 17r; Kurz, F.: Österreich, 2, S. 341.

46 HHStA Wien, AUR, 1429 XI 09, fol. 3r; Kurz, F.: Österreich, 2, S. 339.

47 Die obgeschriben baid summ von sold und scheden wegen die sulln dem hochgeborn fursten herczog Albrechten, herczogen ze Osterreich und markrave ze Merhern etc., angesten unczen auf die nagst kunftig vaschnacht - HHStA 
objektiv stilisiert, aber mittels der unmittelbar anschließenden Corroboratio und dem herzoglichen Siegel durch den Herzog bekräftigt.

Die Forderungen zerfallen in zwei große Gruppen. Erstens geht es um den von 22. April bis 15. August 1429 angefallenen Sold, von welchem die Söldner im November 1429 erst weniger als die Hälfte ausbezahlt bekommen hatten. Insgesamt sollte für diese Zeit jeder Reiter 12 1/2 Gulden bekommen. ${ }^{48}$ Zweitens handelt es sich um Schadenersatz, welchen natürlich nur Söldner geltend machen konnten, die tatsächlich Schäden erlitten hatten. Im Unterschied zum Sold ist der Schadenersatz nicht auf das angeführte Intervall beschränkt; vielmehr werden alle Schäden aufgelistet, die vor Anfertigung des Registers angefallen und noch nicht ersetzt waren. ${ }^{49}$

Das Register teilt sich in vier große Abschnitte, und zwar nach vier Söldnerrotten, die nach ihren jeweiligen Rottmeistern bezeichnet werden: Tannbergs Rotte, Chaczpekchens Rotte, Hadmanstorffers Rotte und Sigismund Grünaus Rotte. In jeder Rotte werden dann die einzelnen Söldner aufgelistet, die jeweils über ein bis sechs Pferde verfügten, woraus sich eine Gesamtanzahl von 187 in Znaim stationierten Reitern ergibt. Die Einträge zu den einzelnen Söldnern sind nach einem einheitlichen Formular aufgebaut, wobei stets die Höhe des Soldes für die Abrechnungsperiode, der bereits ausbezahlte und der noch ausständige Sold sowie ggf. noch ausständiger Ersatz für Schäden angeführt werden. Beim Schadenersatz wird meist näher ausgeführt, wann und wie die Schäden entstanden waren. ${ }^{50}$ Hier bringt das Register zahlreiche bisher ungenutzte Details zur Geschichte des mährischen bzw. österreichischen Hussitenkriegs, die erst in ihren historischen Kontext gesetzt und ausgewertet werden müssen.

Am Ende der Söldnerliste finden sich die Namen einiger Männer, für die kein Sold vermerkt wird, die aber trotzdem Schadenersatz forderten. Die Genannten könnten unter einem anderen Söldner gedient haben und durch diesen bezahlt worden sein, während sie die erlittenen Schäden selbst abrechneten. Eine andere Möglichkeit wäre, dass die Genannten ihren Dienst erst später, d. h. nach dem 15. August 1429 antraten, weshalb sie nicht in der Abrechnung für die Periode davor aufscheinen. Einen Sonderfall stellen jene

Wien, AUR, 1429 XI 09, fol. 17r; Kurz, F.: Österreich, 2, S. 341.

48 Item von erst wirdet man den hernach genanten soldnern von solds wegen schuldig von freitag vor sand Jorigen tag unczen an Unser Frawn der Schidung nagstuergangen, das bringt XVI wochen und II tag, fa(ci)t die egenanten zeit auf ain pherdt XIIt guldein - HHStA Wien, AUR, 1429 XI 09, fol. 3r; Kurz, F.: Österreich, 2, S. 339.

49 Dies wird bereits in der oben zitierten Überschrift prägnant formuliert.

50 Als Beispiel für einen umfangreichen Eintrag sei hier etwa jener über den Sold und die Schäden des Rottmeisters Chaczpekch zitiert, der über fünf Pferde verfügte:

Item Chaczpekch auf $V$ pherd ist man von solds wegen die egenanten czeit schuldig LXII guldein.

Daran hat er emphangen XXVI guldein IIII $\beta$ den.

Also ist man im von der egenanten czeit wegen noch schuldig XXXV guld. $V \beta$ den.

So ist man im von scheden wegen schuldig, die er czu Waidhofen genomen hat, fur III ph(erd), so hat er aber zwai ph(erd) verlorn an aim eilln herab gen Egenburgk und fur II panczir II armbrust und II eysenhüt LXXX guldein - siehe HHStA Wien, AUR, 1429 XI 09, fol. 5v.

Ein Beispiel für einen kurzen Eintrag stellt die folgende Notiz über den Sold des Söldners Wolfl aus der Rotte desselben Chaczpekch dar:

Item dem Wolfl auf I ph(erd) ist man von solds wegen die egenanten zeit schuldig XIIt guldein.

Daran hat er emphangen $V$ guldein LX den.

Also wirdt man im von der egenanten czeit wegen noch schuldig VII guld. XXX den. - siehe ebd. 
20 Söldner aus der Tannberg-Rotte dar, die nur kurz unter Jörg Laun in Znaim dienten und dann nach Budweis verlegt wurden. Sie bekamen vom Znaimer Hauptmann je ein Pfund (insgesamt 20 Pfund, i. e. 26 Gulden 4 Schilling), die Laun von der herzoglichen Kammer ersetzt bekommen sollte (Auch hat der Lawn auf die XX geselln cze rossen, die gen dem Budwais sind gesandt worden, gebn ir yedem I $t$. den., das bringt XX $t$., die sind dem Lawn abgeczogen $)^{51}$

Ganz am Ende des Registers - vor der Verpflichtungserklärung Herzog Albrechts und der Corroboratio - findet sich eine summarische Abrechnung (exklusive jener 26 Gulden 4 Schilling, die an die nach Budweis verlegten Söldner ausbezahlt worden waren): im Zeitraum vom 22. April bis zum 15. August beliefen sich die Kosten für die Znaimer Söldner auf 2.155 Gulden 3 Schilling und 2 Pfennig. Davon waren im November 1429 erst 967 Gulden 4 Schilling beglichen, während die Kammer den Söldnern für denselben Zeitraum noch 1.187 Gulden 5 Schilling 2 Pfennig schuldete. Darüber hinaus schuldete die Kammer den Söldnern im November noch 636 Gulden für erlittene Schäden, obwohl das Register auch hier einen niedrigeren Gesamtbetrag von 582 Gulden angibt. Aufgrund dieser Zahlen lässt sich der Aufwand für die Znaimer Besatzung im Gesamtjahr 1429 auf mindestens 7.000 Gulden, wahrscheinlich jedoch mehr schätzen. ${ }^{52}$

Neben dem Register vom November 1429 gibt es jedoch auch in Znaim zahlreiche urkundliche Quittungen, die zwischen dem 11. März 1430 und dem 8. Jänner 1431 ausgestellt wurden. Diese lassen sich ebenfalls den genannten beiden inhaltlichen Gruppen zuordnen: Quittungen über Sold, den vorwiegend der Hauptmann für die gesamte Besatzung übernahm, und Quittungen über Schadenersatz, den die einzelnen Söldner selbst geltend machen und abrechnen mussten.

Im Frühling 1430 kommen dazu noch Urkunden, mit denen einzelne Söldner dem Herzog sowohl den Erhalt von Schadenersatz, als auch ausständigen Sold vom Vorjahr quittierten, den sie gemäß des Registers vom November 1429 ausbezahlt erhalten hatten. Parallel dazu stellte der Znaimer Hauptman Jörg Laun bereits die üblichen Quittungen über den Sold der unter seinem Kommando dienenden Söldner für die neue Abrechnungsperiode aus. Am 11. März 1430 quittierte er Sold in der Höhe von 840 Gulden für 168 Reiter für ein halbes Quartal vom 13. Februar bis zum 30. März. ${ }^{53}$ Die nächste

51 HHStA Wien, AUR, 1429 XI 09, fol. 7v. Während diese Söldner sich in Znaim aufhielten, belief sich die Gesamtanzahl der herzoglichen Söldner in der Stadt auf über 200.

52 Diese grobe Schätzung geht davon aus, dass der Zeitraum vom 22. April bis zum 15. August 1429 fast ein Jahresdrittel umfasst. Bei einer in etwa konstanten Anzahl von Söldnern dürften sich die Kosten für Sold für das Gesamtjahr auf ca. 6.500 Gulden belaufen haben. Die 636 Gulden für Schadenersatz beschränken sich nicht auf die angeführte Abrechnungsperiode, allerdings handelt es sich dabei nur um jenen Betrag, den die Kammer den Söldnern im November 1429 noch schuldete. Wir wissen also nicht, wie viel an Schadenersatz im Jahr 1429 bereits ausbezahlt worden war. Wenn wir die nachgewiesenen 636 Gulden Schadenersatz zu den geschätzten 6.500 Gulden Sold hinzurechnen, kommen wir auf eine wahrscheinlich am untersten Rand angesetzte Gesamtsumme von rund 7.000 Gulden.

53 HHStA Wien, AUR, 1430 X 18 (sic!); Kurz, F.: Österreich, 2, S. 341-342. Auf dieser Quittung findet sich unter dem Textspiegel die durch den Urkundenschreiber (nachträglich?) hinzugefügte Notiz, dass zwei Söldner auf die angeführte Gesamtzahl fehlten, wofür dem Herzog je fünf Gulden zustünden (Item in der obgenanten summ der soldnêr sind zwen ausgestanden; daran stend meinem gneadigen heren etc. zu fümf guldein). Wann dieser Nachtrag hinzugefügt wurde, ist unklar. Möglicherweise erhielt der Hauptmann zunächst die 
Zahlung verzögerte sich jedoch neuerlich erheblich und der Hauptmann erhielt erst am 16. November 3.000 Gulden für 150 Reiter auf ein halbes Jahr vom 30. März bis zum 28. September ${ }^{54}$ Für die Zeit danach dürfte eine Quittung verloren gegangen sein (für das halbe Quartal vom 28. September bis zum 13. November), und es folgt erst am 26. Dezember 1430 eine weitere Urkunde, mit welcher Laun die Auszahlung von 720 Gulden 5 Schilling und 12 Pfennig bestätigt, die er für 150 Söldner auf ein halbes Quartal vom 13. November bis zum 28. Dezember übernommen hatte. 150 Söldner zu Ross entsprächen zwar 750 Gulden, diese Summe wurde jedoch um 29 Gulden 18 Pfennig reduziert, da sieben Söldner nicht über die ganze Zeit im Dienst waren. ${ }^{55}$

Neben den Quittungen für die in Znaim stationierenden herzoglichen Söldner, die unter dem Kommando des Hauptmanns die Verteidigung der Stadt gewährleisten und ggf. auch andere militärische Aufgaben übernehmen sollten, ${ }^{56}$ stellte Jörg Laun auch noch eine zweite Gruppe von Quittungen aus. Im Unterschied zu Iglau betreffen diese Quittungen nicht die Fußsoldaten, sondern den Sold des Hauptmanns und einer kleinen Truppe von Söldnern, die zusammen mit ihm (bei der Verteidigung der Znaimer Burg) dienen sollten. In der Narratio der zweiten entsprechenden Quittung vom 11. März 1430 wird angeführt, Herzog Albrecht habe den Hauptmann mit 12 berittenen Söldnern engagiert, wofür er ihm 275 Gulden pro Quartal, bzw. 137 1/2 Gulden für das halbe Quartal zu bezahlen hatte. Der Empfang letzterer Summe wird dann auch tatsächlich quittiert. ${ }^{57}$ Wenn der Sold eines berittenen Söldners sich auch in diesem Fall auf fünf Gulden im halben Quartal belief heißt das, dass die übrigen 155 Gulden pro Quartal bzw. 77 1⁄2 Gulden für das halbe Quartal den Sold des Hauptmanns darstellen.

Weitere zwei Quittungen dieser Art sind zwar insgesamt etwas knapper, sie führen jedoch direkt an, dass der Aussteller Dienst bei der Bewachung der Znaimer Burg (an meiner purkchut) leisten sollte. Sowohl die Quittung vom 20. November 1430, als auch jene vom 8. Januar betreffen jeweils ein ganzes Quartal (vom 25. Juli bis zum 24. Oktober 1430 und vom 24. Oktober 1430 bis zum 23. Januar 1431), wobei der Aussteller jeweils den Erhalt von 150 Pfund, i. e. 200 Gulden quittiert. ${ }^{58}$ Wie viele dem Hauptmann direkt unterstehende Reiter möglicherweise in der genannten Summe inbegriffen waren ist nicht zu ermitteln (angesichts der niedrigeren Summe dürfte ihre Anzahl wohl abgenommen haben).

Summe für die ursprünglich vereinbarte Anzahl von Söldnern ausbezahlt und quittierte diese. Als sich jedoch herausstellte, dass zwei Mann fehlten, musste er deren Sold zurückzahlen und die Quittung wurde mittels des angeführten Nachtrags korrigiert.

HHStA Wien, AUR, 1430 XI 16; Kurz, F.: Österreich, 2, S. 344; vgl. QGStW I/7, S. 49, Nr. 14566.

HHStA Wien, AUR, 1430 X 18 (sic!).

56 In der zitierten Quittung vom 26. Dezember 1430 z. B. wie folgt formuliert: als der hochgeborn furst herczog Albrecht [...] mir zu geschaft hat hundert und fumfczig werleich zu rossen zu huet der stat zu Znä̈m und zu anderen sein notdurften... - ebd.

57 HHStA Wien, AUR, 1430 X 18 (sic!).

58 HHStA Wien, AUR, 1430 XI 20, vgl. QGStW I/7, S. 49, Nr. 14567; HHStA Wien, AUR, 1431 I 08; vgl. QGStW I/7, S. 54, Nr. 14574. 
Von den Quittungen des Hauptmanns gehen wir nun zu jenen Urkunden über, die die einzelnen Söldner ausstellten. Wie oben angedeutet, betreffen diese in der ersten Jahreshälfte 1430 häufig nicht nur Schadenersatz, sondern in der Regel auch ausständigen Sold vom Vorjahr, von dem ein bedeutender Teil noch nicht ausbezahlt worden war. Die Quittungen berufen sich häufig auf das Register (vom 9. November 1429), oft kommen jedoch noch weitere, erst nach der Erstellung des Registers eingetretene Schäden hinzu. ${ }^{59}$ Etwas unklar sind jene Fälle, in denen eine Quittung auf das Register verweist, dieses aber der Quittung widersprechende Angaben enthält. In einigen wenigen Fällen wird z. B. in der Quittung angegeben, das Register verzeichne keine Schäden des betreffenden Söldners. Umgekehrt enthält das Register offensichtlich alle Schäden, deren Ersatz durch eine Quittung bestätigt wird. Der paläographische Befund lässt die Annahme zu, dass einzelne Schäden vielleicht erst nachträglich in das Register eingetragen wurden. Dies könnte die oben angeführte Diskrepanz zwischen der im Register angeführten Gesamtsumme von 582 Gulden und der tatsächlichen Summe der verzeichneten Schuldbeträge in Höhe von 636 Gulden erklären. ${ }^{60}$

59 Vgl. als Illustration jener Quittungen, die die Bezahlung ausständigen Soldes und Ersatz für ältere Schäden gemäß des Registers vom 9. November 1429 zugleich mit dem Ersatz neu hinzugekommener Schäden bestätigen, die Quittung Gerwein Primistorffers vom 1. April 1430:

\begin{tabular}{|c|c|}
\hline $\begin{array}{l}\text { Eintrag über ausständigen Sold und erlittene Schä- } \\
\text { den Gerwein Primistorffers im Register vom 9. Novem- } \\
\text { ber } 1429 \text { - HHStA Wien, AUR, } 1429 \text { XI 09, fol. 4v: }\end{array}$ & $\begin{array}{l}\text { Narratio der Quittung Gerwein Primistorffers vom } 1 . \\
\text { April } 1430 \text { - HHStA Wien, AUR, } 1430 \text { IV 01; Kurz, } \\
\text { F.: Österreich, 2, S. 342; vgl. QGStW I/7, S. 42-43, Nr. } \\
\text { 14532: }\end{array}$ \\
\hline $\begin{array}{l}\text { Item dem Gerbein Primenstormer auf II pferd ist man die } \\
\text { egenanten zeit von solds wegen schuldig XXV guld. } \\
\text { Daran hat er emphangen X gulden IIII } \beta \text { den. } \\
\text { Also wirdt man im von der egenanten czeit wegen noch } \\
\text { schuldig XIIII gulden LX den. } \\
\text { So ist man im von scheden wegen schuldig fur I pherd, hat } \\
\text { er zu Krembs verloren, XII guldein. }\end{array}$ & $\begin{array}{l}\text {...daz mich der hochgeborn furst herczog Albrecht }[\ldots] \text { von } \\
\text { meins verdienten solds wegen und auch der scheden, so } \\
\text { ich in seinem dinst ze Znoym under Jorigen dem Lawn, } \\
\text { haubtman daselbs, genomen hab und daruber man dann } \\
\text { mit mir ist ainig worden und abgeraitt hat nach ains re- } \\
\text { gisters aufweisung gancz benugig gemacht und ausgericht } \\
\text { hat, vonerst von dez solds wegen vierczehn guldein und } \\
\text { sechczigk pfening, und fur scheden zwelf gulden. Auch } \\
\text { hat er mir ausgericht fur ander mein schedn, die ich in } \\
\text { seinem dinst genommen hab und in dem benanten register } \\
\text { nicht begriffn sind, sechs und zwainczigk guldein... }\end{array}$ \\
\hline
\end{tabular}

60 Als pars pro toto sei die Quittung Heinrich Wilds vom 1. April 1430 genannt, der neben ausständigem Sold des Vorjahres auch Schadenersatz quittierte, der angeblich nicht im Register aufgeführt war. Im erhaltenen Register ist jedoch unter Wilds Namen ein Schaden in genau jener Höhe angeführt, die er quittierte:

Eintrag über ausständigen Sold und erlittene Schä- Narratio der Quittung Heinrich Wilds vom 1. April den Heinrich Wilds im Register vom 9. November 1430 - HHStA Wien, AUR, 1430 IV 01; vgl. QGStW 1429 - HHStA Wien, AUR, 1429 XI 09, fol. 14r: I/7, S. 43, Nr. 14533:

Item Hainreich Willd auf ain ph(erd) ist man schuldig von solds wegen die eegnant czeit XIIt guldein.

Daran hat er emphangen $V$ guld. LX den. ...daz mich der hochgeboren furst herczog Albrecht [...] von meins verdienten solds wegen, so ich um sein genad ze Znoym under Jorigen dem Lawn haubtman daselbs verAlso ist man im schuldig noch VII guld. XXX den. So ist man im schuldig schaden umb ain ph(erd), das er czu Egenburg hat verloren, VIII guldein. dient hab, nach innhaltung dez registers genczleich ausgerichtt und beczalt hat sybn guldein und dreissigk pfening und fur ettlich mein schédn, so ich in des benanten meins genedigen hern dinst genommen hab und in dem obgenanten register nicht begriffen sind, hat er mir ausgericht acht guldein... 
Individual-Quittungen, die sich auf das Register von 1429 berufen und neben Schadenersatz auch ausständigen Sold quittieren, gibt es nur bis Ende Mai $1430 .{ }^{61}$ Danach ändert sich die Quellenlage wesentlich. Bis auf zwei Ausnahmen ${ }^{62}$ empfängt und quittiert nun der Hauptmann den Sold, während die Söldner in der Regel nur Schadenersatzquittungen ausstellen, wie es sieben Jahre zuvor auch in Iglau üblich war.

Wenn der Verweis auf das Register entfällt, ähnelt das Formular der Znaimer Quittungen sehr stark dem Iglauer. Der Aufbau der Quittungen folgt dann dem dort üblichen Schema: an die Intitulatio des bzw. der Aussteller knüpft die längere Narratio an, in der der/die Aussteller bekennen, im Dienst Herzog Albrechts unter dem Hauptmann in Znaim, Jörg Laun, ${ }^{63}$ näher spezifizierte Schäden erlitten zu haben, für die sie durch den Herzog vollkommen entschädigt worden sind. Hat die Quittung nur einen Aussteller wird an dieser Stelle der Narratio auch die Höhe des Schadenersatzes angeführt, was in Iglau nur ausnahmsweise vorkommt. Wurde die Quittung aber von mehreren Personen ausgestellt sind die einzelnen Beträge, wie in Iglau, in dem charakteristischen

61 Die letzte erhaltene Quittung, die sich auf das Register beruft, wurde am 29. Mai 1430 von acht Söldnern ausgestellt. Sie quittieren keinen ausständigen Sold des Vorjahres, sondern lediglich den älteren Schadenersatz. Trotzdem wird betont, dass die Schäden in dem register nicht begriffen sind - siehe HHStA Wien, AUR, 1430 V 29; vgl. QGStW I/7, Nr. 14543. Die erste Quittung, die das Register nicht mehr erwähnt, datiert vom 30. Mai 1430. Vier Söldner quittieren darin den Ersatz aller Schäden, die sie im Dienst Herzog Albrechts unter dem Kommando Jörg Launs, Hauptmann in Znaim, in Winau/Únanov erlitten hatten - siehe HHStA Wien, AUR, 1430 V 30; vgl. QGStW I/7, Nr. 14544.

62 Die erste Ausnahme stellt die am 30. Juni 1430 ausgestellte Quittung des Heinz Naß dar - siehe HHStA Wien, AUR, 1430 VI 30; vgl. QGStW I/7, S. 45, Nr. 14545. Der Aussteller, welcher mit zwei Pferden unter Jörg Laun in Znaim gedient hatte, quittiert Herzog Albrecht Sold in der Höhe von 10 Gulden für das halbe Quartal vom 15. Mai bis zum 29. Juni. Die zweite Ausnahme bildet die Quittung Sigismund Grünaus vom 23. September 1430 - HHStA Wien, AUR, 1430 X 18 (sic!). Sigismund, der im Jahr 1429 Rottmeister einer der vier in Znaim stationierten Rotten war, quittiert den Erhalt von 100 Gulden an dem sold, so uns unser genadiger here der herczog etc. schuldig ist, welche ihm der Eggenburger Richter ausbezahlt hatte. Die beiden Quittungen hängen wahrscheinlich mit der verspäteten Auszahlung des Gesamtsoldes durch die herzogliche Kammer an Jörg Laun zusammen. Da sich diese über Gebühr verspätete, dürften die beiden Genannten individuelle Zahlungen ausverhandelt haben.

63 In einem Fall, der Quittung Hanušeks des Kleinen vom 7. November 1430, behauptet der Aussteller, die geltend gemachten Schäden unter Jakob Seebeck, Hauptmann in Znaim (under Jacoben Seebekchen, haubtman ze Znoym), erlitten zu haben - siehe HHStA Wien, AUR, 1430 XI 07; vgl. QGStW I/7, S. 49, Nr. 14565. In den übrigen Quittungen aus den Jahren 1429-1431 wird ausschließlich Jörg Laun als Hauptmann genannt. Eine Erklärung wäre, dass die betreffende Quittung sich auf wesentlich ältere, in die Zeit vor Jörg Launs Hauptmannschaft fallende Schäden, bezieht. Ich konnte jedoch keinen Jakob Seebeck als Hauptmann in Znaim nachweisen. In den Jahren 1423 bis 1425 wird in den Znaimer Urkunden und Ratsrechnungen Jörg von Ruckendorf als Hauptmann genannt (Moravský zemský archiv v Brně [= MZA Brno] - Státní okresní archiv [= SOkA] Znojmo, Bestand Archiv města [= AM] Znojmo, Urkunde Nr. 83; ebd., Stadtbücher, Sign. II 240, passim), von 1426 bis 1427 folgte diesem Johann Schweinpeck (ebd., Stadtbücher, Sign. II 241 und II 243, passim) und 1428 erscheint bereits Jörg Laun als Hauptmann (sowohl in den Ratsrechnungen - siehe ebd., als auch in einer summarischen Losungsabrechnung - siehe MZA Brno, Bestand G 1 - Bočkova sbírka, Inv. Nr. 12074). Damit bleibt noch die theoretische Möglichkeit, dass Jakob Seebeck noch vor den Genannten, oder aber irgendwann zwischen ihnen kurz als Hauptmann von Znaim diente. Etwas später, im Jahr 1433, erscheint ein Mann dieses Namens jedenfalls als herzoglicher Hauptmann in Weitra (Státní oblastní archiv [SOA] Třeboň - SOkA České Budějovice, Bestand AM České Budějovice, Chronologische Reihe, Sign. 1433/6 und SOA Třeboň, Bestand Historica Třeboň, Sign. 329a). 
Nachtrag mittig unter dem Text aufgelistet. ${ }^{64}$ Auf die Narratio folgt eine kurze Dispositio, in der der Aussteller den Empfänger für quitt und los erklärt, was in einigen Fällen noch von der Verpflichtung begleitet wird, den Herzog, dessen Länder und Untertanen nie wieder aufgrund der genannten Summe zu behelligen. In der Corroboratio wird das Siegel des Ausstellers, oder aber des/der zugezogenen Siegler/s angekündigt; in einigen Fällen fungiert auch Jörg Laun als Siegler. Bei der Besiegelung der Urkunde durch externe Siegler wird die Corroboratio noch um eine Verpflichtung des/der Aussteller/s ergänzt, die Urkunde einzuhalten ${ }^{65}$ Im Eschatokol findet sich eine einfache Datierung mit abgekürzter Jahreszahl.

Im Gegensatz zu Iglau sind aus Znaim noch zwei weitere Arten von Schriftstücken überliefert, die mit dem Schadenersatzprozedere zusammenhängen. Es sind dies einerseits Bittschriften des Hauptmanns zugunsten seiner Söldner, um den Schadenersatz zu beschleunigen, andererseits Schadenzettel, auf welchen Schäden, die die einzelnen Söldner erlitten hatten, kurz aufgelistet und durch die Betroffenen und ihren Hauptmann geschätzt werden.

Bittschriften Jörg Launs zugunsten einzelner Söldner sind vereinzelt aus dem Spätsommer und Herbst 1430 überliefert. Insgesamt handelt es sich um fünf verschlossene Briefe, die alle durch denselben Schreiber mundiert und in Znaim ausgestellt wurden. ${ }^{66}$ Auch diese Briefe wurden nach einem gemeinsamen Formular stilisiert. Der Aussteller empfiehlt zunächst dem Empfänger, Herzog Albrecht V. von Österreich, den/die Vorweiser des Briefes, seine/n Söldner. Dem Herzog wird mitgeteilt, er schulde dem/den betreffenden Söldner/n eine bestimmte Summe Geldes für den Ersatz ihrer im Krieg erlittenen Schäden. Gelegentlich werden die Schäden kurz charakterisiert (umb ein phärd),

64 In der Quittung Peter Schweinpecks vom 30. Mai 1430 finden sich unter dem Text folgende Namen und Beträge, die von demselben Schreiber geschrieben wurden, der auch den Rest der Quittung mundierte siehe HHStA Wien, AUR, 1430 V 30; vgl. QGStW I/7, S. 45, Nr. 14544:

Item dem Sweinpekchn XXXII guld.

Item dem Wardacher VIII guld.

Item dem Fabian $V$ guld.

Item dem Rauchhaubt XX guld.

Summa huius LXV guld.

65 Diese Formel findet sich z. B. in einer von elf Söldnern gemeinsam ausgestellten Quittung vom 20. November 1430 - HHStA Wien, AUR, 1430 XI 20; vgl. QGStW I/7, S. 50, Nr. 14568 -, die durch das Siegel eines der Aussteller, eines zugezogenen Sieglers und des Hauptmanns Jörg Laun besiegelt wurde. Die Corroboratio lautet wie folgt: Mit urkund des briefs besigelt mit des obgenanten unsers haubtmans Jorigen des Lawns, Jorigen des Muldorff und mit mein vorgenanten Jacoben des Salhinger aufgedrukchten petschad, darunder wir uns obgemeldt aindlef gesellen mit unsern trewn verpinden, alles das stèt ze haben, das an dem brief geschribn steet ungeverlich.

66 Es handelt sich um folgende Bittschriften: 1) zugunsten Sigismunds von Police, 22. August 1430; 2) zugunsten Hanušeks, 27. August 1430; 3) zugunsten Reichart Meixners, 3. September 1430; 4) zugunsten Dietz von Liebenheims, Andre Peilnsteiners, Christoph Langs und Hilbrands [von Zedwitz], 9. September 1430; 5) zugunsten Hans Posars, 2. Oktober 1430. Alle Briefe werden in HHStA Wien, AUR, nicht sub dato, sondern als Beilagen zu einer anderen Quittung aufbewahrt - siehe HHStA Wien, AUR, 1430 X 18 (der Logik nach würde man entweder eine Einreihung sub dato, oder als Beilagen zu den betreffenden Quittungen, die jeweils einige Tage nach der Bittschrift ausgestellt wurden, erwarten). Von den fünf Bittschriften ist nur jene vom 22. August 1430 bereits ediert - siehe Kurz, F.: Österreich, 2, S. 343. Die übrigen vier Bittschriften sind bisher unveröffentlicht. 
immer wird aber auf den beiliegenden, dem Brief angeschlossenen Zettel hingewiesen, auf dem die Schäden genau beschrieben und geschätzt wurden. ${ }^{67}$ In einem Fall wird zusätzlich noch ein Register zitiert, das sich beim Hubmeister befinde. ${ }^{68}$ Dann folgt der eigentliche Kern des Briefes - die Bitte, dem/den Söldner/n ihre Schäden zu ersetzen, welche in zwei Fällen noch um die Aussage verstärkt wird, der betreffende Söldner sei ain armer knecht $[. .$.$] und sünst ewers dinsts nicht vermöcht .^{69}$ Das Eschatokol wird gebildet von der Datierung und der rechts unter dem Textspiegel platzierten Intitulatio (nicht Unterschrift) des Ausstellers, die in allen fünf Briefen wie folgt lautet: Jorig Lawnn, von ewern gnaden hawbtman Znaym [!].

Die Bittschriften des Hauptmanns konnten gelegentlich - wie alle Briefe - auch zur Übermittlung anderer Nachrichten genutzt werden. In der Bittschrift zugunsten Reichart Meixners vom 3. September 1430 teilt der Aussteller dem Empfänger mit, er leite ihm einen Brief weiter, den er von Herrn Zmÿel (Smil von Lichtenburg zu Vöttau/Bítov?) bekommen habe, in dem eine Nachricht enthalten sei, die Zmiels Sohn persönlich aus Tabor gebracht habe. ${ }^{70}$

Noch mehr historische Details enthalten die schon mehrfach erwähnten Schadenzettel. Wie angedeutet waren sie zum Teil ursprünglich in die Bittschriften Jörg Launs eingelegt. Heute liegen sie jedoch nicht mehr bei den Bittschriften, sondern bei den entsprechenden Quittungen, an welche sie zumeist sogar angehaftet wurden. Während es nur noch fünf Bittschriften des Hauptmanns gibt, sind noch zwölf Schadenzettel erhalten.

Innerhalb der Schadenzettel lassen sich zwei Gruppen unterscheiden. Erstens die ursprünglich den fünf erhaltenen Bittschriften beigelegte Zettel, die stets objektiv stilisiert sind und von demselben Schreiber wie die Bittschriften mundiert wurden. Dazu kommen noch zwei Schadenzettel, die ebenfalls objektiv stilisiert sind und von denen einer sogar vom Schreiber der erhaltenen Bittschriften mundiert wurde, deren zugehörige Bittschriften jedoch nicht überliefert sind.

Die zweite Gruppe bilden Schadenzettel, die subjektiv stilisiert sind und von unterschiedlichen Schreibern sehr flüchtig geschrieben wurden. Diese Schadenzettel sind meist auch wesentlich kürzer, als jene der ersten Gruppe.

Von Bedeutung ist außerdem, ob die in den Schadenzetteln genannten Schäden bereits von den herzoglichen Räten anerkannt waren, oder erst noch von diesen anerkannt

67 ... als ich das ewern gnaden an ainer zedel hie inn verslossen verschriben schikch - ebd.

68 In der Bittschrift zugunsten der vier Söldner vom 9. September 1430 wird sowohl auf das Register, als auch auf den Zettel Bezug genommen: ... und in ewer rätt darumb habent abprochen [recte: absprochen], als des der hubmaester ain register hat und dy zedel hie inn verslossen aufweist... - HHStA Wien, AUR, 1430 X 18 (sic!). Es stellt sich naturgemäß die Frage, ob es sich um das Register vom 9. November 1429 handeln könnte. Dies scheint jedoch eher unwahrscheinlich, da von den vier Söldnern lediglich zwei ([Andre] Peilnsteiner und Christoph Lang) in dem erwähnten Register vorkommen und sich die Höhe der jeweils genannten Schäden wesentlich unterscheidet.

69 So in der Bittschrift zugunsten Sigismunds von Police vom 22. August 1430 - siehe Kurz, F.: Österreich, 2 , S. 343. Im gleichen Sinne, jedoch kürzer, siehe die Bittschrift zugunsten Reichart Meixners vom 3. September 1430 in HHStA Wien, AUR, 1430 X 18 (sic!).

70 Auch schikch ich ewren gnaden hern Zmÿels prieff, den er mir zw geschickt hat, den ir wol vernemen werdt, wenn hern Zmiels sun dy mär selb von dem Thabor pracht hat - siehe HHStA Wien, AUR, 1430 X 18 (sic!). 
werden mussten. Der entsprechende Status wird in den Schadenzetteln oft explizit angeführt, ${ }^{71}$ wobei die erste Gruppe zumindest teilweise bereits anerkannte Schäden, die zweite jedoch ausschließlich noch nicht anerkannte Schäden verzeichnet. Verzeichnet ein Schadenzettel noch nicht anerkannte Schäden, findet sich darunter üblicherweise eine Notiz der herzoglichen Kammer über den anerkannten - meist wesentlich geringeren - Schadenersatz. ${ }^{72}$

Auf fast allen Schadenzetteln werden die Umstände beschrieben, unter denen es zu den angegebenen Schäden kam. Die Schadenzettel werden so - mehr noch als die Quittungen der Söldner, die Bittschriften des Hauptmanns und sogar das Register vom 9. November 1429 - zu einer interessanten Quelle für die Ereignisgeschichte des Hussitenkriegs in Südmähren und Niederösterreich.

Insgesamt erlauben es die Quellen aus Znaim viel besser, den Verlauf der Sold- und Schadenersatzabrechnungen zu rekonstruieren, als in Iglau; auch tritt eine breitere Palette an Zeugnissen der pragmatischen Schriftlichkeit ans Licht. Ob die gleiche Art von Schriftstücken auch 1423 in Iglau in Verwendung war, ist schwer zu sagen. Man kann wohl von der Existenz von Schadenzetteln und vielleicht auch Bittschriften des Hauptmanns ausgehen. Eher unwahrscheinlich ist es, dass es ein vergleichbares Register über ausbezahlten und ausständigen Sold bzw. Schadenersatz gab, da das Znaimer Register wahrscheinlich aus der spezifischen Lage des Jahres 1429 erwuchs, als die herzogliche Kammer den dortigen Söldnern hohe Summen schuldete.

\section{Beispiele für die historische Auswertung der Znaimer und Iglauer Akten}

An dieser Stelle kann keine eingehende historische Auswertung der vorgestellten Quellen erfolgen. Wie oben angedeutet, werde ich hier lediglich etwas näher auf die finanziellen Aufwendungen eingehen, die durch den Unterhalt der Besatzungen in Iglau und Znaim entstanden. Zu diesem Thema werden auch noch andere Quellen herangezogen, sodass insgesamt ein interessanter Einblick in die landesherrlichen Finanzen Herzog Albrechts V. von Österreich während des Hussitenkriegs entsteht. Darüber hinaus werde

71 In erstem Fall wird auf dem Schadenzettel z. B. angeführt: dafür ist ÿm gesprochen siben gulden, vgl. etwa der Schadenzettel Reichart Meixners - HHStA Wien, AUR, 1430 X 18 (sic!); QGStW I/7, S. 47, Nr. 14555. Im anderen Fall wird auf dem Schadenzettel entweder negativ formuliert: darum ist ÿm nicht ausgesprochen, wie z. B. auf dem Schadenzettel Peter Schweinpecks - siehe HHStA Wien, AUR, 1430 IX 30; vgl. QGStW I/7, S. 48, Nr. 14559, oder aber es findet sich gar keine Angabe.

72 Bemerkenswert ist der Schadenzettel Sigismunds von Police. Der Hauptmann, der diesen Schadenzettel im Zusammenhang mit einer Bittschrift zugunsten Sigismunds ausfertigen ließ, führt darin etwas überraschend an, dass Sigismund sein totes Pferd auf 20 Gulden schätze, er dieses jedoch, wie allgemein bekannt, um lediglich 15 Gulden gekauft habe (...da ist ym ain phard tod, das schäczt er umb XX guldein. Es ist aber wissenleich, das er es kauft hat umb XV guldein). Wie die Notiz auf der betreffenden Quittung vom 11. September 1430 zeigt, erkannten die herzoglichen Räte Sigismund dann lediglich 10 Gulden Schadenersatz zu (Item dem Sigmunden X gulden) - siehe HHStA Wien, AUR, 1430 IX 11; vgl. QGStW I/7, S. 47, Nr. 14556. 
ich noch drei weitere Themenkreise aufzeigen, die sich anhand der untersuchten Quellen in Zukunft noch bearbeiten lassen würden.

\subsection{Die finanziellen Aufwendungen für die in Iglau und Znaim stationierten Söldnertruppen}

Die Iglauer Quittungen ermöglichen es, die jährlichen Aufwendungen für die dortige österreichische Besatzung ziemlich genau zu berechnen, wie es bereits František Hoffmann getan hat. ${ }^{73}$ Den berittenen Söldnern wurden von 7. Januar 1423 bis 6. Januar 1424 insgesamt 6.915 Gulden an Sold ausbezahlt, für die Rotten Teuffenbachers, Pairhofers und Lugasters, die zu Beginn des Jahres 1423 (nicht nur) die Iglauer Besatzung verstärkten, wurden weitere 650 Gulden ausgegeben. Dazu kamen zumindest im ersten Halbjahr 1423 noch weitere 733 Pfund 1 Schilling, i. e. 977 Gulden 3 Schilling für die Fußsoldaten von der Etsch. Insgesamt wurden somit zumindest 8.542 Gulden 3 Schilling an Sold ausbezahlt. Diese Summe könnte auch noch höher gewesen sein, falls die Fußsoldaten auch in der zweiten Jahreshälfte 1423 in der Stadt stationiert waren (ab Juli fehlen entsprechende Quittungen). Der Schadenersatz belief sich auf insgesamt 967 Gulden 5 Schilling 12 Pfennig, wobei jedoch unklar ist, wie vollständig die Quittungen über den Schadenersatz überliefert sind. Wir können daher jedenfalls festhalten, dass die Gesamtkosten für die Iglauer Besatzung sich im Jahr 1423 auf mindestens 9.510 Gulden beliefen, was allerdings einen Minimalwert darstellt.

Das Znaimer Register aus dem Jahr 1429 ermöglicht uns keinen vergleichbar detaillierten Einblick in die Aufwendungen für die Znaimer Besatzung. Trotzdem lassen sich aufgrund der summarischen Abrechnung am Ende des Registers die Kosten für Sold und Schadenersatz in Znaim im Jahr 1429 auf mindestens 7.000 Gulden veranschlagen, was eine sehr konservative Schätzung darstellt. ${ }^{74}$

Auch die Znaimer Quittungen aus dem Jahr 1430 sind weniger geschlossen erhalten, als jene aus Iglau. Zudem lassen sich die einzelnen Summen hier nicht einfach aufrechnen, da in den Quittungen teilweise auch Soldzahlungen für das Jahr 1429 bestätigt werden, die bereits in den Ausgaben für das Jahr 1429 enthalten sind und somit von den Kosten des Jahres 1430 abgezogen werden müssen.

Problemlos aufsummieren lassen sich nur die Quittungen des Hauptmanns für den Sold des Jahres 1430, welche aber nicht vollständig überliefert sind. Im halben Quartal vom 13. Februar bis zum 30. März wurden jedenfalls 840 Gulden für 168 Söldner, in dem halben Jahr vom 30. März bis zum 28. September ca. 3.000 Gulden für 150 Söldner

73 Siehe Hoffmann, F.: Jihlava, S. 157-159. In dessen Auflistung des ausbezahlten Soldes sind zwei Posten zu korrigieren: In der ersten Quittung Dürings von Hallwyl muss es anstelle von 1.000 Gulden 1.030 Gulden heißen und die Quittung desselben über den Erhalt des Soldes für die Fußsoldaten vom 8. April 1423 lautet nicht, wie fälschlich bei Hoffmann angeführt, über 143 Pfund 6 Schilling, sondern vielmehr über 243 Pfund 6 Schilling. Nicht zum ausbezahlten Schadenersatz gehören die 100 Gulden außerordentliche oder reguläre Entlohnung des Hauptmanns Düring von Hallwyl, ebenso wenig wie die 82 Pfund 5 Schilling 3 Pfennig, die die herzogliche Kammer für Düring bezahlte, um ihn aus dem Einlager in Wien zu lösen.

Für die Berechnung siehe oben, besonders Anm. 52. 
und im halben Quartal vom 13. November bis zum 28. Dezember 1430720 Gulden 5 Schilling 12 Pfennig ebenfalls für 150 Söldner ausgegeben, von denen allerdings nicht alle die ganze Zeit über im Sold standen. Obwohl die Quittungen für zwei halbe Quartale fehlen, lassen sich die Ausgaben für Sold im Jahr 1430 auf zumindest 6.000 Gulden schätzen.

Dazu kommen in Znaim noch die gesonderten Quittungen über die Besoldung des Hauptmanns und dessen zwölf Söldner, die die Znaimer Burg bewachten. Diese sind für das halbe Quartal im Frühjahr 1430 (137 Gulden 3 Schilling; für das ganze Quartal wären es 275 Gulden gewesen), und dann für zwei ganze Quartale vom 25. Juli bis zum 24. Oktober bzw. von diesem Tag bis zum 23. Januar 1431 erhalten (jeweils 150 Pfund, i. e. 200 Gulden). Daraus ergeben sich als jährliche Ausgaben für die Besoldung des Hauptmanns und die Bewachung der Znaimer Burg mindestens 875 Gulden. ${ }^{75}$

Schließlich muss noch der Schadenersatz berücksichtigt werden, der sich in Znaim im Jahr 1430 auf 755 Gulden belief, so man jene Schäden abzieht, die nachweislich auf das Jahr 1429 zurückgingen und im Register vom November 1429 verzeichnet wurden. (Auch hier stellt sich selbstverständlich die Frage, wie vollständig die Schadenersatzquittungen sind.) Die jährlichen Ausgaben für Sold und Schadenersatz lassen sich damit in Znaim für das Jahr 1430 auf mindestens 7.600 Gulden beziffern. ${ }^{76}$

Sämtliche Schätzungen (Iglau 1423: mindestens 9.510 Gulden, Znaim 1429: mindestens 7.000 Gulden, Znaim 1430: mindestens 7.600 Gulden) sind eher konservativ angesetzt. Trotzdem handelt es sich um sehr hohe Summen, die sehr anschaulich zeigen, wie kostspielig Albrechts Pfandherrschaft über die ihm verpfändeten mährischen Städte bzw. über die ganze Markgrafschaft Mähren war. Wenn allein die Verteidigung von zwei - wenn auch großen und strategisch gelegenen - Städten die Kammer pro Jahr rund 15.000-17.000 Gulden kostete, müssen die Gesamtkosten für die Verteidigung Mährens gegen die Hussiten ab 1424 sicherlich das Doppelte, vielleicht sogar das Dreifache betragen haben (30.000-50.000 Gulden). ${ }^{77}$

Diese Annahme lässt sich mittels einer anderen Quelle verifizieren, und zwar den summarischen Abrechnungen (Raitbriefen) des Hubmeisters Berthold von Mangen, die

75 Es ist ungewiss, wie hoch der Sold zwischen dem 30. März 1430 und dem 25. Juli war. In der obigen Schätzung von 875 Gulden kalkuliere ich damit, dass der Hauptmann im zweiten Quartal nur noch 200 Gulden - wie im dritten und vierten Quartal - bekam. Sollte er 275 Gulden wie im ersten Quartal erhalten haben, läge die Gesamtsumme bei 950 Gulden.

76 Es handelt sich um eine etwas höhere Summe, als die obige Schätzung für das Jahr 1429, die auf dem erhaltenen Register basiert. Die Diskrepanz erklärt sich wohl dadurch, dass der Sold für den Hauptmann und dessen zwölf Söldner im Register unberücksichtigt bleibt. Das heißt, dass wohl auch die Schätzung für das Jahr 1429 um die entsprechende Summe zu erhöhen ist.

77 Die Überprüfung dieser Schätzung muss zukünftigen Forschungen überlassen bleiben. Neben den kleineren verpfändeten Städten Jamnitz und Pohrlitz unterhielt Albrecht ab 1424 zusätzliche Besatzungen in Brünn inkl. der Burg Spielberg, in Olmütz inkl. der Burg, in Ungarisch Hradisch/Uherské Hradiště und zeitweise auch in Littau/Litovel. Andererseits ist es sehr wahrscheinlich, dass die Iglauer Garnison nach dem Jahr 1423 wesentlich verkleinert wurde (womit man offenbar schon während des Jahres 1423 schrittweise begann) und dass entsprechend die Kosten für deren Unterhalt sanken. Aus den anderen Städten besitzen wir jedoch so gut wie keine Quellen, die jenen aus Iglau (1423) und Znaim (1429/1430) vergleichbar sind. 
für die ein- bzw. mehrjährigen Rechnungsperioden 1412-1416, 1423, 1424-1425, 14311433, 1434 und 1435 erhalten sind und eine Gesamtübersicht über die landesfürstlichen Finanzen Albrechts V. gewähren. ${ }^{78}$

Die Rechnungsperiode 1412-1416 lasse ich beiseite, da sie für die mährischen Verhältnisse irrelevant ist, und komme sofort zum Raitbrief für das Jahr 1423. In diesem wird ausgeführt, dass für die behüttung und versargnuss unserr fümf stet und geslos zu Behem und in Merhern gelegen, und die genant sind Budweis, Igla, Jemnitz, Znoim und Boherlicz 28.850 Pfund 6 Schilling 19 Pfennig (i. e. 38.467 Gulden 4 Schilling 19 Pfennig) ausgegeben wurden. ${ }^{79}$ Diese Summe korrespondiert exakt mit den oben errechneten Mindestausgaben für die Iglauer Söldner. In Budweis und Znaim dürften die Kosten ungefähr gleich bzw. etwas niedriger, in den kleineren Städten Jamnitz und Pohrlitz wohl deutlich geringer gewesen sein.

In der zweijährigen Abrechnungsperiode von 1424/1425 fielen für die Verteidigung Mährens - dieses Mal nicht nur der verpfändeten Städte, sondern auch der übrigen markgräflichen Städte und Burgen sowie des gesamten Landes - insgesamt 118.635 Pfund 3 Schilling 27 Pfennig (i. e. 158.181 Gulden 27 Pfennig) an. ${ }^{80}$ Daraus ergeben sich durchschnittlich 59.317 Pfund (i. e. 79.090 Gulden) pro Jahr, was noch wesentlich über meiner obigen Schätzung (30.000-50.000 Gulden) liegt. In diesen wahrhaft enormen Summen, die $60 \%$ der Ausgaben der herzoglichen Kammer in diesen Jahren ausmachten, dürften jedoch auch die Kosten jener drei großen Kriegszüge enthalten sein, die Herzog Albrecht im betreffenden Zeitraum nach Mähren unternahm. ${ }^{81}$

In der dreijährigen Abrechnungsperiode 1431-1433 wurden für die Verteidigung Mährens nur noch 65.121 Pfund 2 Schilling 8 Pfennig (i. e. 86.828 Gulden 2 Schilling 8 Pfennig) ausgegeben. ${ }^{82}$ Dies ergibt ca. 21.707 Pfund (i. e. 28.943 Gulden) pro Jahr, was dieses Mal etwas unter meiner obigen Schätzung liegt. In die Gesamtsumme eingerechnet ist vermutlich ein großer Kriegszug nach Mähren im Jahr 1431. Diese Diskrepanz lässt sich wohl nur erklären, wenn man annimmt, dass die österreichischen Besatzungen in Mähren im Vergleich zu den Vorjahren stark reduziert wurden, weil Herzog Albrecht seine Kräfte nun auf die Verteidigung des Herzogtums Österreich konzentrierte.

Der Vollständigkeit halber sei noch angeführt, dass die Verteidigung Mährens im Jahr 1434 mit 23.053 Pfund 3 Pfennig (i. e. 30.737 Gulden 2 Schilling 3 Pfennig) zu

78 Siehe dazu Schalk, Karl: Oesterreichs Finanzverwaltung unter Berthold von Mangen 1412-1436. Blätter des Vereines für Landeskunde von Niederösterreich, Neue Folge 15, 1881, S. 277-299.

79 Die Edition des betreffenden Raitbriefs bei Kurz, F.: Österreich, 2, S. 325-328, Beilage Nr. 21, hier S. 327.

80 Die Edition des betreffenden Raitbriefs bei Schalk, K.: Oesterreichs Finanzverwaltung, S. 290-291, Nr. 3, hier S. 291: So werdent auch in der egenanten raittung aigenleich beruert die hunderttausent achtzehentausent sechshundert und fumfunddreyssig phunt drey schilling und sybenundzwainczig phening, die die zway jar auf soeldnen behuettung und versargnuss auf unser lande ze Maerhern und auf unser stet und gesloesser daselbs sind ausgegeben worden und versoldnet. In Unterschied dazu wurden in derselben zweijährigen Periode für die Bemannung der österreichischen Burgen sowie zweier Grenzstädte, Drosendorf und Waidhofen an der Thaya, lediglich 8.975 Pfund 82 Pfennig (i. e. 11.967 Gulden 22 Pfennig) ausgegeben.

81 Die Aufteilung der Kosten zwischen der Verteidigung der befestigten Orte und den Kriegszügen bleibt völlig im Dunkeln.

82 Die Edition des betreffenden Raitbriefs bei Schalk, K.: Oesterreichs Finanzverwaltung, S. 292-294, Nr. 4. 
Buche schlug, ${ }^{83}$ im Jahr 1435 dann sogar mit 32.330 Pfund 4 Schilling 8 Pfennig (i. e. 43.107 Gulden 2 Schilling 8 Pfennig), was eine neuerliche Erhöhung der Kriegsausgaben darstellt, die aber vermutlich auch die Rückeroberung oder Auslösung einiger Burgen umfassten. ${ }^{84}$

Dieser detaillierte Exkurs zeigt, dass die Ausgaben in Iglau 1423 und in Znaim 1429/1430 auch im Vergleich zu den übrigen Ausgaben der herzoglichen Kammer für die Verteidigung Mährens durchaus bedeutsame Summen darstellten. Albrecht muss beide Städte für strategisch wichtig erachtet haben; besonders natürlich Znaim, das eine wichtige Straße nach Niederösterreich sicherte.

Im Zusammenhang mit der Entwicklung der herzoglichen Finanzen ist aber noch eine weitere Beobachtung von besonderem Interesse. Wenn wir die Quittungen aus dem Jahr 1423 mit dem Register von 1429 vergleichen, sehen wir, dass die Kammer 1423 stets zu Beginn der sechswöchigen Abrechnungsperiode alle Söldner rechtzeitig bezahlte, während sie den Söldnern in Znaim 1429 etwa 1.800 Gulden schuldig geblieben war. Im darauffolgenden Jahr war die Zahlungsmoral wieder besser, aber auch damals verzögerten sich einzelne Zahlungen beträchtlich. Dies könnte einerseits auf eine zunehmende Verschuldung der Kammer im Lauf des Hussitenkriegs hindeuten, andererseits aber auch bestätigen, dass die finanzielle Lage des Herzogs zu Beginn der 1420er Jahre ungewöhnlich günstig war, nachdem sich die landesherrlichen Finanzen durch die außerordentlichen Einnahmen im Zuge der flächendeckenden Vertreibung bzw. Ermordung der österreichischen Juden (die sog. Wiener Gesera) vorübergehend erhöht hatten. ${ }^{85}$ Dies belegen auch die besprochenen Raitbriefe Bertholds von Mangen ganz eindeutig. Während aus den Jahren 1420-1422 keine Raitbriefe erhalten sind, wissen wir aus dem Raitbrief für das Jahr 1423, dass die Kammer einen riesigen Rechnungsüberschuss von 23.572 Pfund (i. e. 31.429 Gulden) aus dem Vorjahr verbuchen konnte und auch im laufenden Jahr immer noch einen Überschuss von 16.707 Pfund (i. e. 22.276 Gulden) erzielte. ${ }^{86}$ Diese völlig irreguläre Situation dürfte entsprechend auch für die pünktliche Bezahlung der Iglauer Söldner verantwortlich gewesen sein.

83 Ebd., S. 294-296, Nr. 5, hier S. 296: Item auf behüttung, verwesung und soldnen unsers lands ze Merhern, unsern haubtleuten, ettleichen unsern reten, landleuten und dienern daselbs sind gangen 23.053 pfund 3 pfennig. Die analogen Kosten in Österreich machten lediglich 13.133 Pfund 5 Schilling 12 Pfennig (i. e. 17.511 Gulden 3 Schilling 12 Pfennig) aus.

84 Ebd., S. 296-298, Nr. 6, hier S. 298: Item auf behuttung, verwesung und soeldnen unsers lands ze Merhern, auf gewinnen und losung ettleicher geslos, die wir aus der veind hannden pracht haben, hat er ausgerichtt unsern haubtleuten, reten, lantleuten und dienern daselbs zu sold, scheden, phantlosung und salniter und andern geczeug 32.330 pfund 4 schilling 8 pfennig. Die Verteidigung Österreichs kostete im selben Jahr nur 7.327 Pfund 5 Schilling 10 Pfennig (i. e. 9.770 Gulden 1 Schilling 10 Pfennig).

$85 \mathrm{Zu}$ den finanziellen Aspekten der Wiener Gesera siehe Elbel, Petr - Ziegler, Wolfram: Am schwarczen suntag mardert man dieselben juden, all die zaigten vill guets an under der erden... Die Wiener Gesera: eine Neubetrachtung. In: Teufel, Helmut - Kocman, Pavel - Ǩepa, Milan (Hgg.): Avigdor, Benesch, Gitl. Juden in Böhmen, Mähren und Schlesien im Mittelalter. Samuel Steinherz zum Gedenken (1857 Güssing - 1942 Theresienstadt). Brünn - Prag - Essen 2016, S. 201-268, hier S. 224-260. 


\subsection{Weitere Möglichkeiten der historischen Auswertung}

Einen zweiten Themenkreis, der hier nur noch ansatzweise vorgestellt werden kann, stellt die Militärgeschichte des spätmittelalterlichen Söldnerwesens dar. Zu diesem Themenkreis gehören z. B. Stärke, Struktur und Organisation von Söldnertruppen, Ausrüstung der Söldner, Preise von Waffen, Pferden usw. Von diesen Fragen lässt sich hier lediglich die erste verhältnismäßig leicht beantworten: jene nach der zahlenmäßigen Stärke der österreichischen Garnisonen in Iglau und Znaim. Wie bereits bei der Vorstellung der Quittungen gezeigt wurde, schwankte die Anzahl der in den beiden Städten stationierten berittenen Söldner zwischen ca. 100 und 300, in der Regel bewegte sie sich jedoch zwischen 150 und 200 Söldnern. In Iglau kamen dazu noch 50-100 Fußsoldaten; es ist jedoch unklar, ob diese dauerhaft oder lediglich vorübergehend in der Stadt anwesend waren. Ebenso unklar ist, ob es auch in Znaim ein gesondertes Kontingent Fußvolk gab. In Znaim lässt sich wiederum eine kleine, dem Hauptmann unterstellte Sondereinheit von zwölf Mann belegen, die speziell die Znaimer Burg bewachte.

$\mathrm{Zu}$ den herzoglichen Söldnern kamen jedoch in beiden Städten noch das städtische Aufgebot und die durch die Städte angeworbenen Söldner. Das Aufgebot dürfte sowohl in Iglau als auch in Znaim mehrere Hunderte Mann gezählt haben. Nach František Hoffmann kann man in Iglau mit etwa 1.500 waffenfähigen Männern rechnen, jedoch waren wohl nur ca. $10 \%$ von ihnen beritten, während der Rest das Fußvolk bildete. ${ }^{87}$ Die von den Städten angeworbenen Söldnertruppen, die die Reihen der berittenen Bürger verstärken sollten, waren in Iglau sowie in Znaim zahlenmäßig eher bescheiden und umfassten höchstens einige Dutzend Männer. Größere Kontingente konnten sich die mährischen Städte offensichtlich nicht leisten. ${ }^{88}$

Einen dritten Themenkreis, der sich anhand der Quellen bearbeiten lässt, bildet die Frage nach der territorialen, nationalen und sozialen Zusammensetzung der Söldnertruppen, die auch mit der Frage der Anwerbung zusammenhängt, wozu die erhaltenen Quellen allerdings keine direkten Aussagen liefern.

Eine prosopographische Analyse der österreichischen Söldner in Iglau und Znaim wäre wohl sehr anspruchsvoll, da die Söldner offensichtlich nicht nur aus den habsburgischen Territorien von Niederösterreich bis in die Schweiz und aus den böhmischen Ländern, sondern auch aus Bayern und anderen süddeutschen Territorien stammten. Zu dem

87 Hoffmann, F.: Jihlava, S. 155-156.

88 Nach Hoffmann, F.: Jihlava, S. 158, können städtische Söldner in Iglau nur im ersten Losungbuch aus dem Jahr 1425 zuverlässig nachgewiesen werden; danach dürfte die Stadt keine Söldner mehr unterhalten und sich auf die Besatzung Herzog Albrechts und im Notfall auf das städtische Aufgebot verlassen haben. Die im Jahr 1425 für Sold verbuchte Summe entspricht nach Hofmann 56 Reitern oder 75 Fußsoldaten. In Znaim finden sich städtische Söldner in den detaillierten sogenannten Ratsrechnungen, die für einige Rechnungsjahre, z. B. 1427-1428, erhalten sind (MZA Brno - SOkA Znojmo, Bestand AM Znojmo, Stadtbücher, Sign. II 243, fol. 23v-24r; 119r-v). Ein kurzer Blick auf das letztgenannte Rechnungsbuch zeigt eine überraschende Tatsache: Einige Männer, die 1429-1431 unter Jörg Laun in Znaim dienten, waren (zuvor) im Dienst der Stadt tätig. Wir haben aus den Jahren 1429-1431 keine Liste der von der Stadt bezahlten Söldner, weswegen wir nicht wissen, ob die Betreffenden zwischen 1428 und 1429 den städtischen Dienst verließen und nur mehr dem herzoglichen Hauptmann dienten, oder ob sie parallel von der Stadt und Herzog Albrecht bezahlt wurden, was allerdings eher unwahrscheinlich scheint. 
riesigen geographischen Raum kommt noch die Tatsache hinzu, dass die Söldner in der Regel kleinadeliger, oft aber auch nicht-adeliger Herkunft waren, sodass es nicht leicht ist, ihre Prädikate, geschweige denn ihre Zu- und Rufnamen irgendwie einzuordnen.

Die Identifizierung der Söldner aus Böhmen und Mähren wird zudem noch durch die Tatsache verkompliziert, dass die deutschsprachigen Schreiber ihre Namen häufig verstümmelten. So dürfte z. B. ein Mann, der in den Znaimer Ratsrechnungen des Jahres 1427 als Štěpánek (in der latinisierten Form Sczepanko) erscheint, ${ }^{89}$ mit dem [Steffen] Tschepenko des Registers vom 9. November 1429 und der Quittung vom 19. April 1430 ident sein. ${ }^{90}$

Eine Tatsache, die schon bei der oberflächlichen Lektüre des Materials ins Auge fällt, sind die zahlenmäßigen Unterschiede bei den eindeutig tschechischen Namen, die auf eine mährische bzw. böhmische Herkunft der Söldner hindeuten. In Iglau scheint der tschechische Anteil sehr bescheiden gewesen zu sein. Während etwa 50 Personen eindeutig deutsche Namen tragen, scheinen nur fünf bis sechs Personen aus Böhmen und Mähren gekommen zu sein (mit Sicherheit lässt sich das nur von dem böhmischen Ritter Ulrich Močihub von Kralovice sagen).$^{91}$

In Znaim, wo deutlich mehr Söldner namentlich bekannt sind, war der böhmischmährische Anteil wesentlich höher. So gibt es beispielsweise im Register vom November 142920 Personen mit (eher) tschechischen ${ }^{92}$ und 65 Personen mit (eher) deutschen oder aber neutralen Namen; Nicolesch Unger dürfte ein Ungar oder Slowake gewesen sein. ${ }^{93}$ Der Anteil der einheimischen Söldner scheint in Znaim ungefähr bei einem Viertel gelegen zu haben, wobei sich unter den sprachlich neutralen und den deutschen Namen noch weitere Mährer verbergen könnten. ${ }^{94}$

Einen vierten Themenkreis, für welchen die vorgestellten Quellen herangezogen werden können, bildet schließlich die Ereignisgeschichte des Hussitenkriegs, der man sich vor allem im Zusammenhang mit der Beschreibung erlittener Schäden annähern

89 MZA Brno - SOkA Znojmo, Bestand AM Znojmo, Stadtbücher, Sign. II 243, fol. 119r-v (Nota dampna stipendiariorum).

90 HHStA Wien, AUR, 1429 XI 09, fol. 9v, bzw. HHStA Wien, AUR, 1430 IV 19. Für die Identifizierung des Štěpánek (Sczepanko) der Ratsrechnungen mit dem [Steffen] Tschepenko der Quittungen spricht auch die Tatsache, dass neben diesem jeweils ein zweiter Söldner namens Licek (Liczko, Lyczko) erscheint. In den Ratsrechnungen von 1427 sowie im Register vom 9. November 1429 werden die beiden nacheinander genannt, die Quittung vom 19. April 1430 stellten sie gemeinsam aus.

91 Neben Ulrich Močihub kamen möglicherweise folgende Personen aus Böhmen und Mähren: Liczko Pechiner, Gråbo Pechiner, Peter Zedliczer, Peter Lyebusch und Polåko, wobei der Letztgenannte vielleicht eher aus Polen oder Schlesien stammte - siehe die Quittungen vom 25. und 29. Mai 1423; HHStA Wien, AUR, 1422 IV 22; Loserth, J. - Beck, J.: Urkundliche Beiträge, 1896, S. 178-179, Nr. 25; S. 179, Nr. 26.

92 HHStA Wien, AUR, 1429 XI 09, fol. 4r-5r, 6v, 8r-11r, 14v-15v. Eindeutig oder eher tschechische Namen tragen folgende Personen: Noss, Nicolesch Pehëm, Niklas Serkowicz, Nicklas Machwicz, Wenczlab Rotenperger (?), Henuschko, Welgko, Hanns Huss, junger Lautterlepisch, klein Hanuschko, Liczko, Tschepenko, Wenczlab, Sigmund von der Pulicz, alter Lawtterleppisch, Sokal, Hewgko, Nossko, Jenko, Petereschk. Bei der Familie Lawtterleppisch muss die Quittung vom 20. November 1434 zugezogen werden, die Hanusko und Marcus Lautterleappisch ausstellten. Der Vorname Hanušek ist tschechisch (es handelt sich um eine Verkleinerungsform des Namens Hanuš/Hans), was auf eine tschechische Herkunft dieser Familie hindeutet.

93 Ebd., fol. 16r.

94 So findet sich im Register etwa ein gewisser Philipp, der identisch mit Philipp von Wischau/Vyškov aus der Quittung vom 29. Mai 1430 sein könnte. 
kann. Vor allem im Znaimer Register vom 9. November 1429 und in den erhaltenen Quittungen erfahren wir von zahlreichen bekannten und bisher unbekannten Episoden des mährisch-österreichischen Hussitenkriegs: hussitische Züge über Znaim, der Raub städtischen Viehs durch hussitische Truppen, ${ }^{95}$ Gegenzüge der Znaimer Garnison zu den hussitischen Burgen und Städten Jeispitz, Mährisch Kromau und Eibenschitz, ${ }^{96}$ die Beteiligung der Garnison an Kriegsaktionen in entfernteren Regionen Mährens und in Niederösterreich, ${ }^{97}$ Geleit für diverse Reisende und ähnliches. ${ }^{98}$

\section{Schlussfolgerungen}

Zusammenfassend lässt sich festhalten, dass die in diesem Aufsatz besprochenen Zeugnisse der pragmatischen Schriftlichkeit eine hoch interessante und bisher nur wenig genutzte Quelle zur Geschichte des mährischen und österreichischen Hussitenkriegs darstellen. Dies gilt sowohl für deren historische Auswertung, die hier nur angedeutet werden konnte und der ich mich an anderem Ort noch ausführlicher widmen werde, als auch für deren Form, die hier im Vordergrund stand. Unter dem Blickwinkel der Diplomatik muss betont werden, dass es sich hier um die älteste Schicht der mit dem Söldnerwesen verbundenen pragmatischen Schriftlichkeit im böhmisch-mährischen Raum handelt, die gleichzeitig einen hohen Entwicklungsstand aufweist, was sich durch die österreichische Provenienz dieser Schriftstücke erklärt.

Im Anhang finden sich zunächst drei Tabellen, die dem/der Leser/in die Orientierung erleichtern, eine Konkordanz mit den vorhandenen Editionen und Regesten bieten, sowie die bisher unedierten Stücke erstmals erschließen. ${ }^{99}$ Am Ende sind schließlich Abbildungen ausgewählter Schriftstücke beigegeben, die die Vielfalt des besprochenen Materials veranschaulichen.

95 Im Schadenzettel Reichart Meixners heißt es z. B.: Aber ist im ewer gnad schuldig umb ain phärd, ist im tod, als dy von Krumbnaw hie vor der stat am nachsten das vich genomen haben, als wir in das wider abgeeilt haben; das hat er kauft umb zwelf guldein... - HHStA Wien, AUR, 1430 X 18 (sic!); vgl. QGStW, S. 47, Nr. 14555. Noch detaillierter wird dasselbe Ereignis im Schadenzettel Sigismunds von Police geschildert: Ewr gnad ist dem Sigmund von der Pulicz schuldig von schaden wegen yecz pey sechs wochen als dy von Krumbnaw und dy von Ë̈waczschicz ain halt hie vor der stat gehabt haben und namen hie das vich; das eylt wir in wider ab, da ist ym ain phard tod, das schäczt er umb XX guldein... - HHStA Wien, AUR 1430 IX 11; vgl. QGStW, S. 47, Nr. 14556.

96 Der Schadenzettel Hans Posars verzeichnet einen Zug nach Jeispitz nördlich von Znaim: Aber ist im ewer gnad schuldig um ain phard, hat er verlorn gen Jäwspicz, schäczt er umb czwelf guldein, und hat verlorn ain eisenhut, ain armbst, ain swert, schäczt er als umb vier guldein - HHStA Wien, AUR, 1430 X 04; vgl. QGStW I/7, S. 48 , Nr. 14560 .

97 Derselbe Schadenzettel Hans Posars erwähnt auch einen Zug nach Hradisch: Ewr gnad ist dem Posar schuldig von schäden wegen umb ain phärd, ist ̈̈m tod, als er mit dem Ebsar ist gein Rädis geritten, das schäczt er umb $\stackrel{e}{a}$ cht schokch - ebd. Im Register vom 9. November 1429 heißt es in dem Eintrag unter dem Namen Licek: So ist man im schuldig von scheden wegen fur II ph(erd) czu Waihofen und zu Krembs XX guldein - siehe HHStA Wien, AUR, 1429 XI 09, fol. 9v.

98 Im selben Register heißt es unter dem Namen Tschepenko/Štěpánek: So ist man im schuldig fur I ph(erd) herren Heschken glaits VIIII guld. - siehe ebd.

99 Angesichts der historischen und diplomatischen Bedeutung dieses Quellenkorpus wäre jedoch eine Volltextedition aller hier bearbeiteten Schriftstücke an einem Ort sehr wünschenswert. 


\section{Anhang}

Vorbemerkung zu den Tabellen 1-3: Die Namen der Söldner, Hauptleute oder Siegler werden bewusst buchstabengetreu wiedergegeben, auch wenn etliche Personen bereits identifiziert werden konnten. Der Inhalt der einzelnen Urkunden wird in From von Kurzregesten präsentiert. Nähere Beschreibungen erlittener Schäden im Urkundentext, etwaige Nachträge unter dem Textspiegel sowie Schadenzettel werden in extenso transkribiert. Für Geld- und Rechnungseinheiten werden die üblichen Kürzel verwendet: Gulden = fl. (in den Quellenzitaten auch guld.), Pfund = lb. (in den Quellenzitaten auch t. [den.]), Schilling $=\beta$, Pfennig $=\delta$ (in den Quellenzitaten auch den.). 


\begin{tabular}{|c|c|c|c|c|c|c|}
\hline 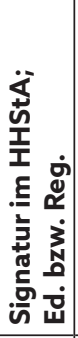 & 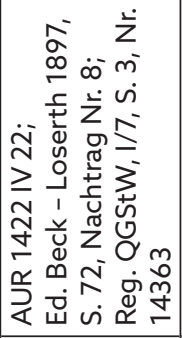 & 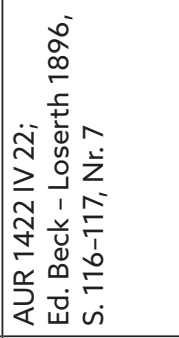 & 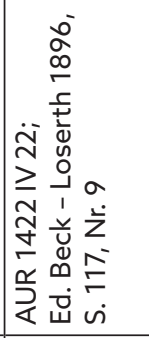 & 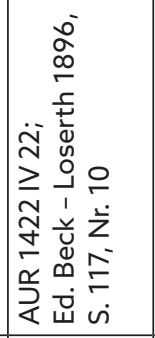 & 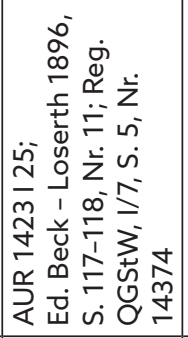 & 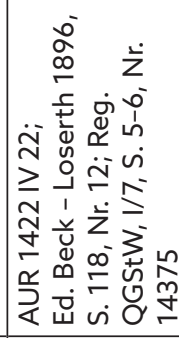 \\
\hline 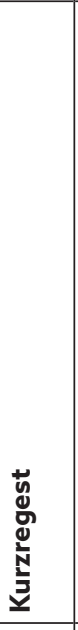 & 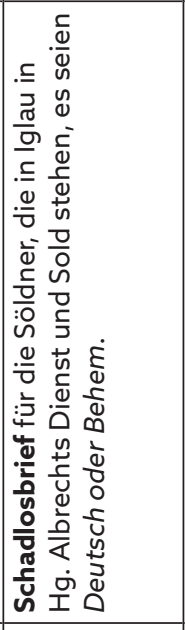 & 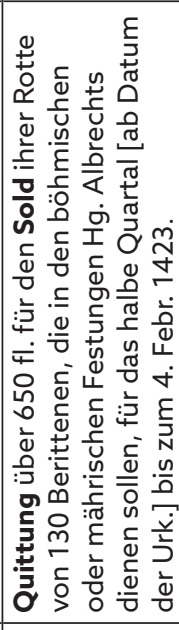 & 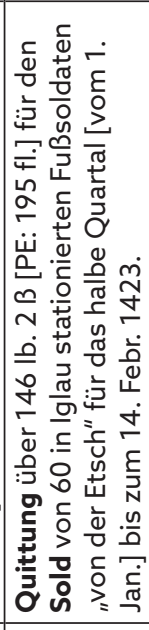 & 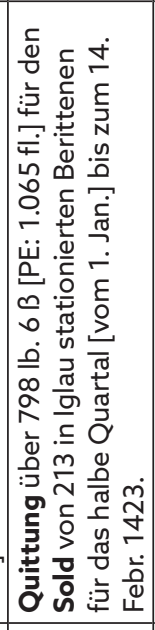 & 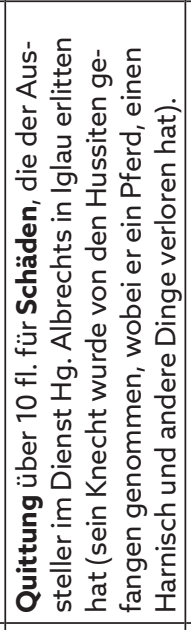 & 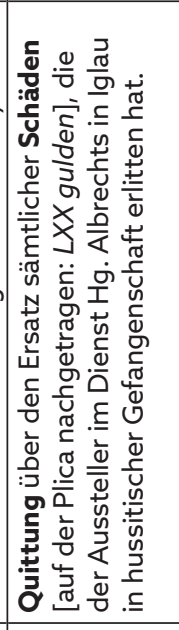 \\
\hline $\begin{array}{l}\frac{1}{0} \\
\frac{\omega}{\omega}\end{array}$ & 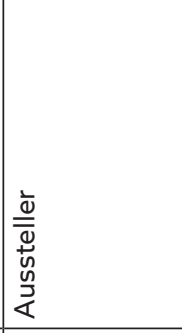 & 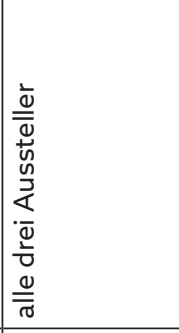 & 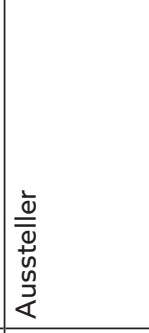 & 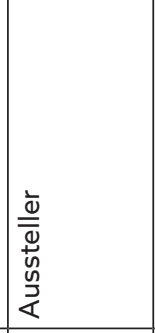 & 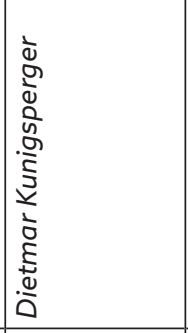 & 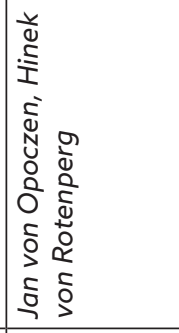 \\
\hline 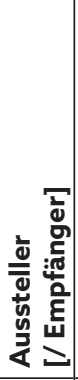 & 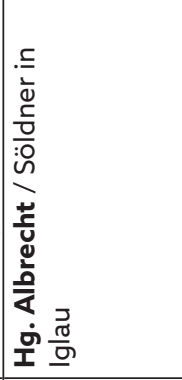 & 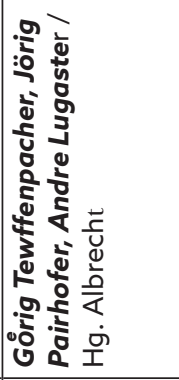 & 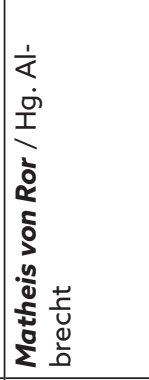 & 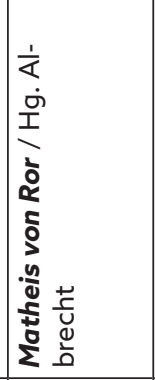 & 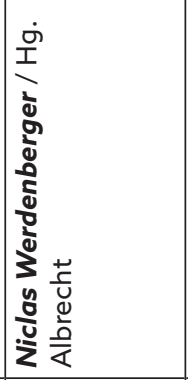 & 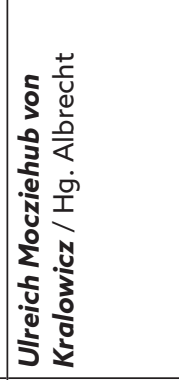 \\
\hline 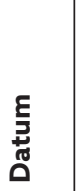 & 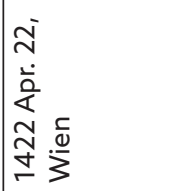 & 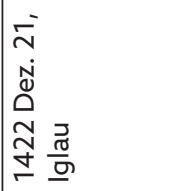 & 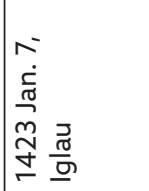 & 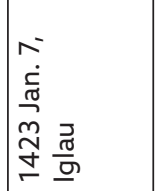 & 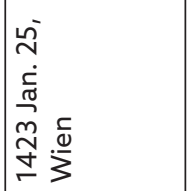 & 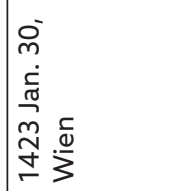 \\
\hline
\end{tabular}




\begin{tabular}{|c|c|c|c|c|c|}
\hline 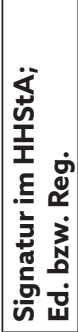 & 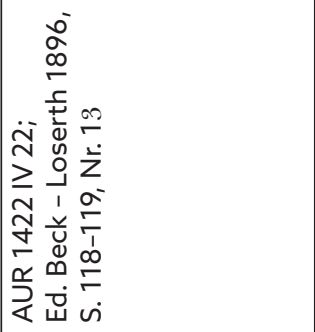 & 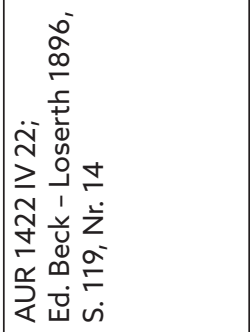 & 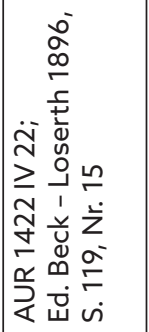 & 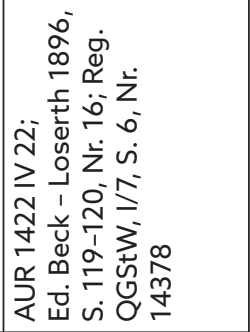 & 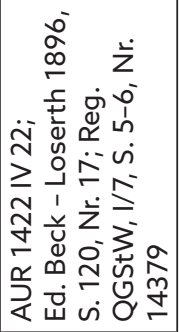 \\
\hline 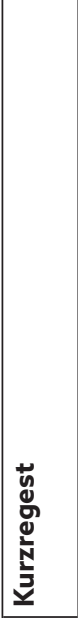 & 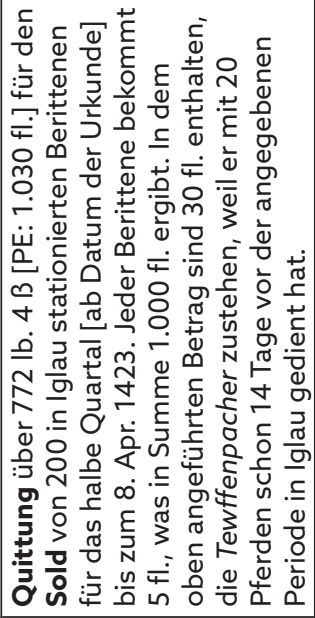 & 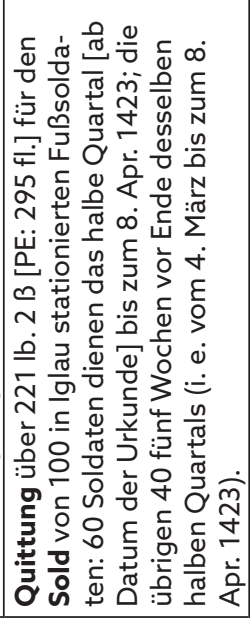 & 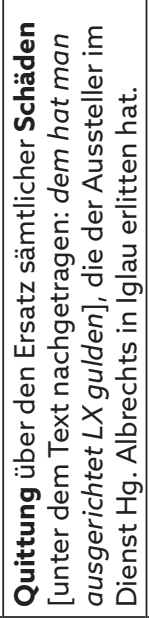 & 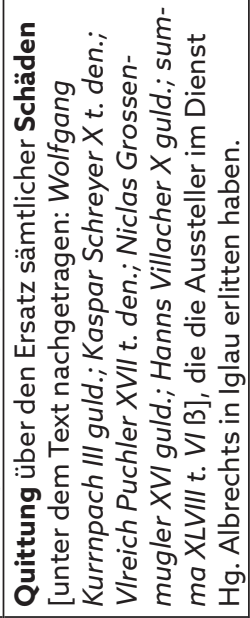 & 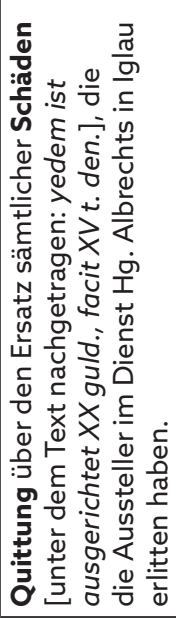 \\
\hline $\begin{array}{l}\frac{2}{0} \\
\frac{\omega}{\sigma} \\
\text { ज }\end{array}$ & 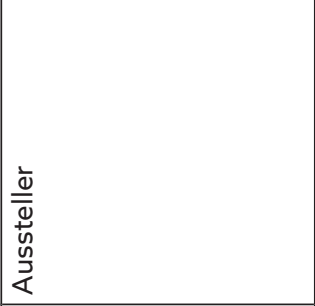 & 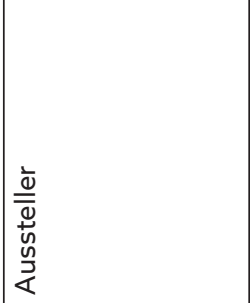 & 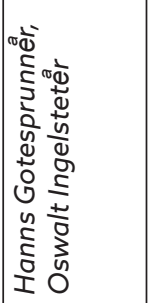 & 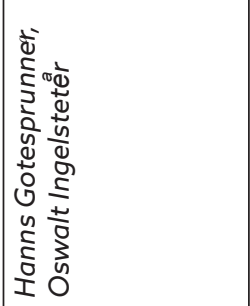 & 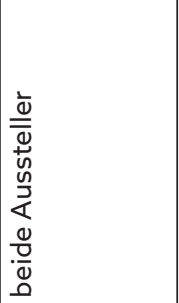 \\
\hline 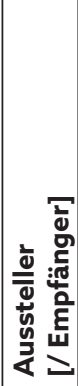 & 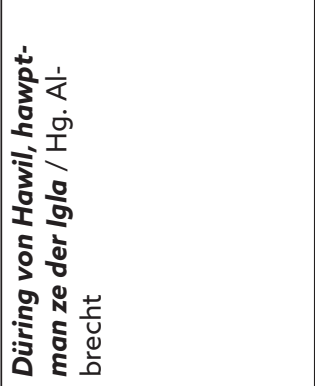 & 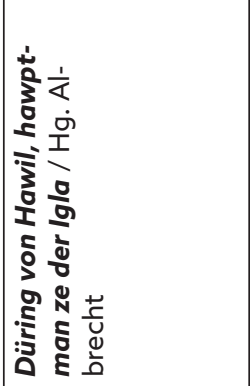 & 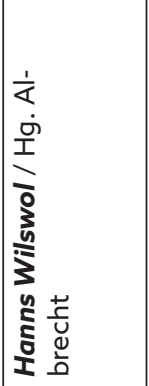 & 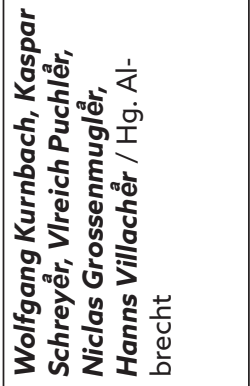 & 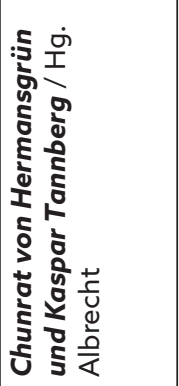 \\
\hline 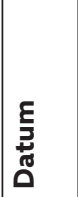 & 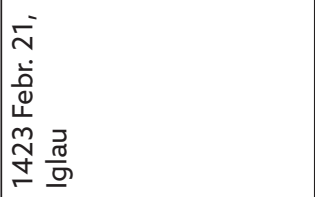 & 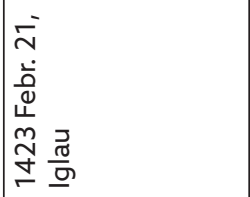 & 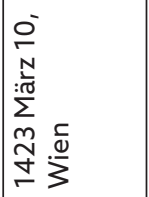 & 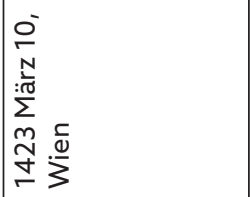 & 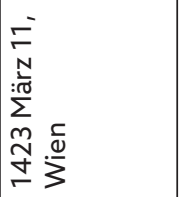 \\
\hline
\end{tabular}




\begin{tabular}{|c|c|c|c|c|c|c|}
\hline 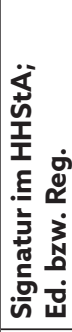 & 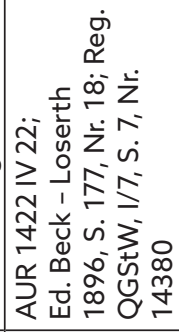 & 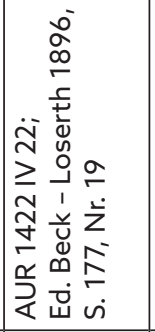 & 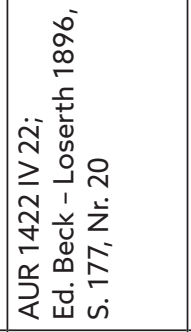 & 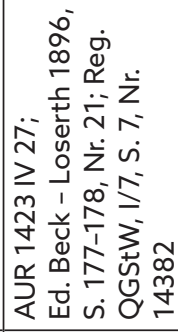 & 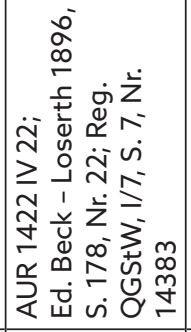 & 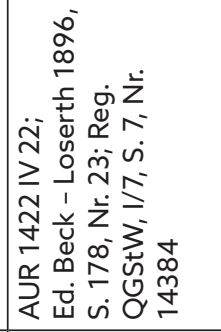 \\
\hline 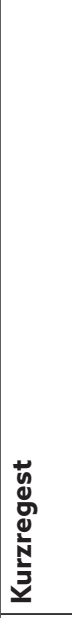 & 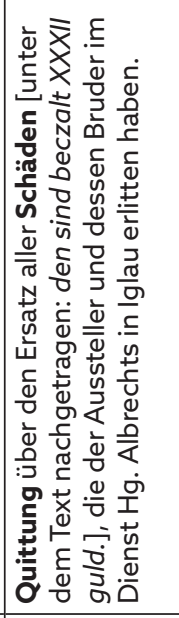 & 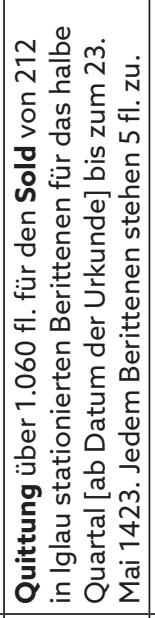 & 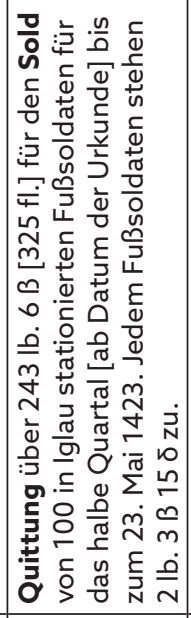 & 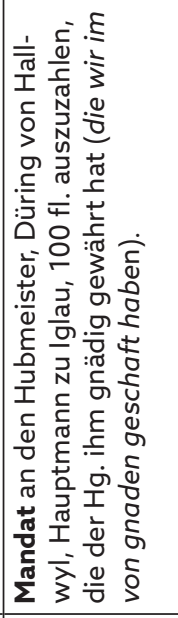 & 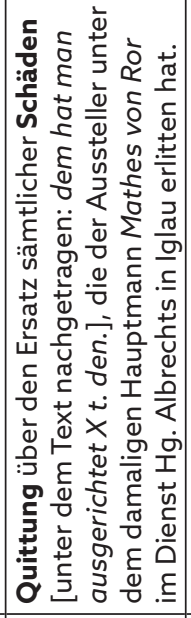 & 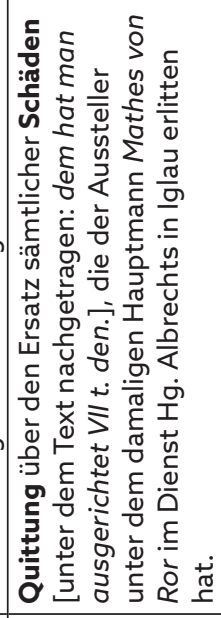 \\
\hline $\begin{array}{l}\frac{2}{0} \\
\frac{\omega}{5}\end{array}$ & 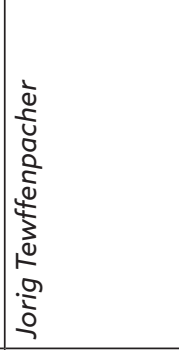 & 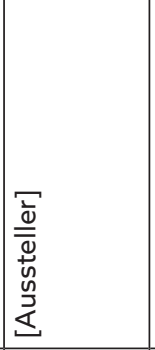 & 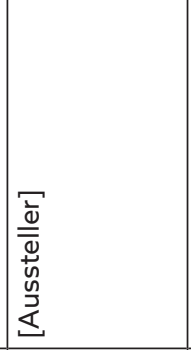 & 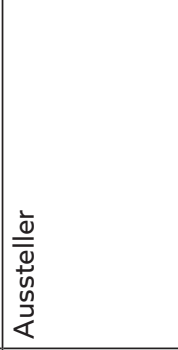 & 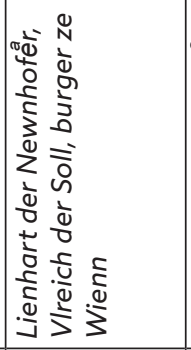 & 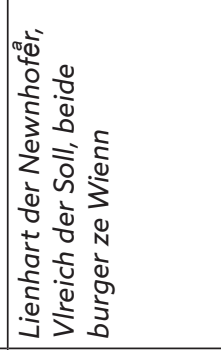 \\
\hline 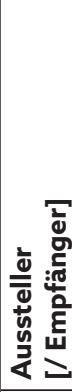 & 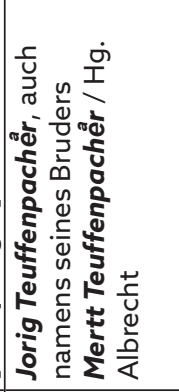 & 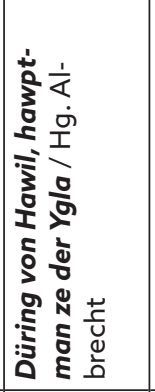 & 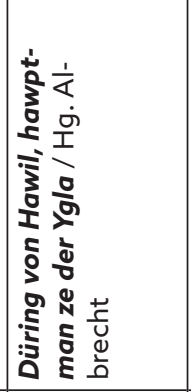 & 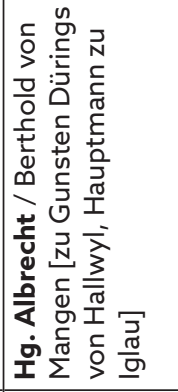 & 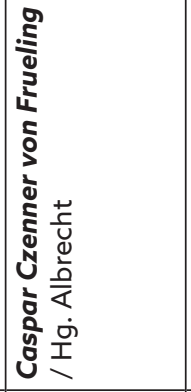 & 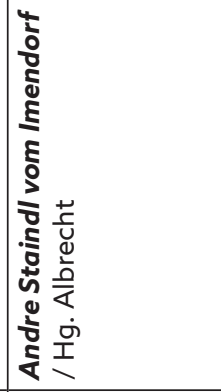 \\
\hline 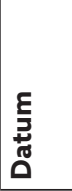 & 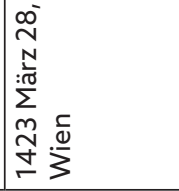 & 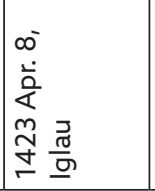 & 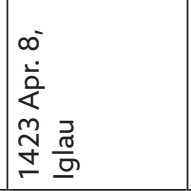 & 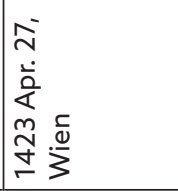 & 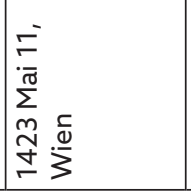 & 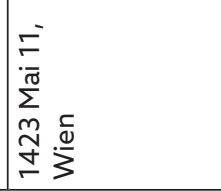 \\
\hline
\end{tabular}


Die Verschriftlichung des Kriegsalltages. Die Akten der während des Hussitenkrieges in Znaim ...

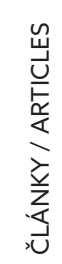

\begin{tabular}{|c|c|c|c|}
\hline 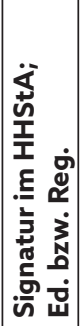 & 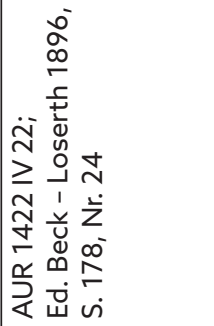 & 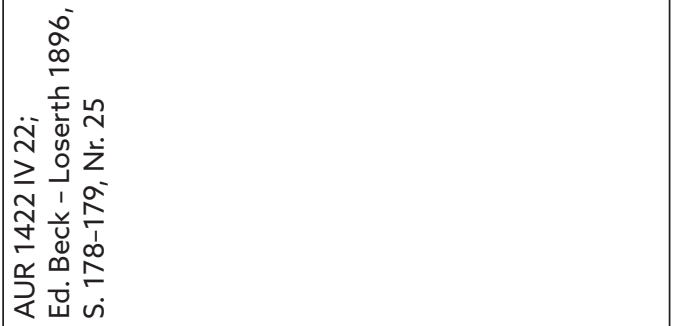 & 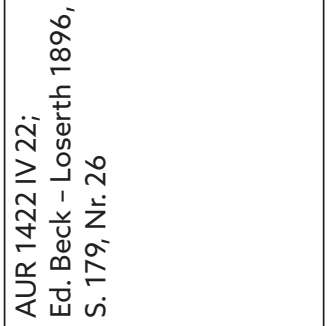 \\
\hline & 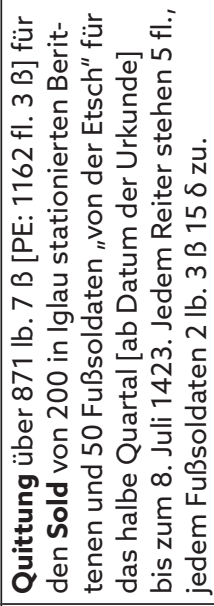 & 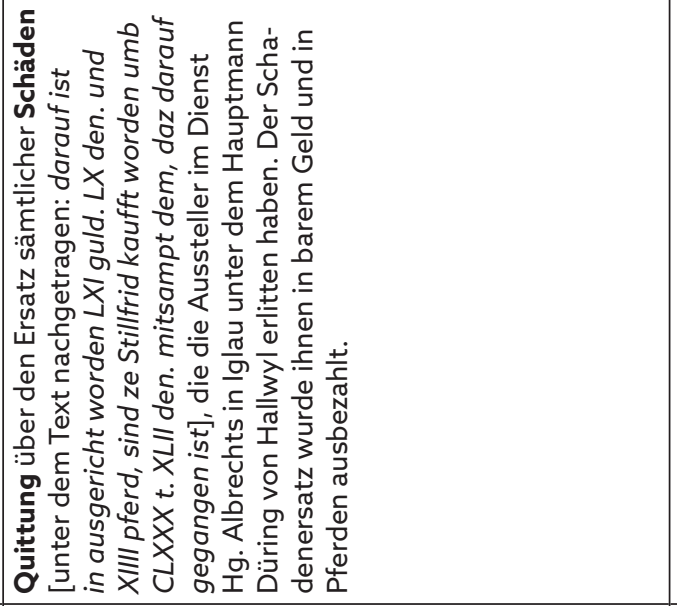 & 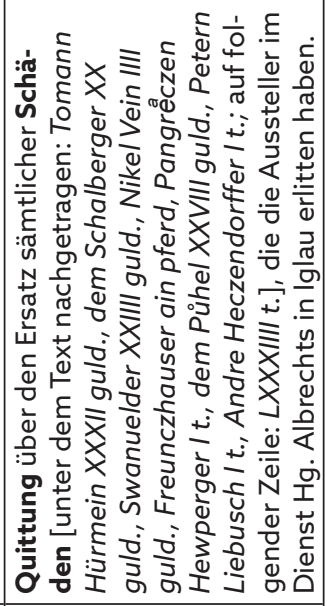 \\
\hline $\begin{array}{l}\frac{2}{0} \\
\frac{\pi}{6}\end{array}$ & & 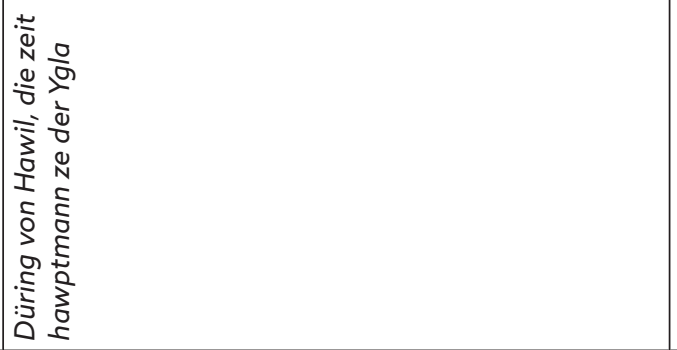 & 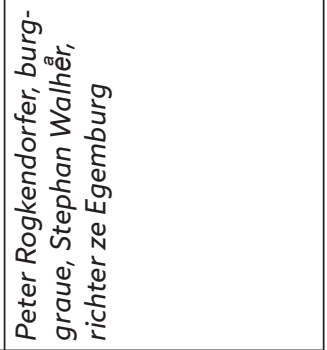 \\
\hline 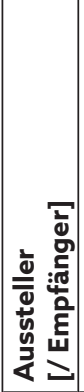 & 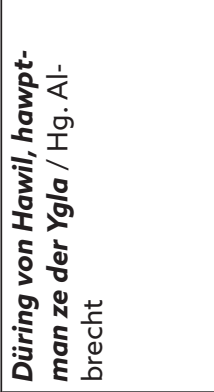 & 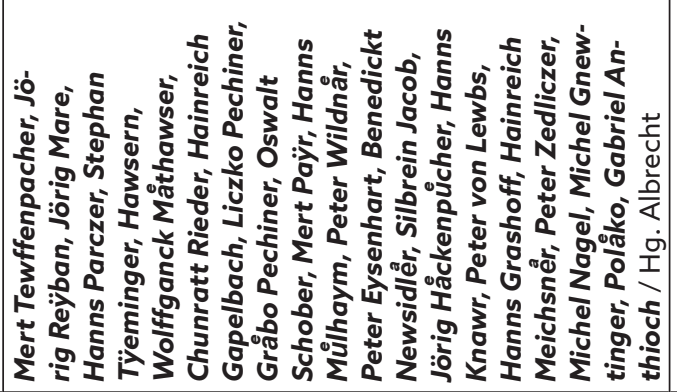 & 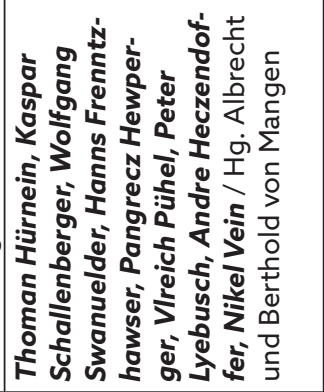 \\
\hline 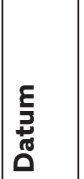 & 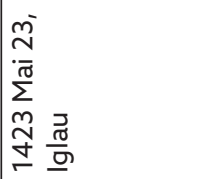 & 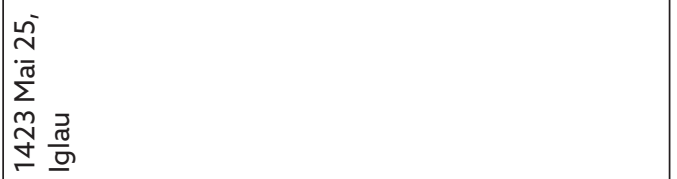 & 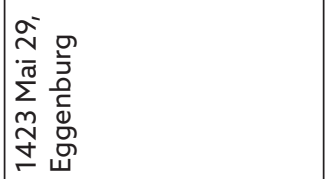 \\
\hline
\end{tabular}




\begin{tabular}{|c|c|c|c|c|c|}
\hline 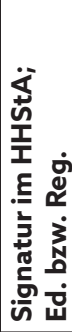 & 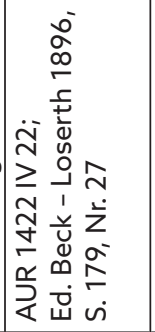 & 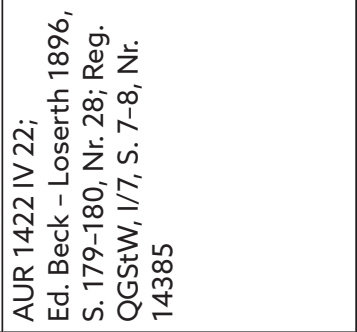 & 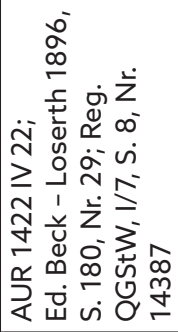 & 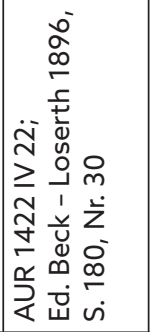 & 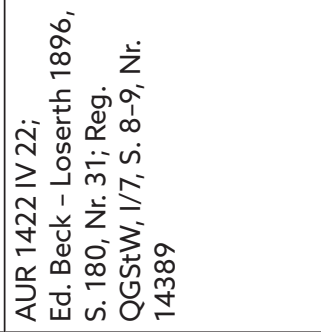 \\
\hline 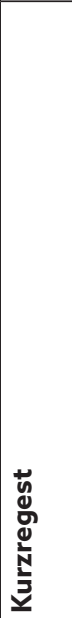 & 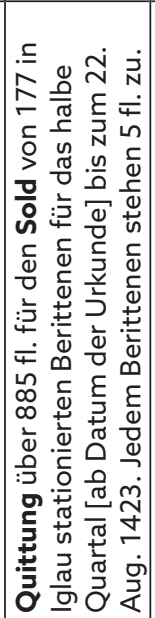 & 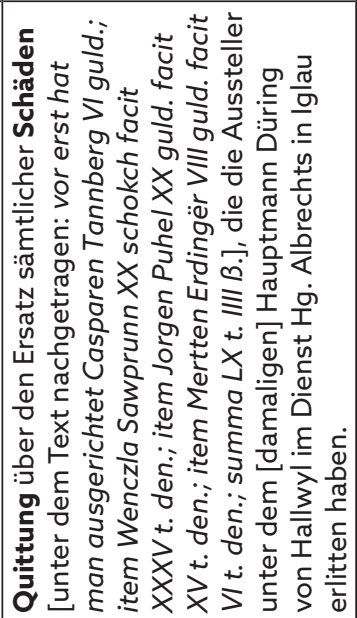 & 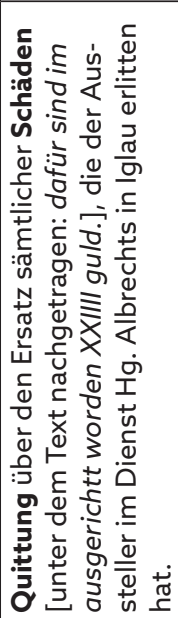 & 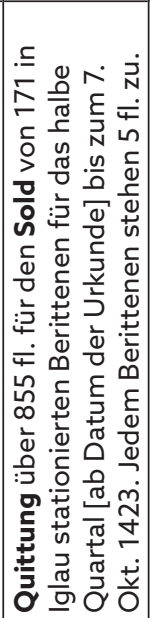 & 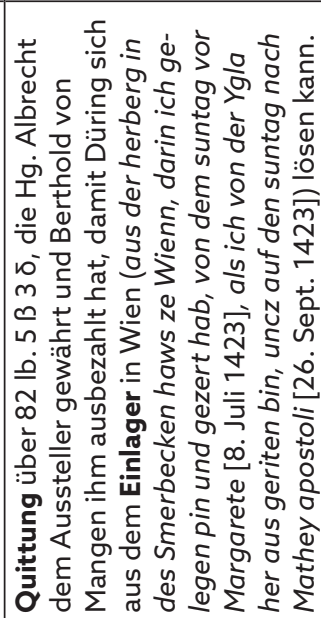 \\
\hline 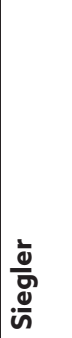 & & 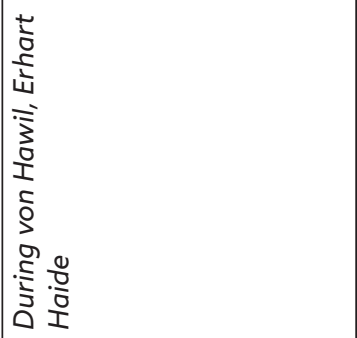 & 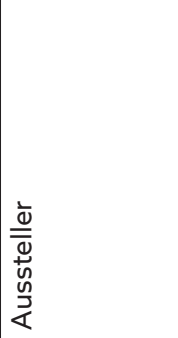 & 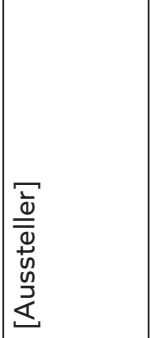 & 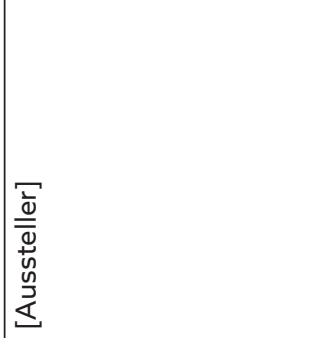 \\
\hline 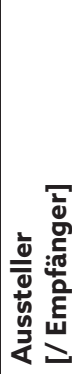 & 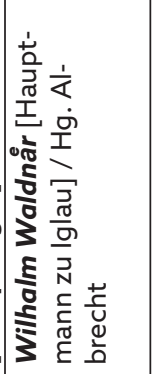 & 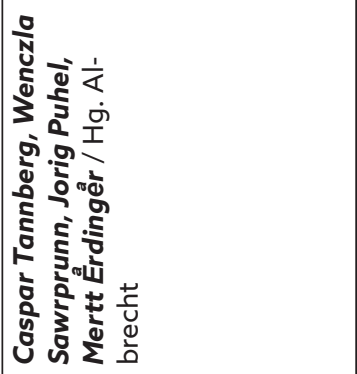 & 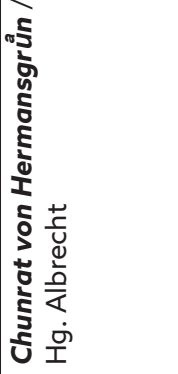 & 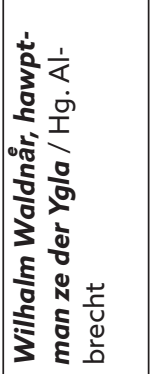 & 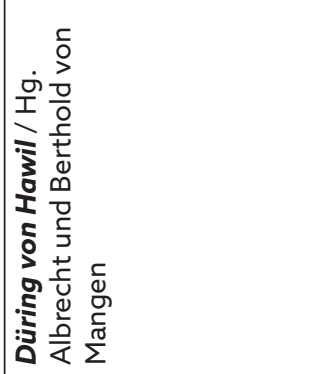 \\
\hline 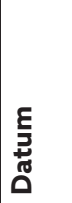 & 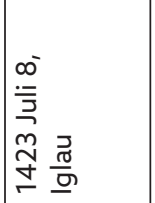 & 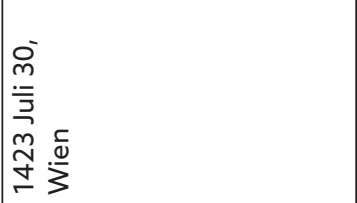 & 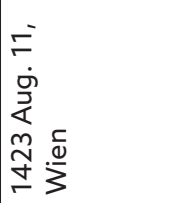 & 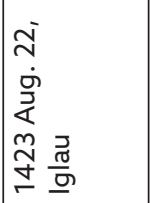 & 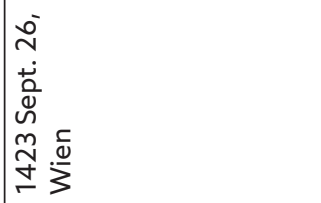 \\
\hline
\end{tabular}




\begin{tabular}{|c|c|c|c|}
\hline 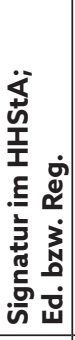 & 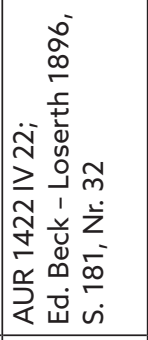 & 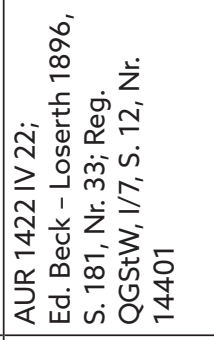 & 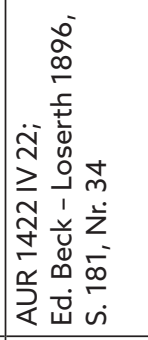 \\
\hline 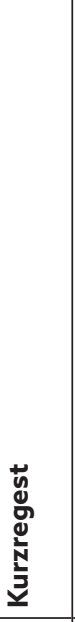 & 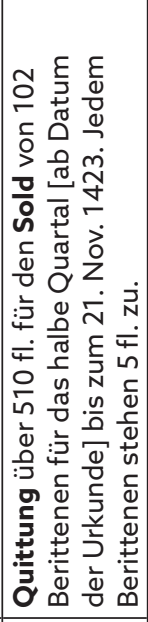 & 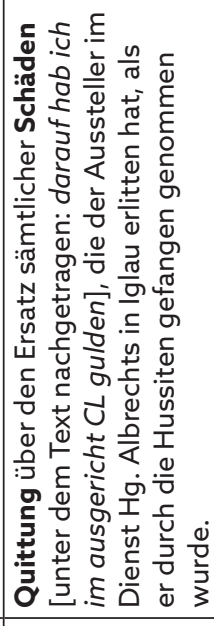 & 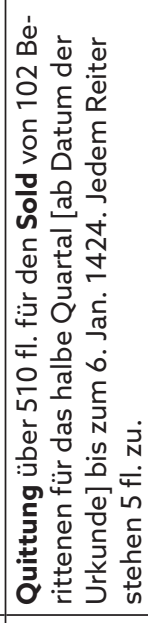 \\
\hline 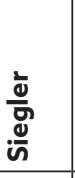 & 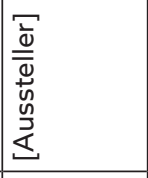 & 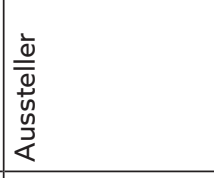 & 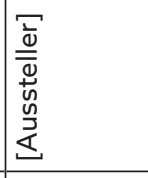 \\
\hline 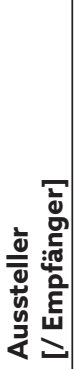 & 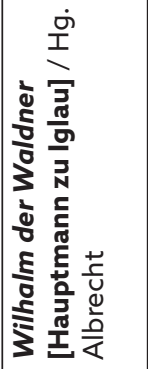 & 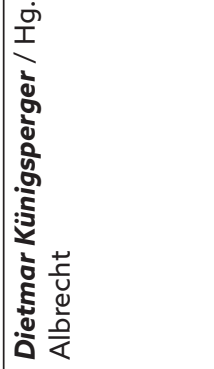 & 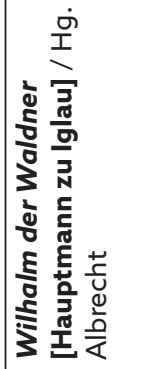 \\
\hline 点 & 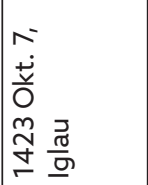 & 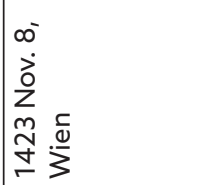 & 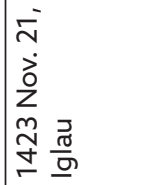 \\
\hline
\end{tabular}




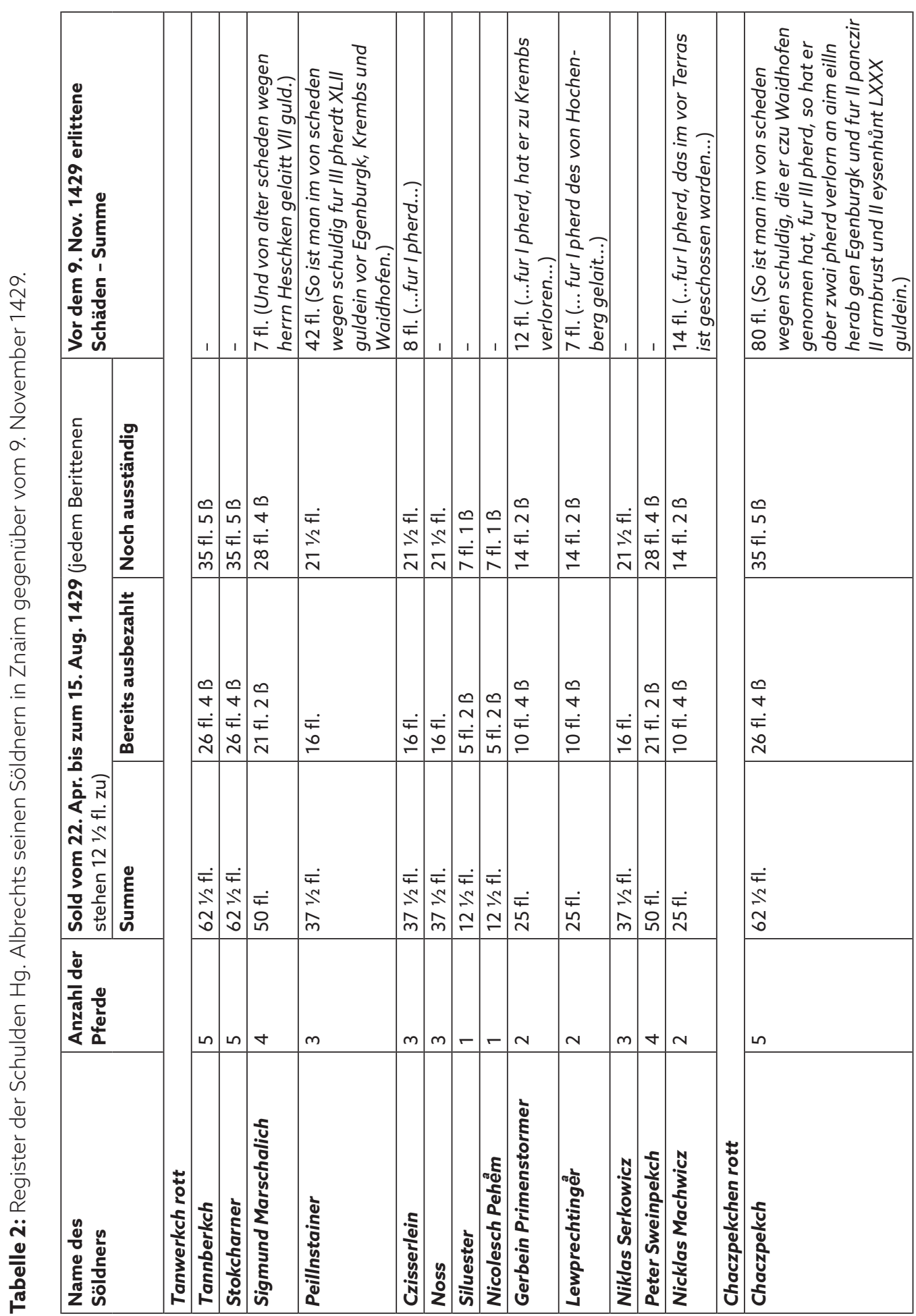




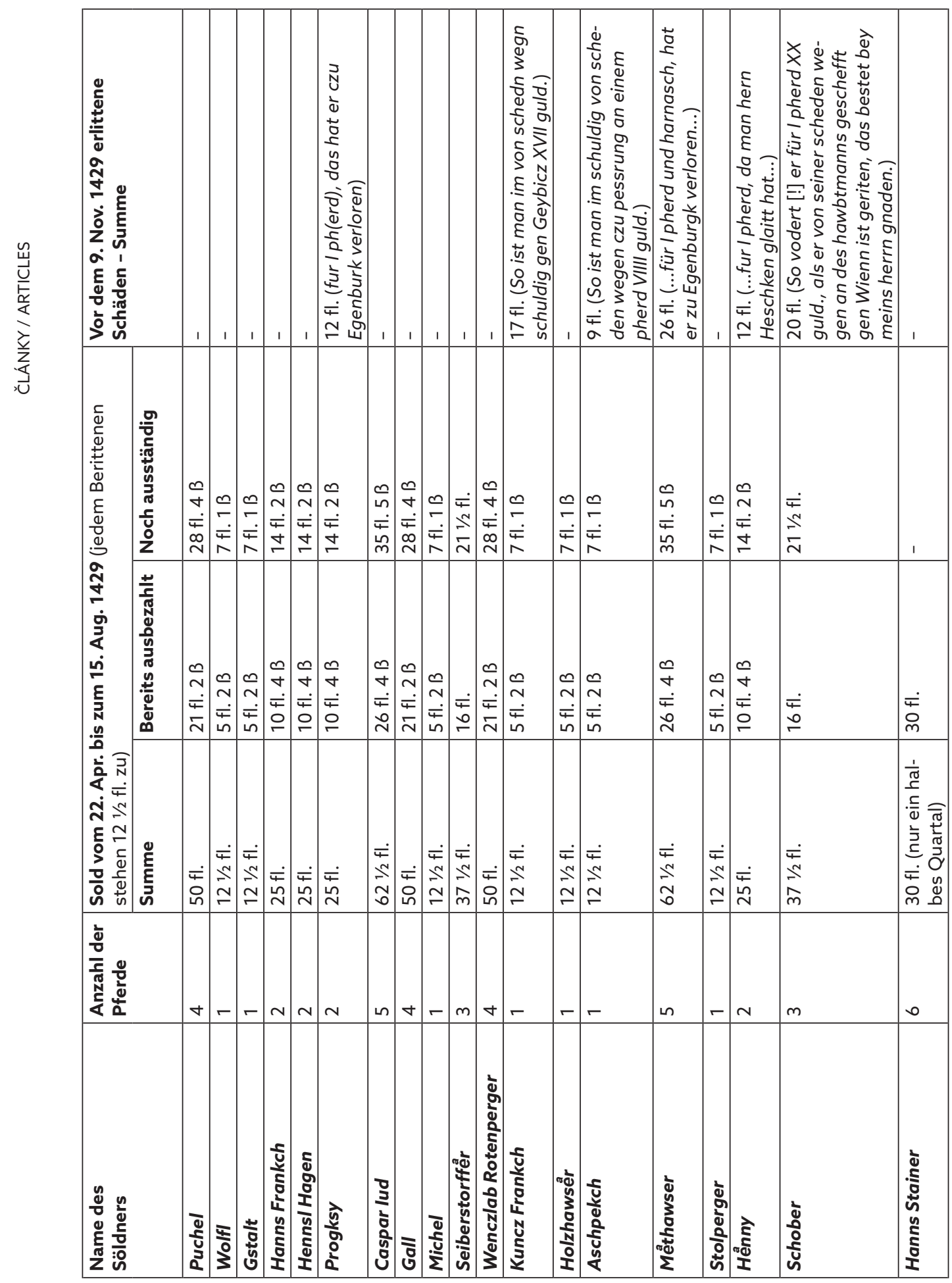




\begin{tabular}{|c|c|c|c|c|c|c|c|c|c|c|c|c|c|c|c|c|c|}
\hline 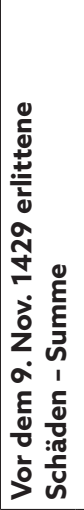 & & 1 & 1 & 1 & 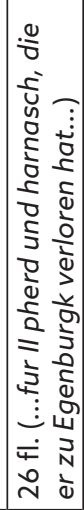 & 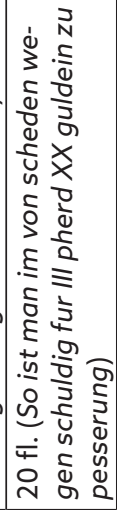 & 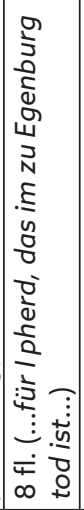 & & 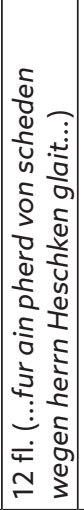 & 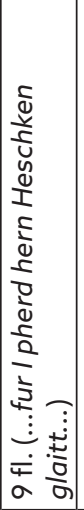 & & 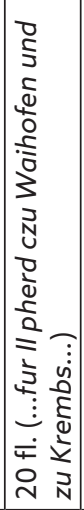 & 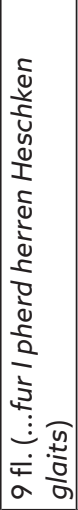 & 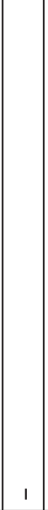 & 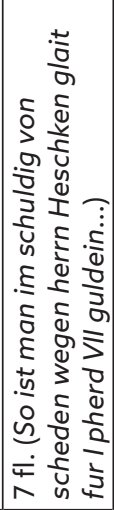 & 1 & 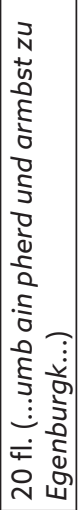 \\
\hline 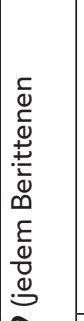 & 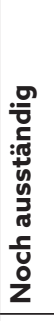 & 1 & $\begin{array}{l}\infty \\
\dot{v} \\
\dot{4} \\
\stackrel{+}{\sim} \\
\stackrel{N}{v}\end{array}$ & $\begin{array}{l}\simeq \\
\sim \\
\dot{\leftarrow} \\
\pm \\
\pm\end{array}$ & $\begin{array}{l}\infty \\
\dot{v} \\
\dot{4} \\
\infty \\
\sim \\
\end{array}$ & 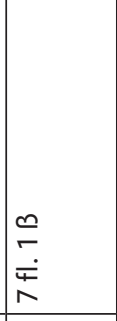 & 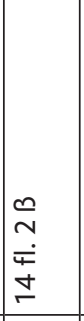 & 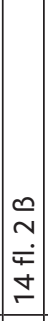 & 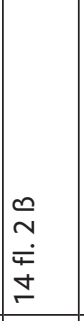 & $\begin{array}{l}\infty \\
\dot{v} \\
\dot{4} \\
\infty \\
\sim \\
\sim\end{array}$ & 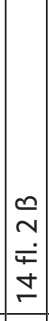 & 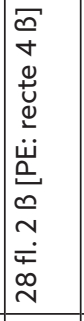 & 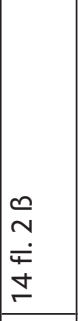 & 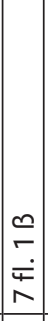 & 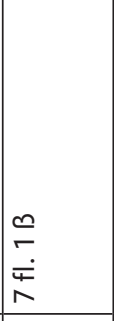 & $\mid \begin{array}{l}0 \\
+ \\
\dot{+} \\
n \\
\end{array}$ & 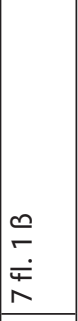 \\
\hline 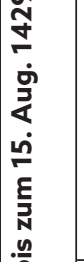 & 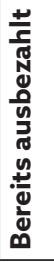 & $\begin{array}{l}n \\
\dot{\sigma} \\
\dot{4} \\
\stackrel{\sim}{v}\end{array}$ & $\begin{array}{l}\stackrel{n}{N} \\
\stackrel{5}{\leftarrow} \\
\bar{N}\end{array}$ & \begin{tabular}{|l|}
0 \\
$\dot{0}$ \\
$\dot{+}$ \\
0 \\
0 \\
\end{tabular} & $\begin{array}{l}\stackrel{n}{N} \\
\stackrel{\sim}{\leftarrow} \\
\check{n}\end{array}$ & $\begin{array}{l}\infty \\
\sim \\
\dot{\leftarrow} \\
\llcorner \\
\llcorner\end{array}$ & 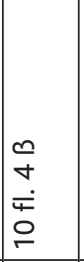 & 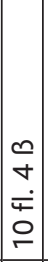 & \begin{tabular}{l}
0 \\
$\dot{v}$ \\
$\stackrel{+}{+}$ \\
0 \\
\hdashline
\end{tabular} & $\begin{array}{l}\infty \\
\sim \\
\dot{亠} \\
\dot{\leftarrow} \\
\check{N}\end{array}$ & \begin{tabular}{l}
0 \\
$\dot{0}$ \\
$\dot{+}$ \\
0 \\
\multicolumn{1}{c}{} \\
\end{tabular} & 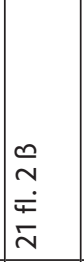 & $\begin{array}{l}n \\
\dot{v} \\
\dot{\varphi} \\
\dot{\varphi} \\
-\end{array}$ & $\mid \begin{array}{c}n \\
v \\
\dot{\leftarrow} \\
\llcorner n \\
\end{array}$ & $\begin{array}{l}\infty \\
\sim \\
\dot{\leftarrow} \\
\dot{L} \\
\text { in }\end{array}$ & 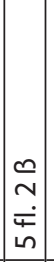 & $\begin{array}{l}\infty \\
\sim \\
\dot{\leftarrow} \\
\text { Ln }\end{array}$ \\
\hline 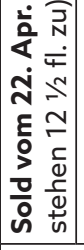 & $\begin{array}{l}\stackrel{\Xi}{\xi} \\
\xi \\
\text { ज̆ }\end{array}$ & 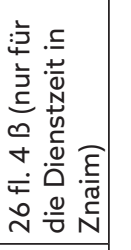 & $\begin{array}{l}\dot{4} \\
\text { 足 }\end{array}$ & $\mid \begin{array}{l}\dot{\bar{\leftarrow}} \\
\stackrel{\sim}{\sim} \\
\stackrel{2}{\sim}\end{array}$ & $\begin{array}{l}\dot{4} \\
\text { 우 }\end{array}$ & 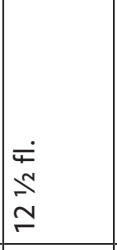 & $\begin{array}{l}\stackrel{+}{\leftarrow} \\
\stackrel{\omega n}{N}\end{array}$ & $\begin{array}{l}\dot{\leftarrow} \\
\stackrel{\omega}{\sim} \\
\sim\end{array}$ & $\begin{array}{l}\dot{\leftarrow} \\
\stackrel{\leftarrow}{\sim}\end{array}$ & $\begin{array}{l}\overrightarrow{+} \\
\text { in }\end{array}$ & 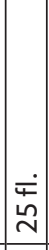 & $\begin{array}{l}\overrightarrow{4} \\
\text { in } \\
\text { in }\end{array}$ & $\begin{array}{l}\stackrel{+}{\leftarrow} \\
\stackrel{\omega}{\sim}\end{array}$ & 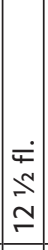 & 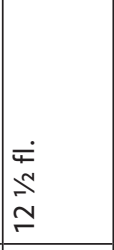 & 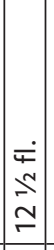 & 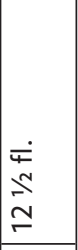 \\
\hline 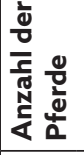 & & 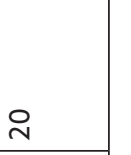 & $\nabla$ & $\sim$ & + & - & $N$ & $v$ & $N$ & 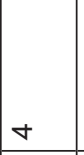 & $N$ & + & $N$ & - & - & - & - \\
\hline 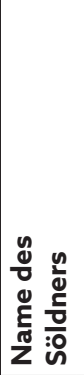 & & 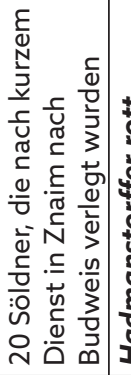 & 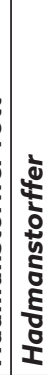 & 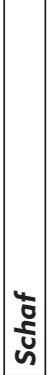 & 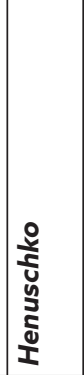 & 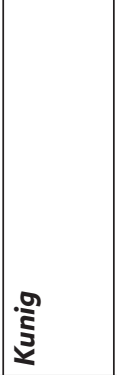 & $\frac{1}{0}$ & $\frac{0}{\frac{9}{9}}$ & 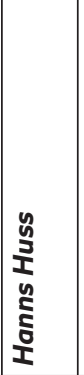 & 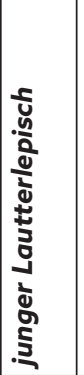 & 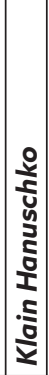 & 总 & 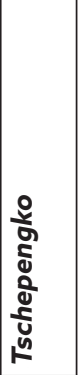 & 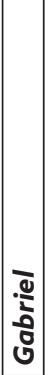 & 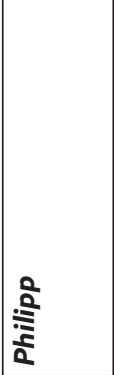 & 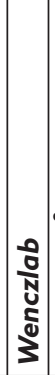 & |ळ \\
\hline
\end{tabular}




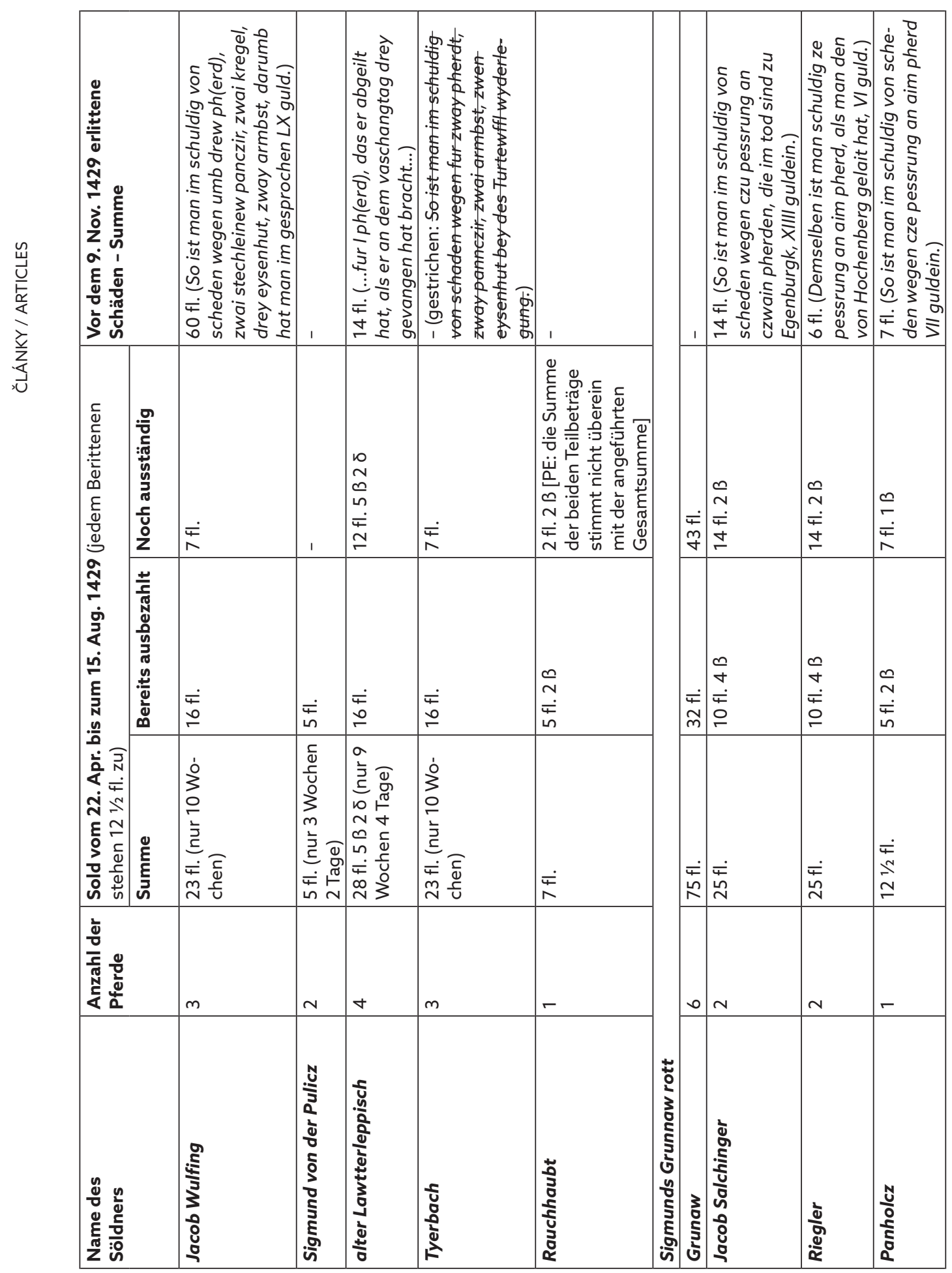




\begin{tabular}{|c|c|c|c|c|c|c|c|c|c|c|c|c|c|c|c|c|c|c|c|c|}
\hline 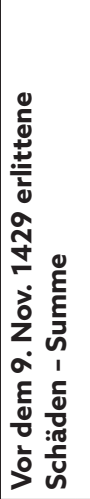 & & 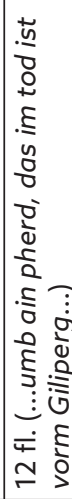 & & 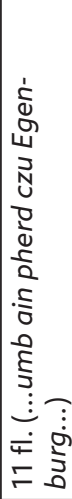 & 1 & 1 & 1 & 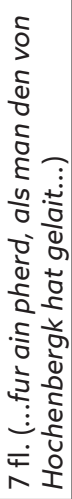 & & 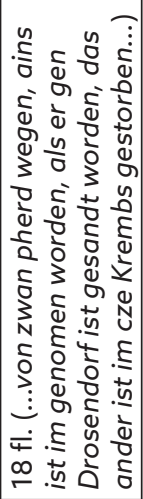 & 1 & 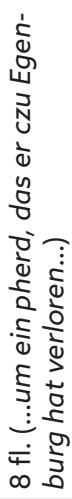 & 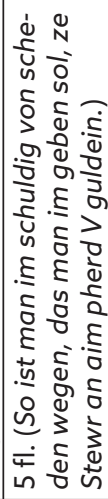 & 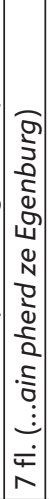 & 1 & 1 & 1 & 1 & 1 & 1 \\
\hline 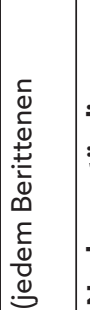 & 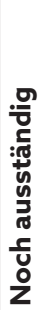 & 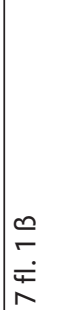 & 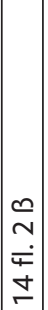 & 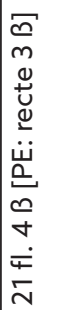 & $\begin{array}{l}0 \\
\sim \\
\dot{L} \\
\pm \\
\end{array}$ & 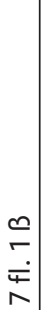 & $\begin{array}{l}\infty \\
r \\
\dot{\leftarrow} \\
n\end{array}$ & 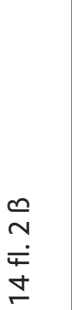 & 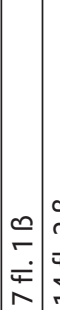 & 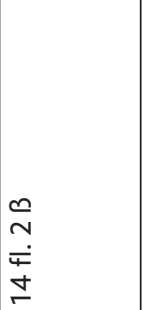 & 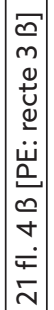 & 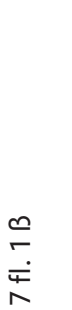 & 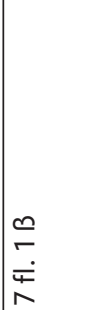 & $\mid \begin{array}{l}0 \\
+ \\
\dot{+} \\
\sim \\
n\end{array}$ & 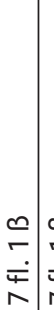 & 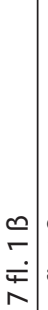 & 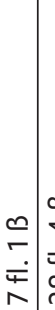 & $\begin{array}{l}\infty \\
\dot{v} \\
\dot{c} \\
\dot{\infty} \\
\stackrel{N}{N}\end{array}$ & $\begin{array}{l}0 \\
\dot{\sigma} \\
\dot{\varphi} \\
\dot{q}\end{array}$ & $\underset{⿱ 亠 䒑}{\sim}$ \\
\hline 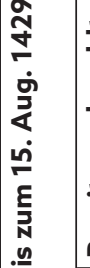 & 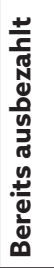 & 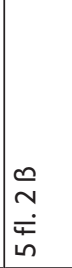 & \begin{tabular}{l}
0 \\
$\dot{0}$ \\
$\dot{\varphi}$ \\
0 \\
\hdashline
\end{tabular} & $\begin{array}{l}\dot{\Psi} \\
\stackrel{0}{0}\end{array}$ & \begin{tabular}{c|c}
0 \\
0 \\
+ \\
$\dot{f}$ \\
0 \\
\end{tabular} & $\begin{array}{c}\infty \\
\stackrel{n}{c} \\
\stackrel{4}{\leftarrow} \\
i n\end{array}$ & $\begin{array}{c}\infty \\
\sim \\
\sim \\
\dot{\leftarrow} \\
\text { in }\end{array}$ & $\begin{array}{l}0 \\
\dot{0} \\
\dot{4} \\
0 \\
\end{array}$ & 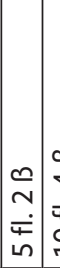 & $\begin{array}{l}n \\
\dot{v} \\
\dot{4} \\
\circ \\
0\end{array}$ & 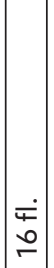 & $\begin{array}{l}\cong \\
\sim \\
\dot{\leftarrow} \\
\text { in }\end{array}$ & 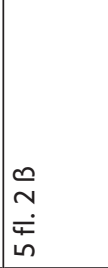 & 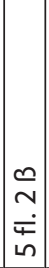 & \begin{tabular}{c|c}
$\infty$ & \\
$\sim$ & \\
$亡$ & \\
& \\
$\omega$ &
\end{tabular} & $\begin{array}{c}\infty \\
\stackrel{1}{\sim} \\
\stackrel{\leftarrow}{\leftarrow} \\
\sim\end{array}$ & 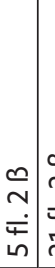 & \begin{tabular}{l|}
0 \\
$\sim$ \\
$\vdots$ \\
$\bar{\leftarrow}$ \\
$\check{v}$
\end{tabular} & $\begin{array}{l}0 \\
\dot{t} \\
\dot{4} \\
\text { 음 }\end{array}$ & $\begin{array}{l}\dot{\Psi}+ \\
\stackrel{0}{0}\end{array}$ \\
\hline 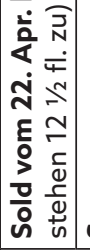 & 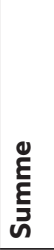 & 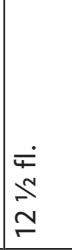 & $\begin{array}{l}\dot{\leftarrow} \\
\stackrel{\omega}{\sim} \\
\sim\end{array}$ & $\begin{array}{l}\dot{+} \\
\stackrel{N}{N} \\
\hat{m}\end{array}$ & 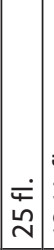 & 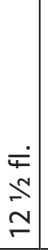 & $\begin{array}{l}\dot{E} \\
\mathbb{E} \\
\mathbb{2} \\
\mathbb{I}\end{array}$ & 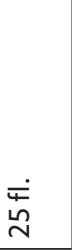 & 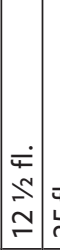 & 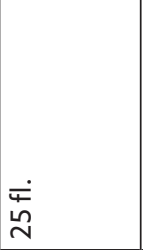 & $\mid \begin{array}{l}\dot{F} \\
\mathbf{N} \\
\hat{n} \\
m\end{array}$ & 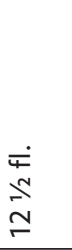 & $\begin{array}{l}\dot{+} \\
\stackrel{+}{N} \\
\stackrel{N}{N}\end{array}$ & 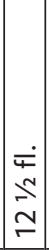 & 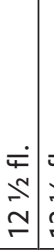 & $\begin{array}{l}\dot{+} \\
\stackrel{+}{\sim} \\
\stackrel{\sim}{\simeq}\end{array}$ & 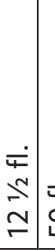 & $\begin{array}{l}\dot{+} \\
\dot{+} \\
\text { 요 }\end{array}$ & 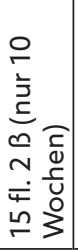 & 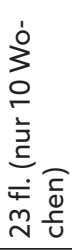 \\
\hline 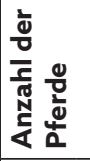 & & - & $N$ & $m$ & $\sim$ & - & - & $\sim$ & $-\sigma$ & $N$ & $m$ & - & - & - & - & - & - & $\nabla$ & $N$ & $m$ \\
\hline 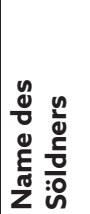 & & 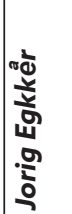 & $\mid$ & 离 & 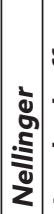 & 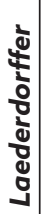 & $\begin{array}{l}\vdots \\
\vdots \\
\vdots \\
\vdots \\
\vdots\end{array}$ & 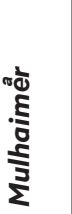 & ह & 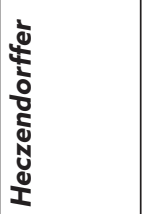 & $\mid \begin{array}{l}\bar{y} \\
\underline{y} \\
\mathbf{v} \\
\mathbf{z}\end{array}$ & 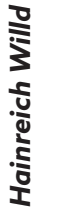 & 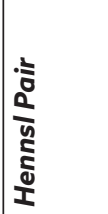 & $\begin{array}{l}\overline{\bar{g}} \\
\overline{0} \\
\dot{\omega}\end{array}$ & $\begin{array}{c}0 \\
0 \\
\vdots \\
0 \\
0 \\
\text { I. }\end{array}$ & $\begin{array}{l}0 \\
\frac{2}{u} \\
0 \\
2\end{array}$ & 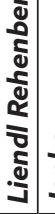 & 일 & 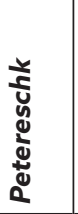 & $\begin{array}{l}\text { ڤँ } \\
\text { जे } \\
\text { जे }\end{array}$ \\
\hline
\end{tabular}




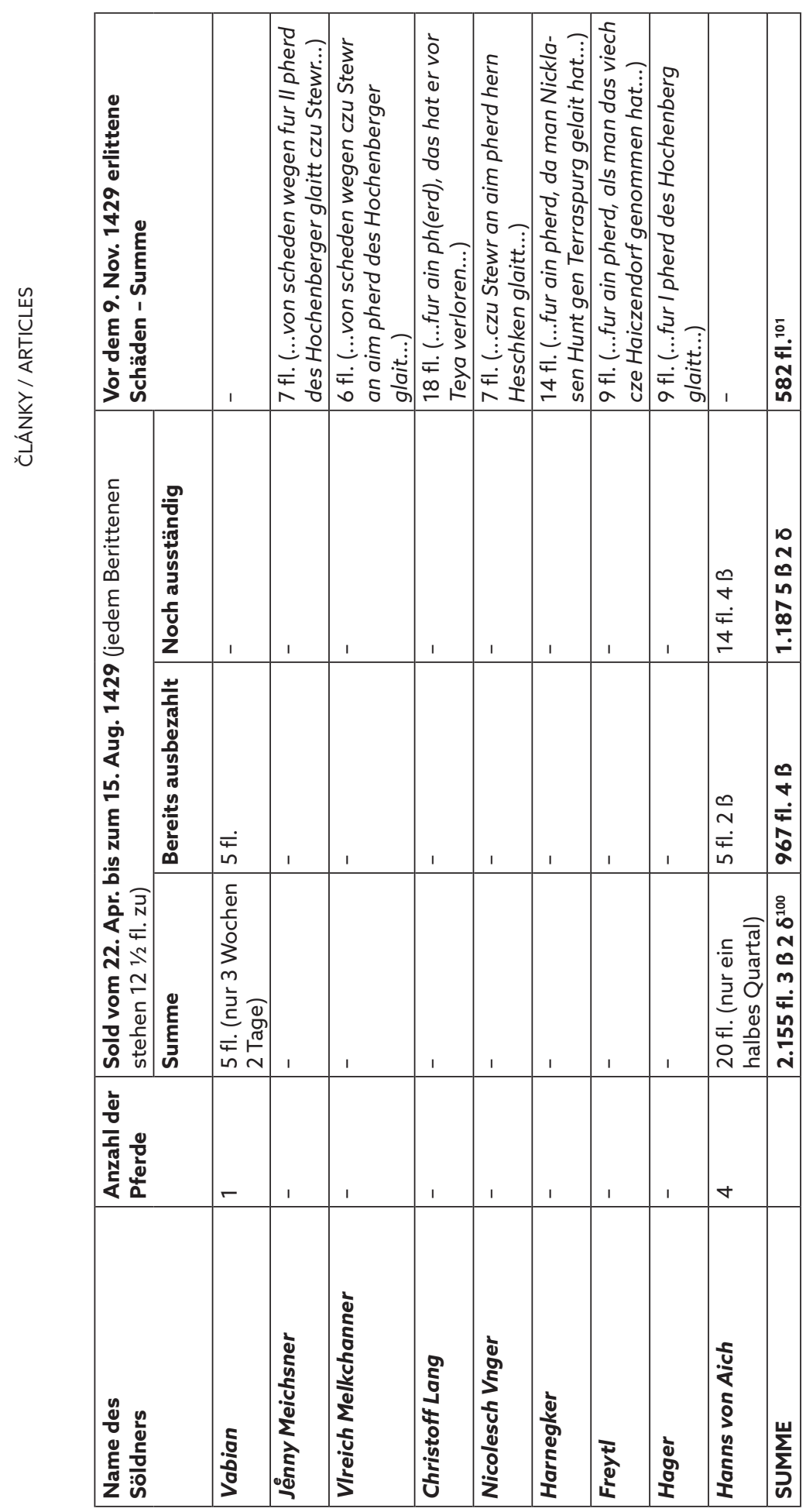

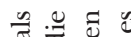

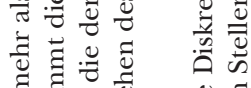
है ही की चै a $0 . \overline{0}$

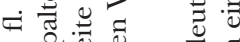

की की

घ

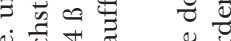

ن :

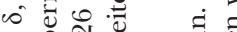

ข $=$ ข

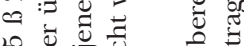

10.

प클 छ

$\infty$ 舟

v :

$\circ$ 氙 苛

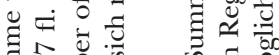

घิ ลे은 की

ज्ञ

氖员

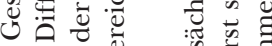

.

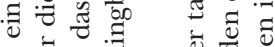

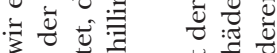

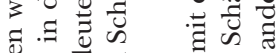

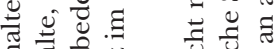

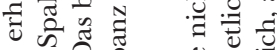

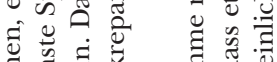

है छ $\frac{\tilde{y}}{\mathrm{~g}}$

啳

苟:

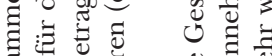

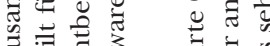

ส

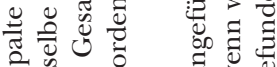

की

पै

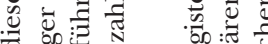

$\Xi$ च्च

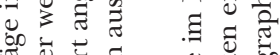

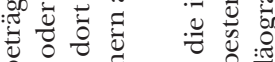

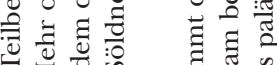

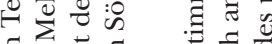

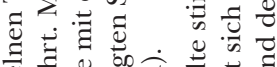

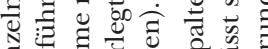

व

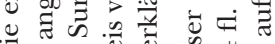

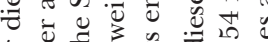

.

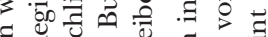

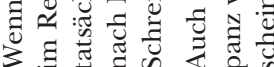

8

ᄒ 


\begin{tabular}{|c|c|c|c|c|c|c|c|}
\hline 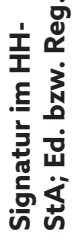 & 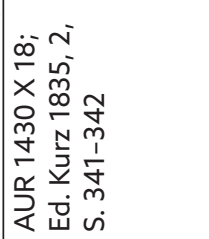 & 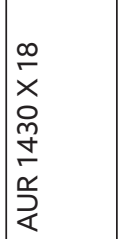 & 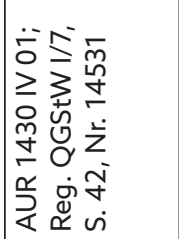 & 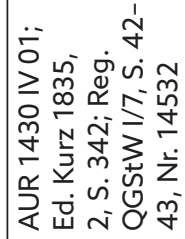 & 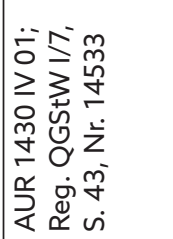 & 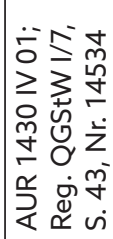 & 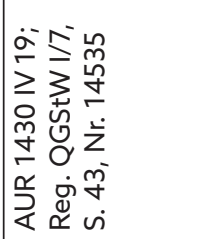 \\
\hline 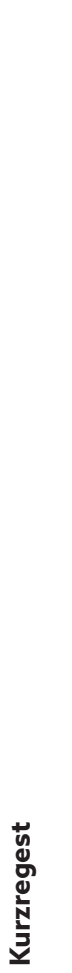 & 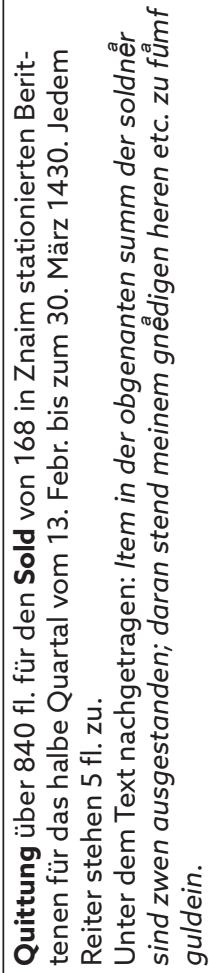 & 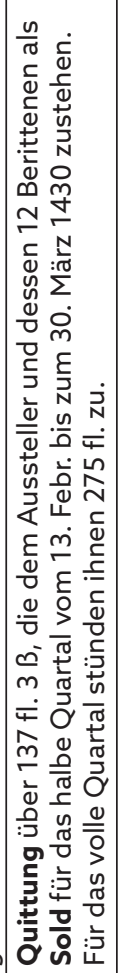 & 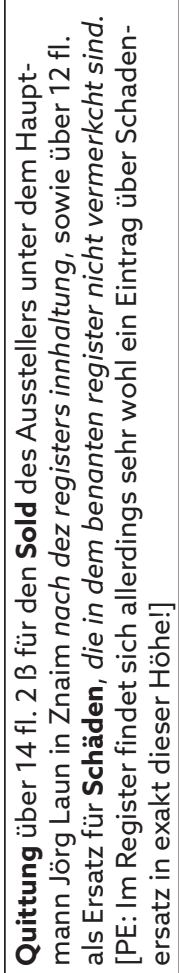 & 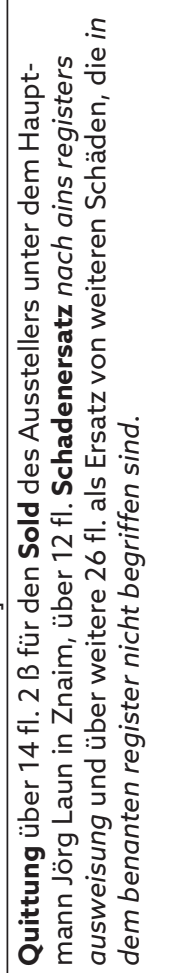 & 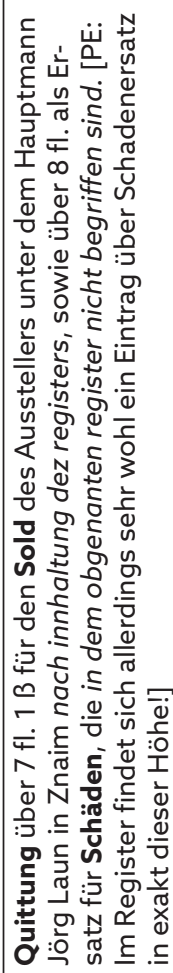 & 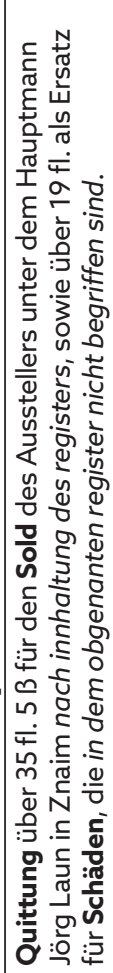 & 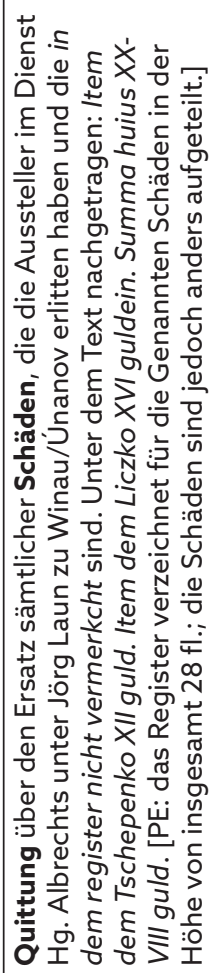 \\
\hline $\begin{array}{l}\frac{2}{8} \\
\frac{\omega}{\omega}\end{array}$ & 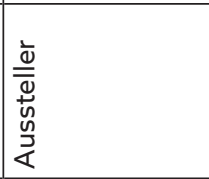 & 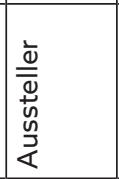 & 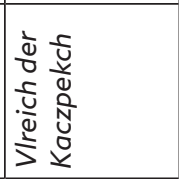 & 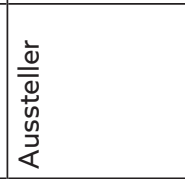 & 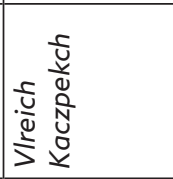 & 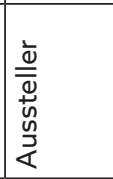 & 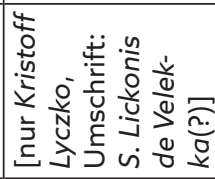 \\
\hline 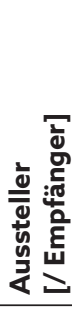 & 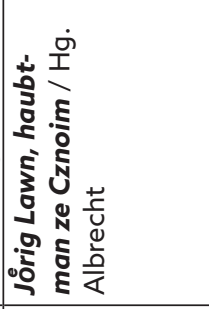 & 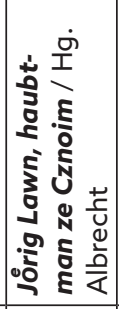 & 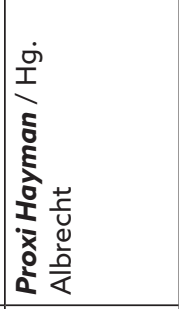 & 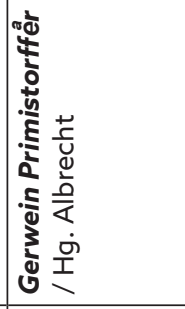 & 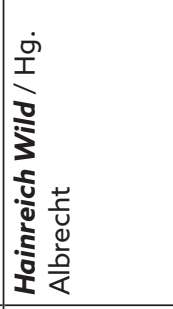 & 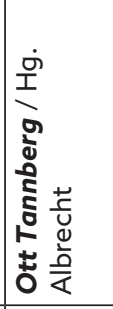 & 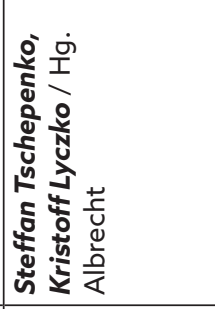 \\
\hline 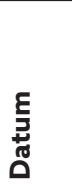 & 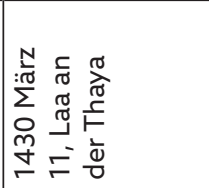 & 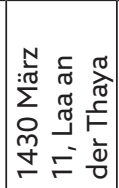 & 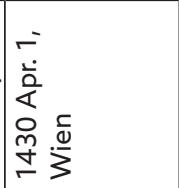 & 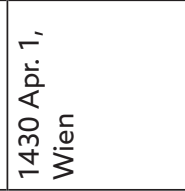 & 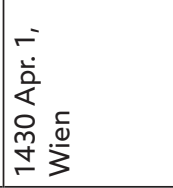 & 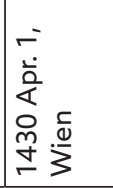 & 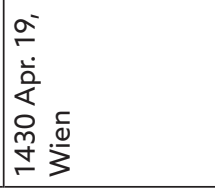 \\
\hline
\end{tabular}




\begin{tabular}{|c|c|c|c|c|c|c|c|c|}
\hline 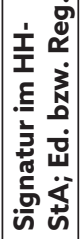 & 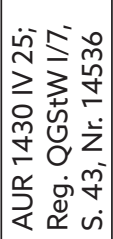 & 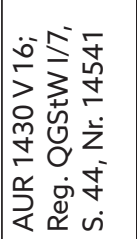 & 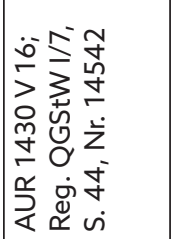 & 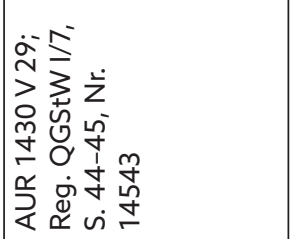 & 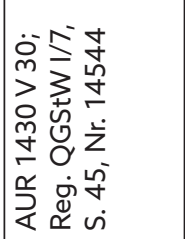 & 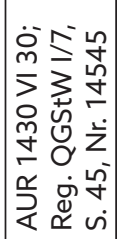 & 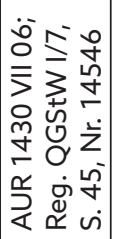 & 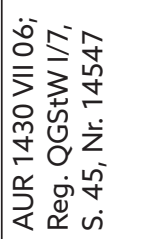 \\
\hline 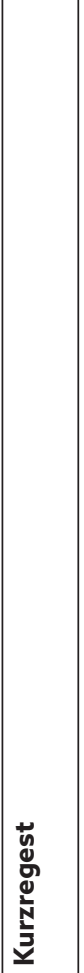 & 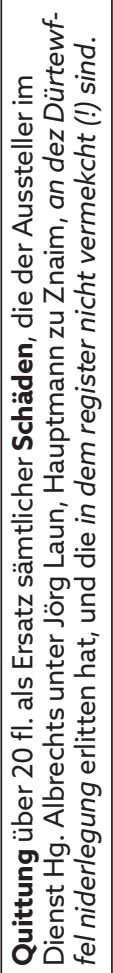 & 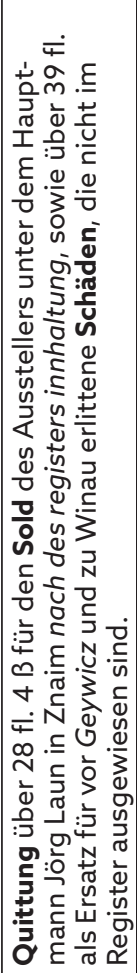 & 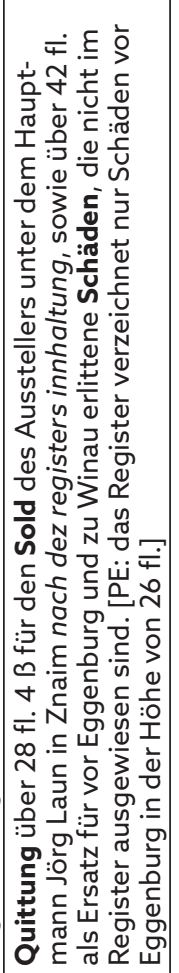 & 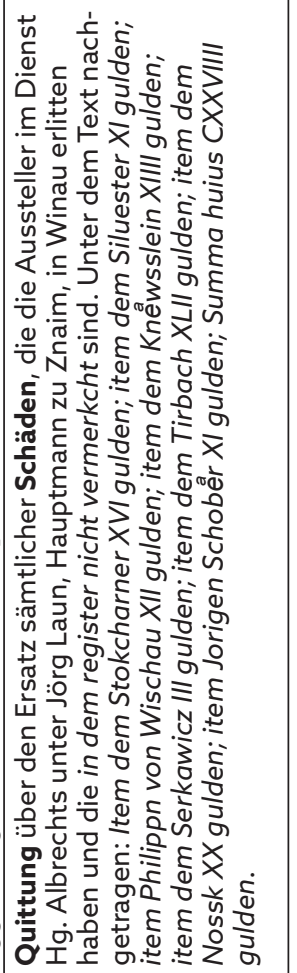 & 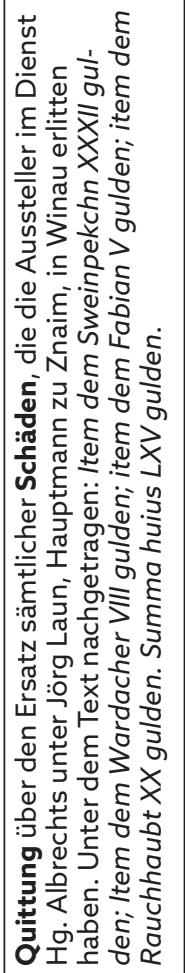 & 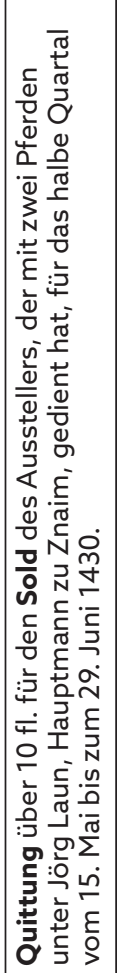 & 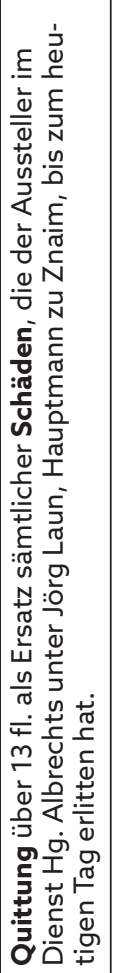 & 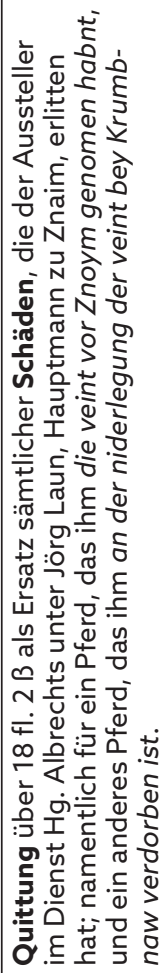 \\
\hline $\begin{array}{l}\frac{2}{0} \\
\frac{\omega}{0}\end{array}$ & 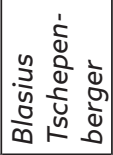 & 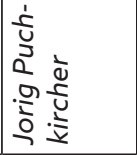 & 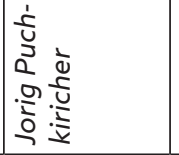 & 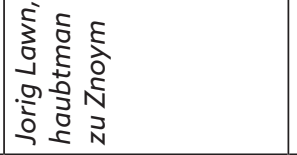 & 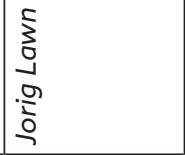 & 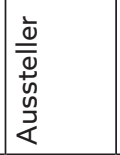 & 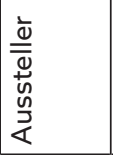 & 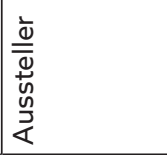 \\
\hline 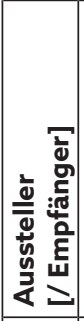 & 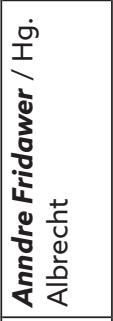 & 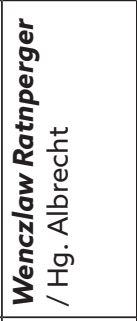 & 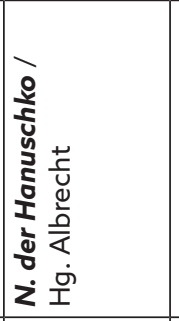 & 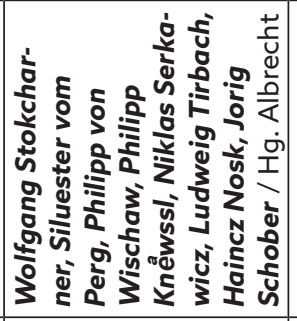 & 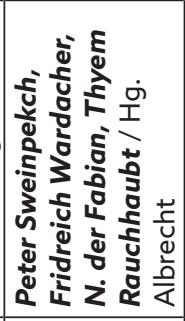 & 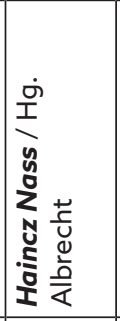 & 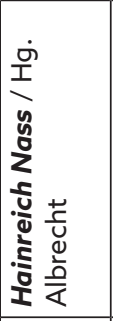 & 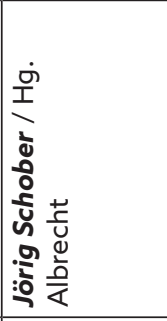 \\
\hline 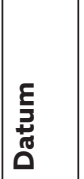 & 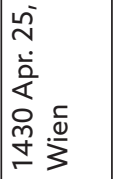 & 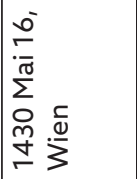 & 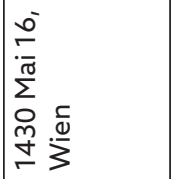 & 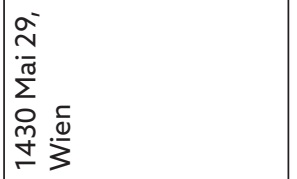 & 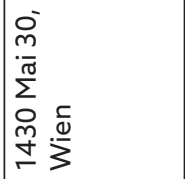 & 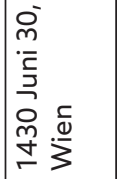 & 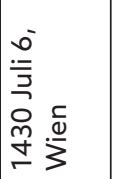 & 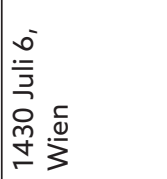 \\
\hline
\end{tabular}




\begin{tabular}{|c|c|c|c|c|c|c|c|}
\hline 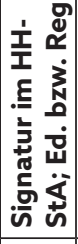 & 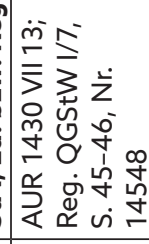 & 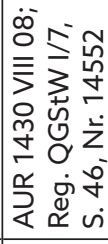 & 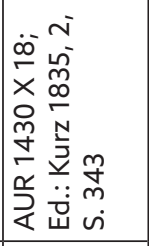 & 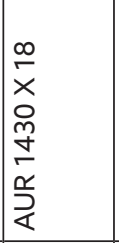 & 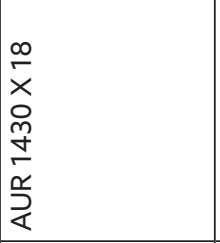 & 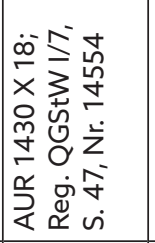 & 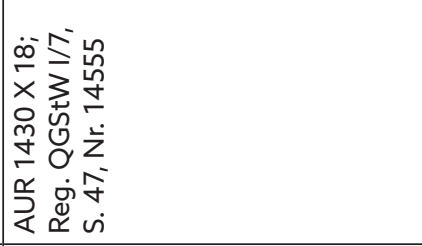 \\
\hline & 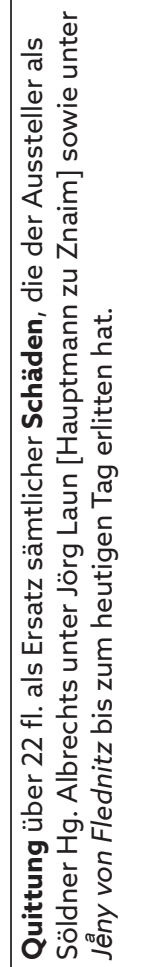 & 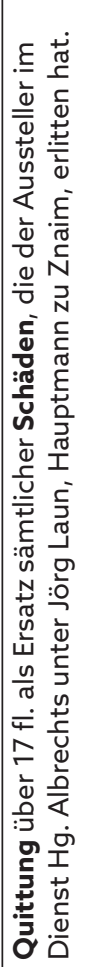 & 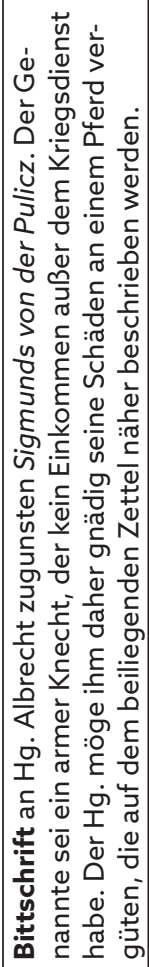 & 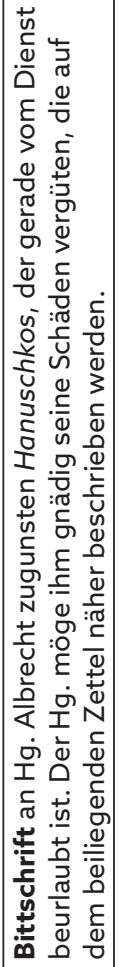 & 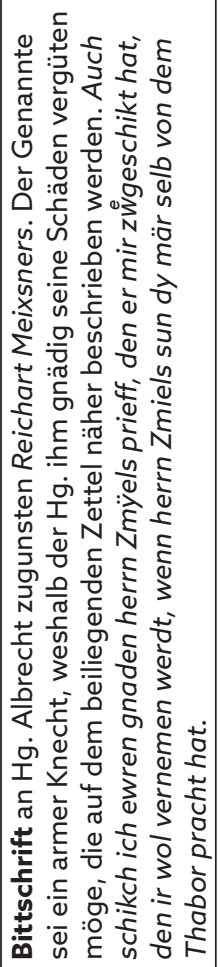 & 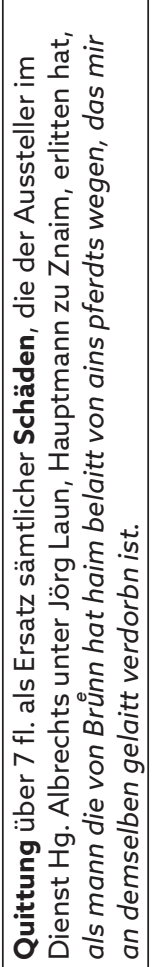 & 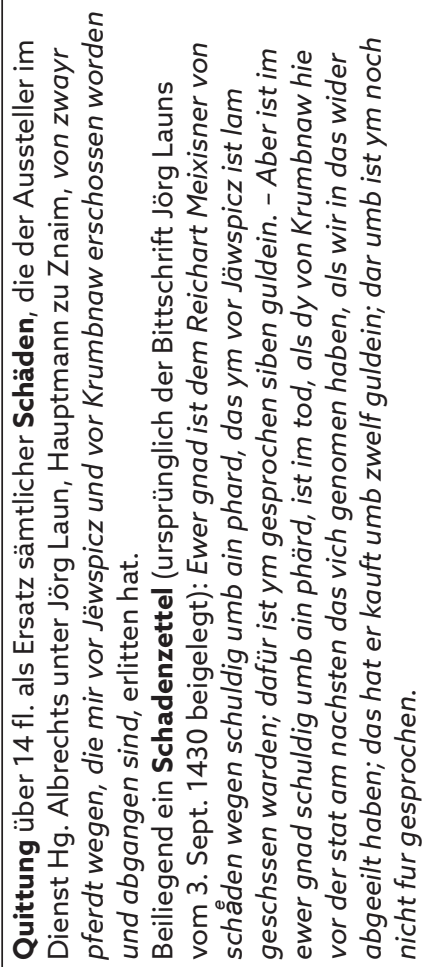 \\
\hline $\begin{array}{l}\frac{2}{0} \\
\frac{\omega}{\sigma} \\
\text { जे }\end{array}$ & 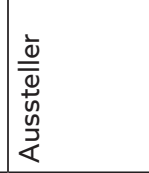 & 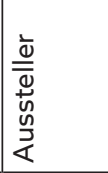 & 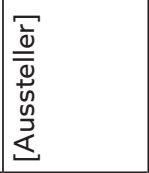 & 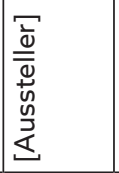 & 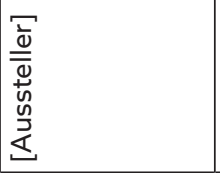 & 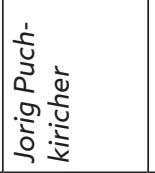 & 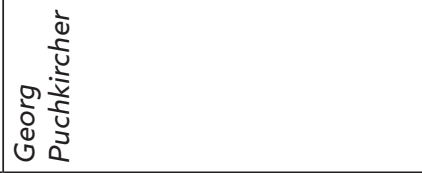 \\
\hline 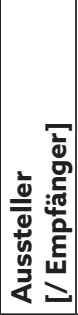 & 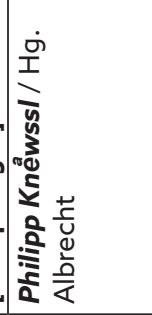 & 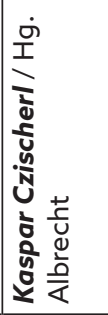 & 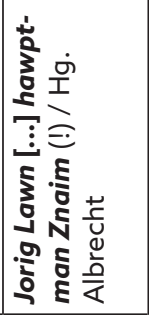 & 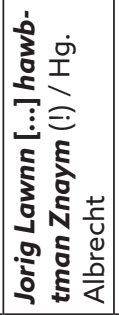 & 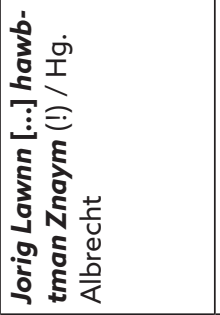 & 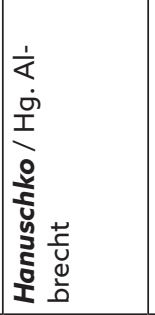 & 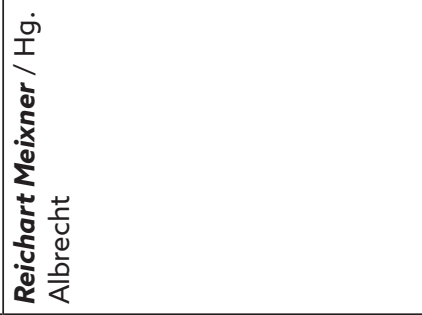 \\
\hline 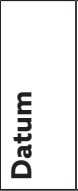 & 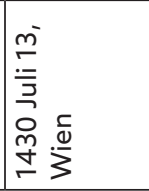 & 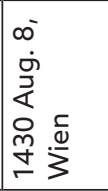 & 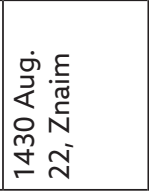 & 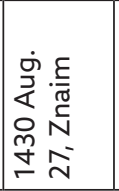 & 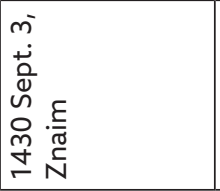 & 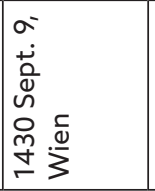 & 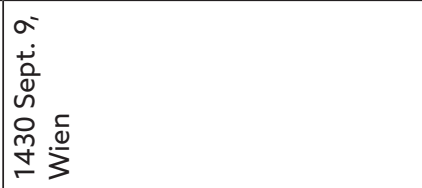 \\
\hline
\end{tabular}




\begin{tabular}{|c|c|c|c|c|}
\hline 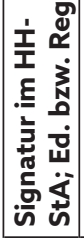 & 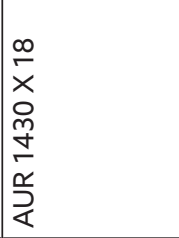 & 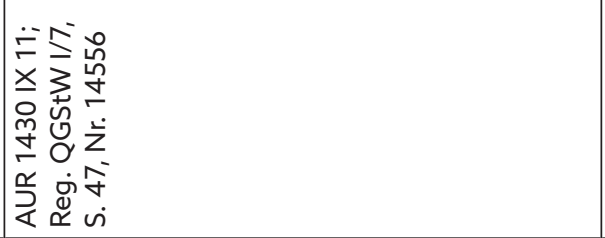 & 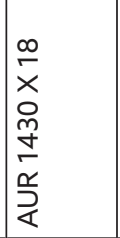 & 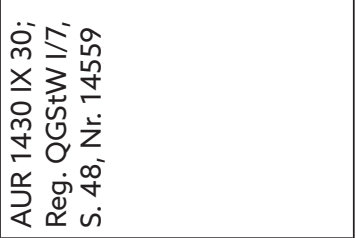 \\
\hline 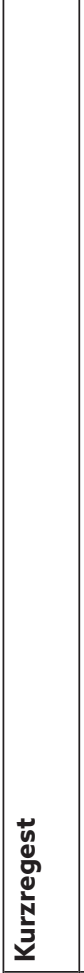 & 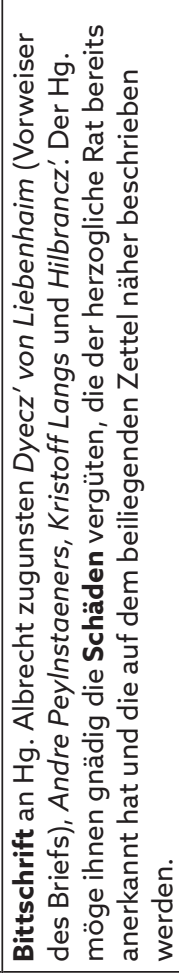 & 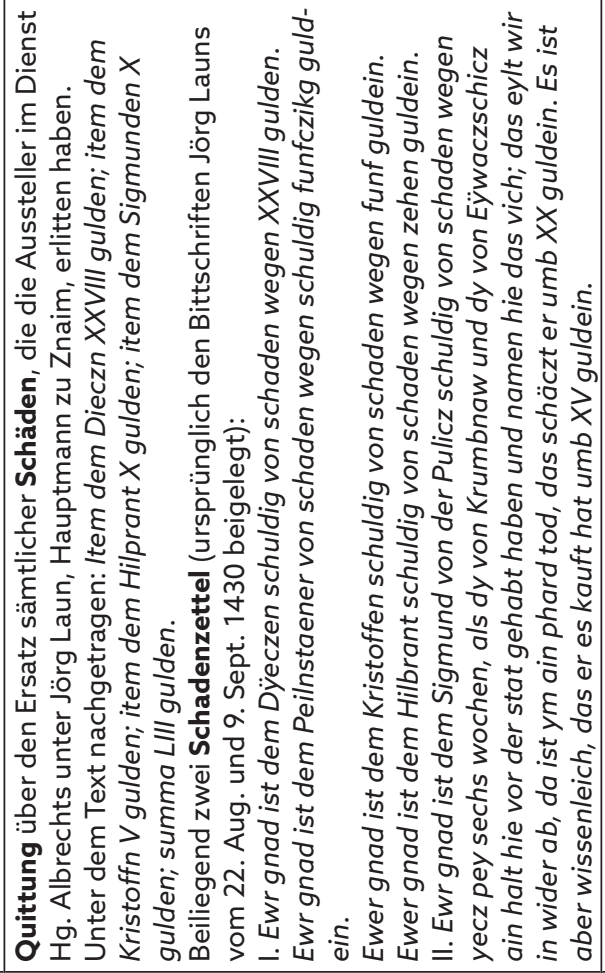 & 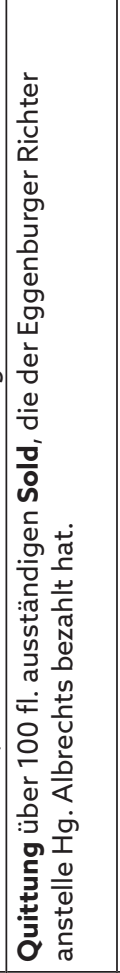 & 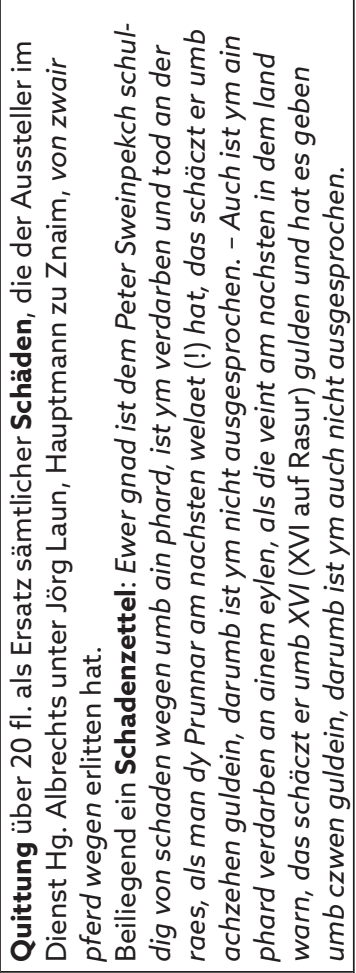 \\
\hline 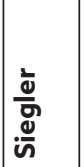 & & 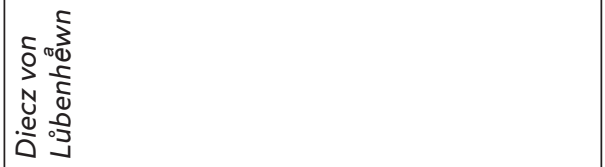 & $\mid \begin{array}{l}0 \\
0.5 \\
0 \\
0 \\
0 \\
0 \\
0 \\
0\end{array}$ & 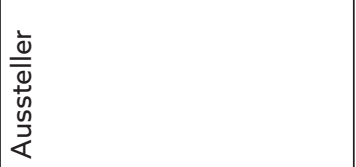 \\
\hline 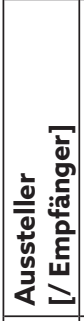 & 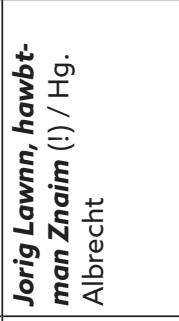 & 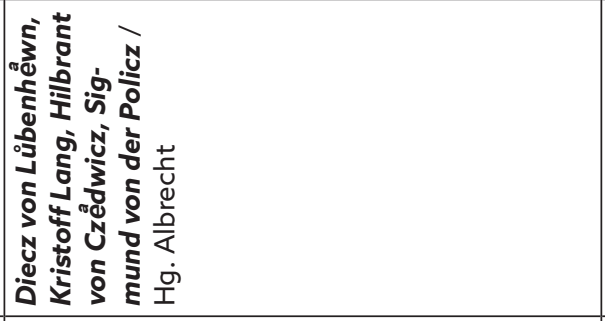 & 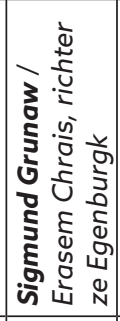 & 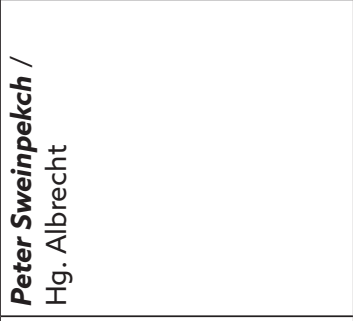 \\
\hline 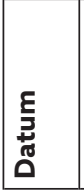 & 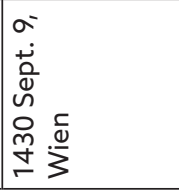 & 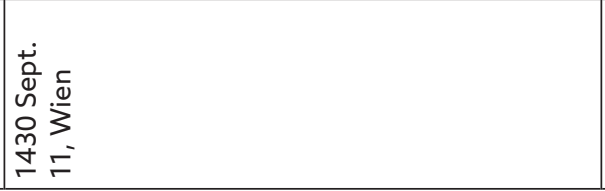 & 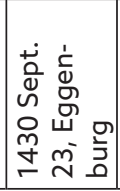 & 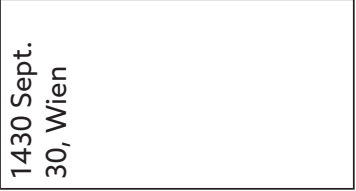 \\
\hline
\end{tabular}




\begin{tabular}{|c|c|c|c|c|c|}
\hline 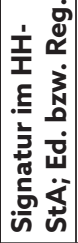 & 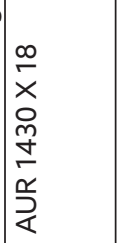 & 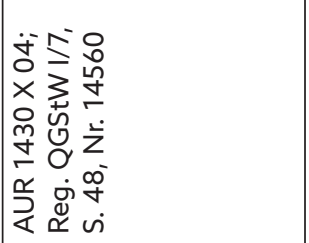 & 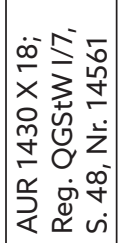 & 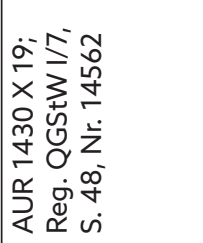 & 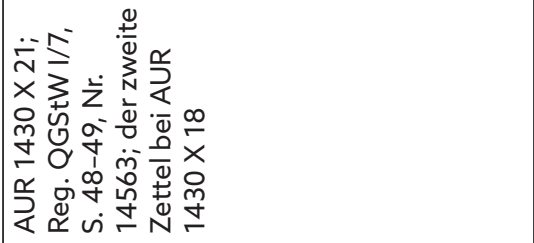 \\
\hline 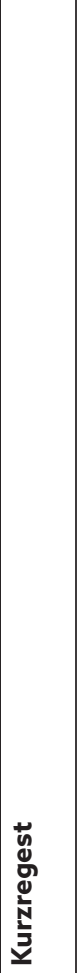 & 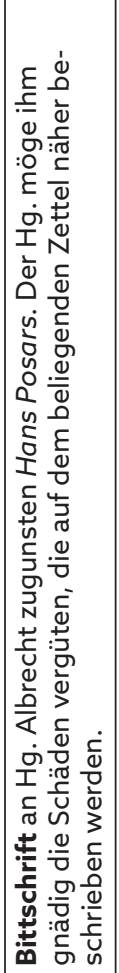 & 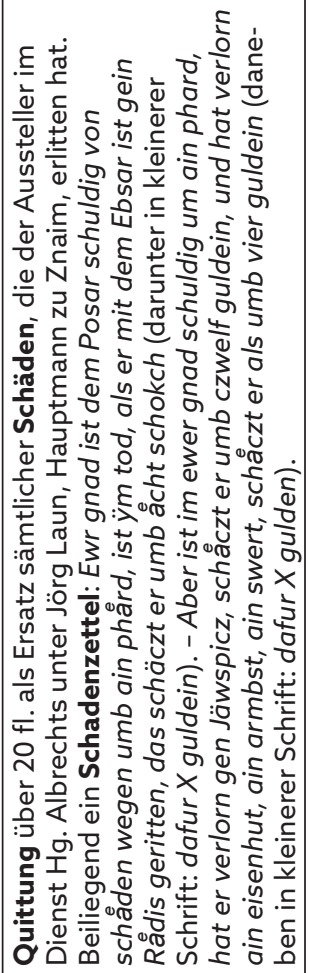 & 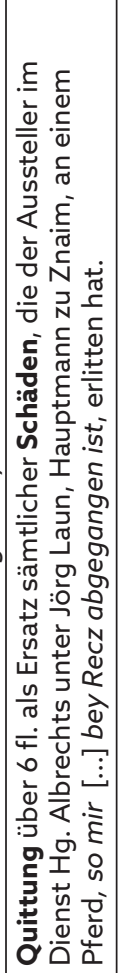 & 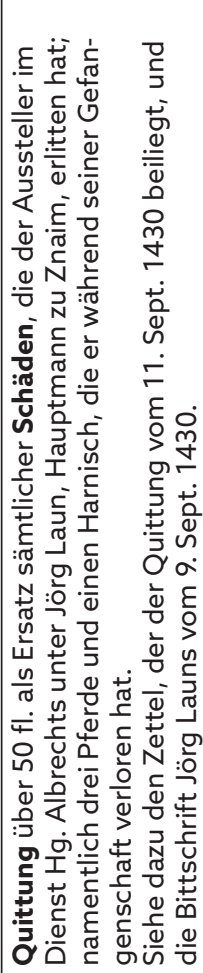 & 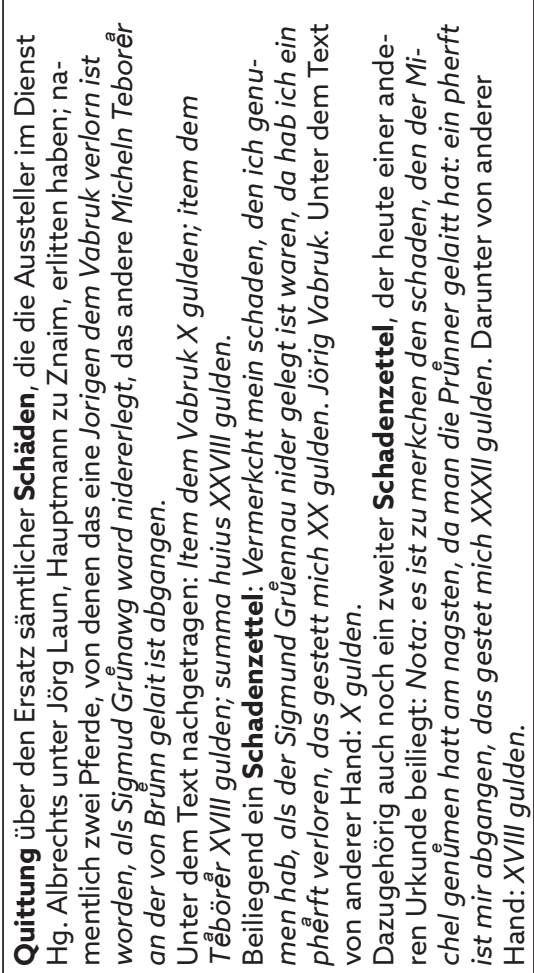 \\
\hline $\begin{array}{l}\frac{2}{0} \\
\frac{\omega}{\sigma} \\
\text { जे }\end{array}$ & 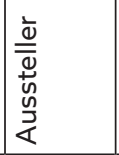 & 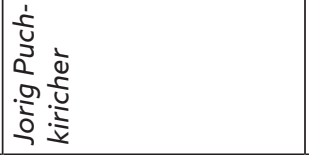 & 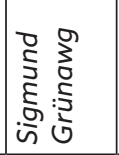 & 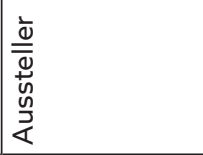 & 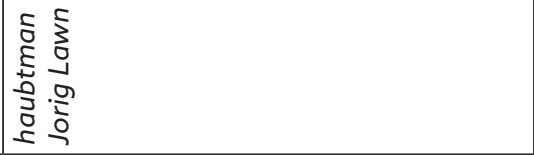 \\
\hline 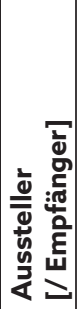 & 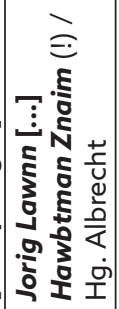 & 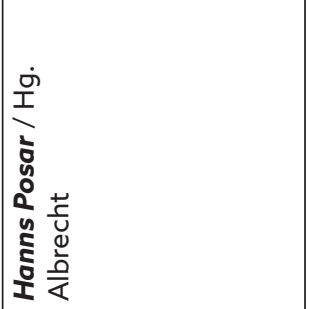 & 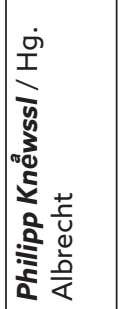 & 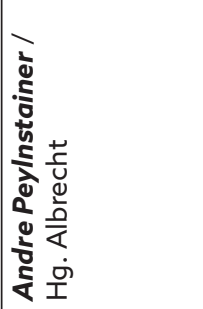 & 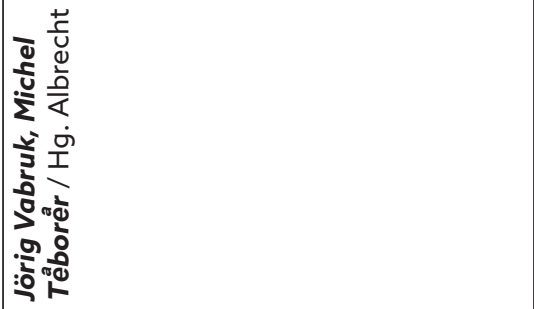 \\
\hline \begin{tabular}{|l}
$\frac{5}{3}$ \\
$\stackrel{2}{\pi}$ \\
0
\end{tabular} & 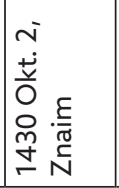 & 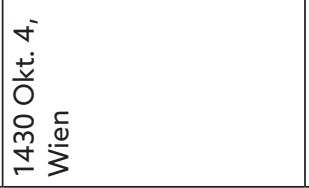 & 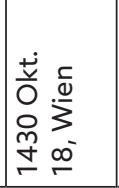 & 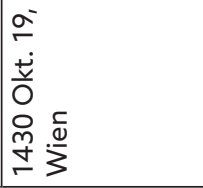 & 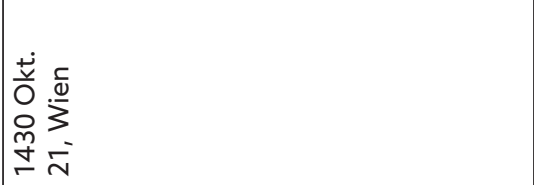 \\
\hline
\end{tabular}




\begin{tabular}{|c|c|c|c|c|}
\hline 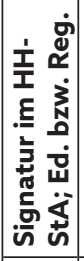 & 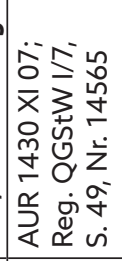 & 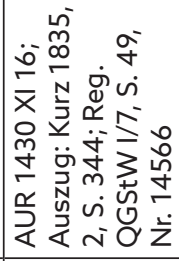 & 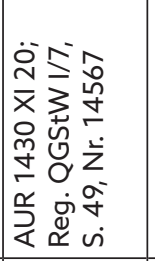 & 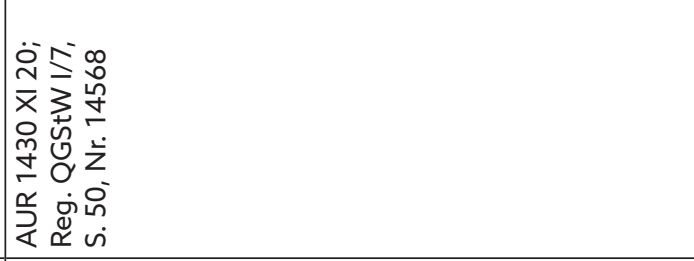 \\
\hline 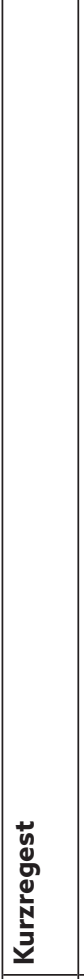 & 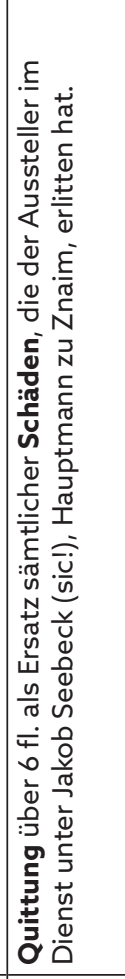 & 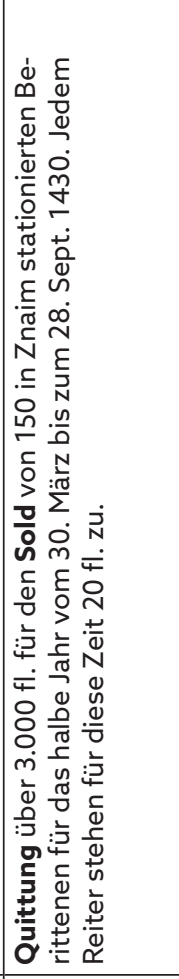 & 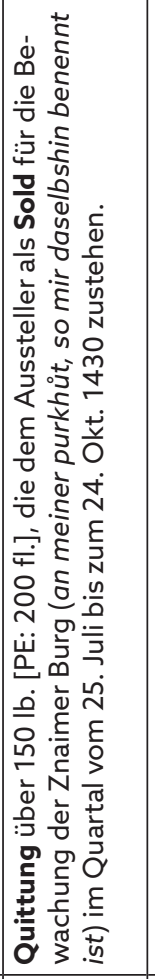 & 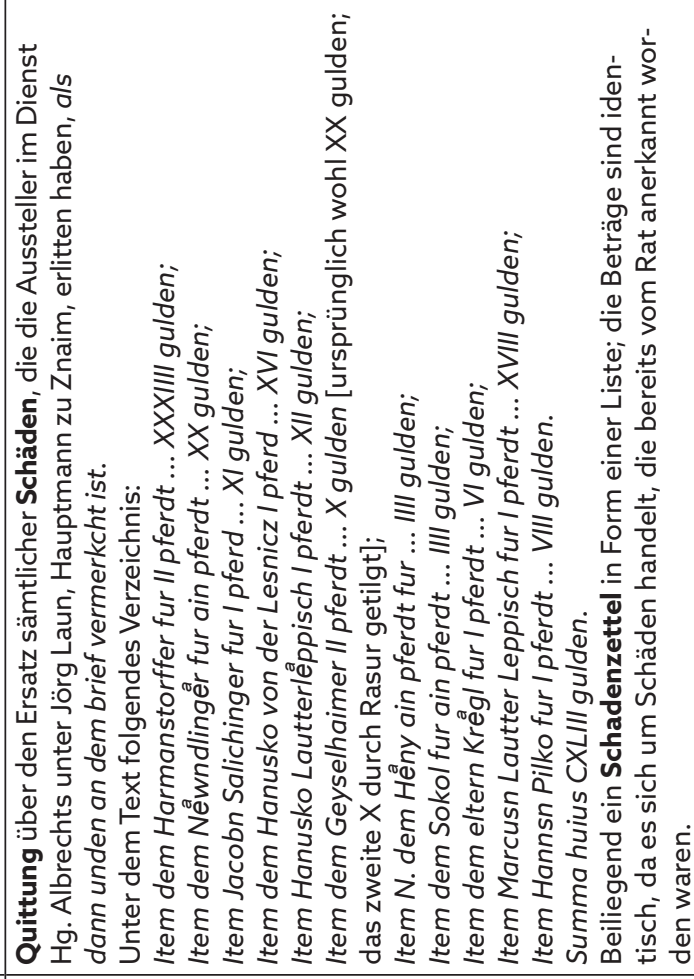 \\
\hline 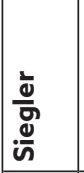 & 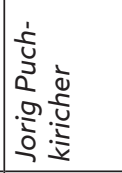 & 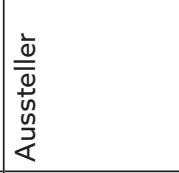 & 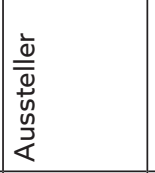 & 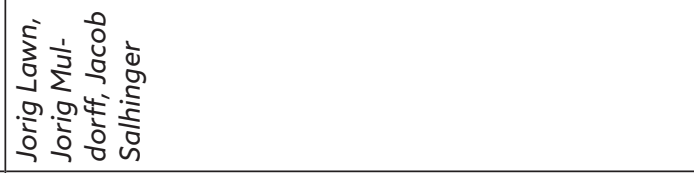 \\
\hline 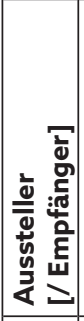 & 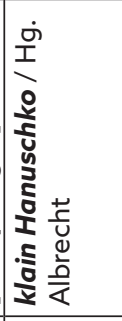 & 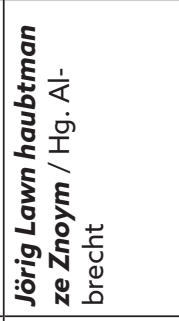 & 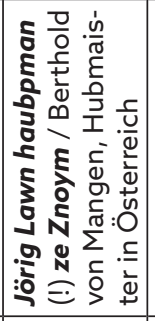 & 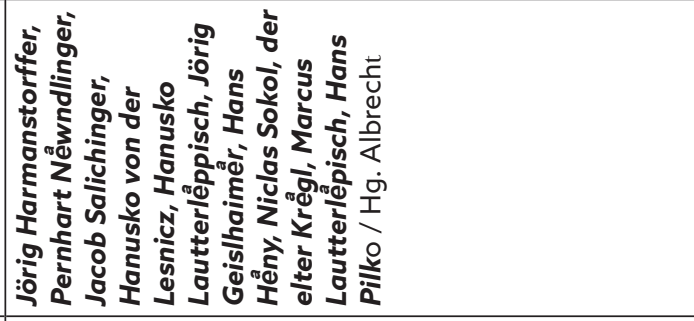 \\
\hline 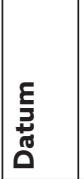 & 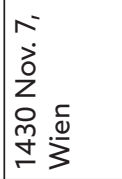 & 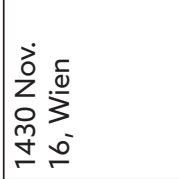 & 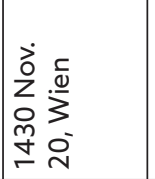 & 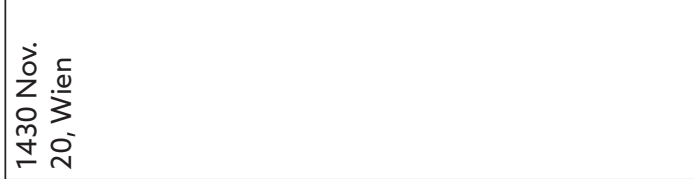 \\
\hline
\end{tabular}




\begin{tabular}{|c|c|c|c|}
\hline 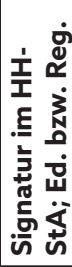 & 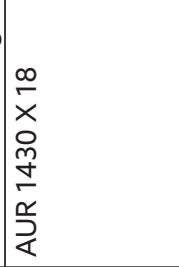 & 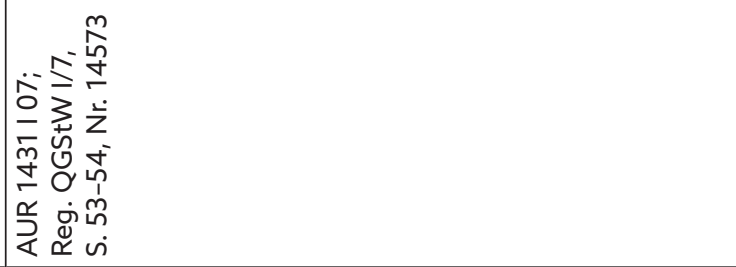 & 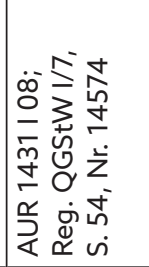 \\
\hline 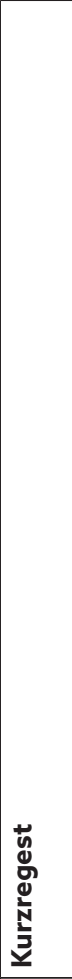 & 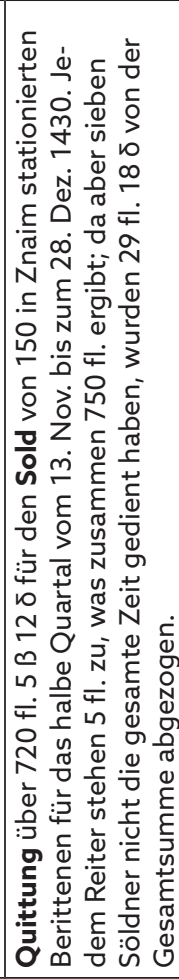 & 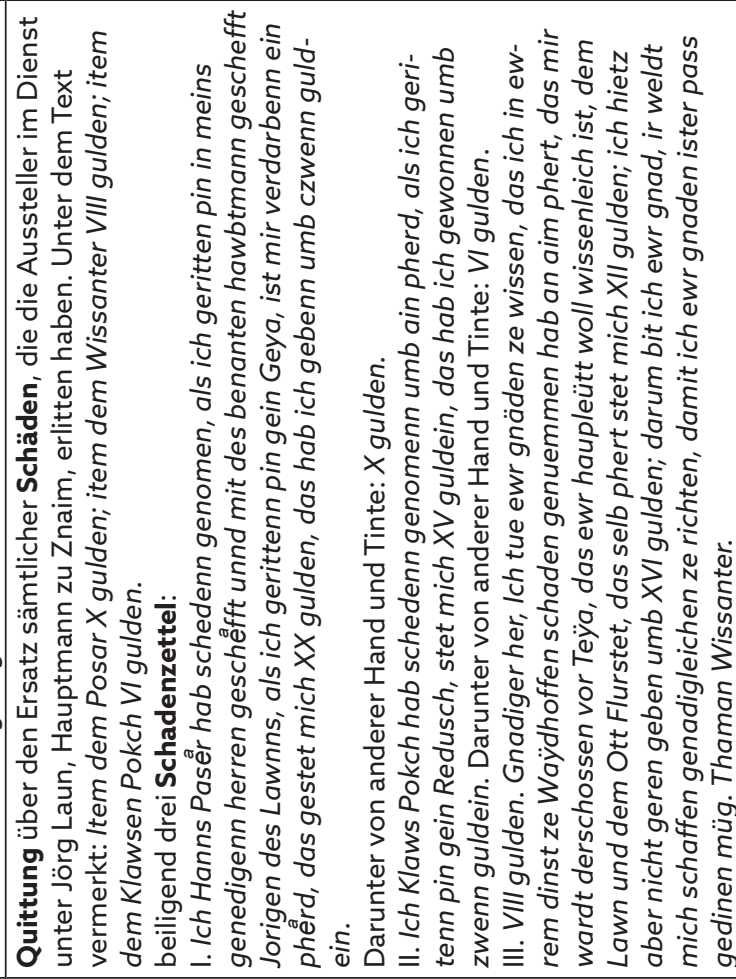 & 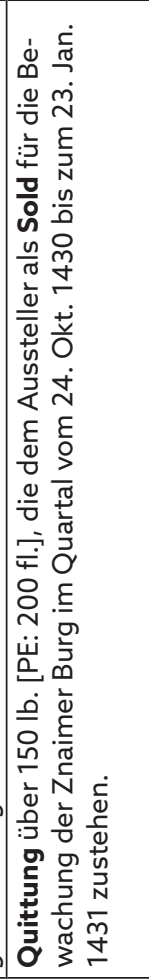 \\
\hline $\begin{array}{l}\frac{2}{0} \\
\frac{\omega}{0} \\
\text { जे }\end{array}$ & 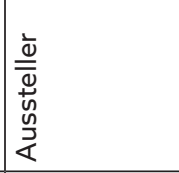 & 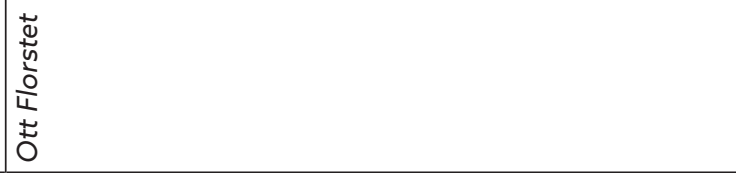 & 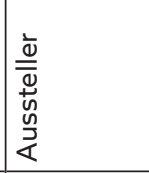 \\
\hline 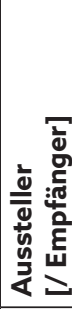 & 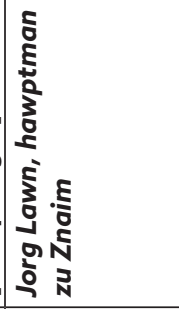 & 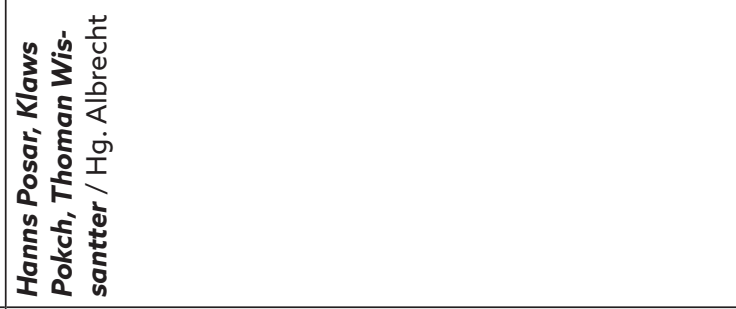 & 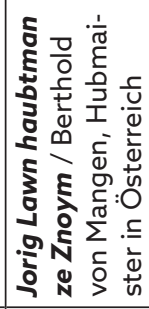 \\
\hline 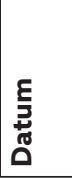 & 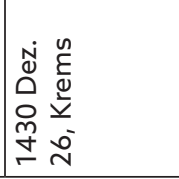 & 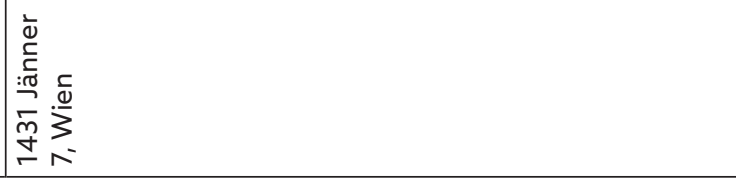 & 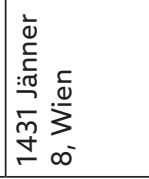 \\
\hline
\end{tabular}


Die Verschriftlichung des Kriegsalltages. Die Akten der während des Hussitenkrieges in Znaim ...

Abb. 1a-b: Schadlosbrief Herzog Albrechts V. vom 22. April 1422 für die in Iglau in seinem Dienst und Sold stehenden Söldner. Offener Brief auf Pergament aus der herzoglichen Kanzlei mit verso aufgedrücktem Sekretsiegel des Ausstellers; links durchgeschnitten (HHStA Wien, AUR 1422 IV 22).

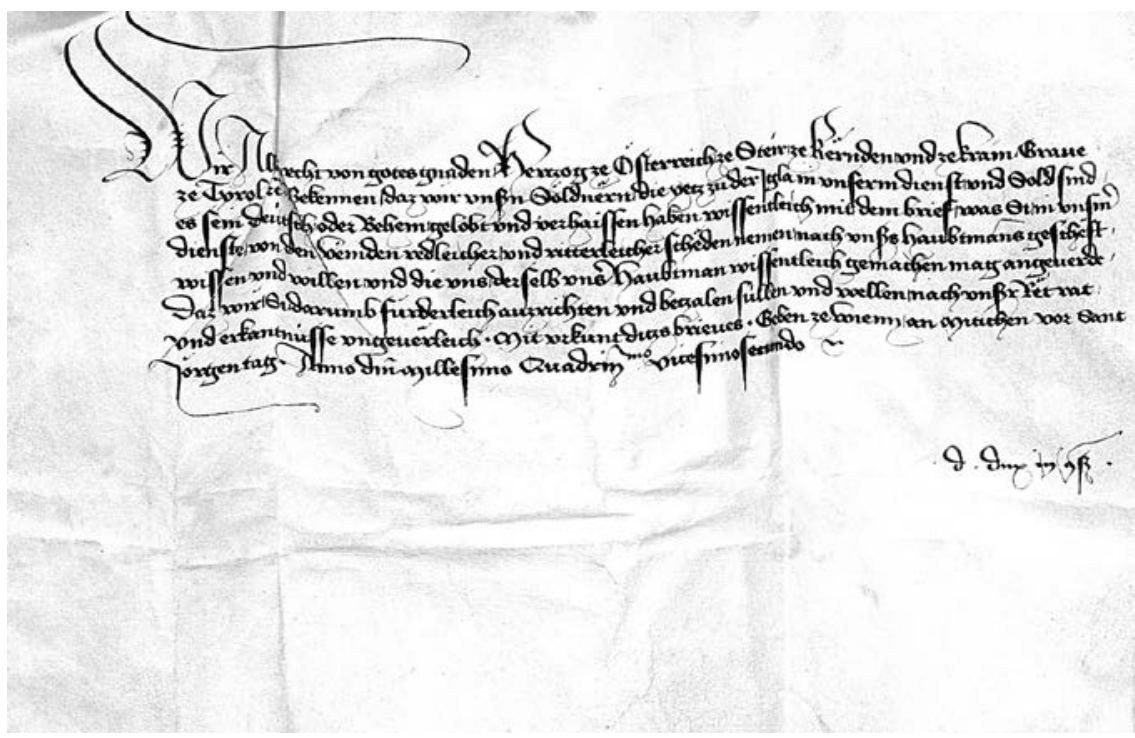

Abb. 1a

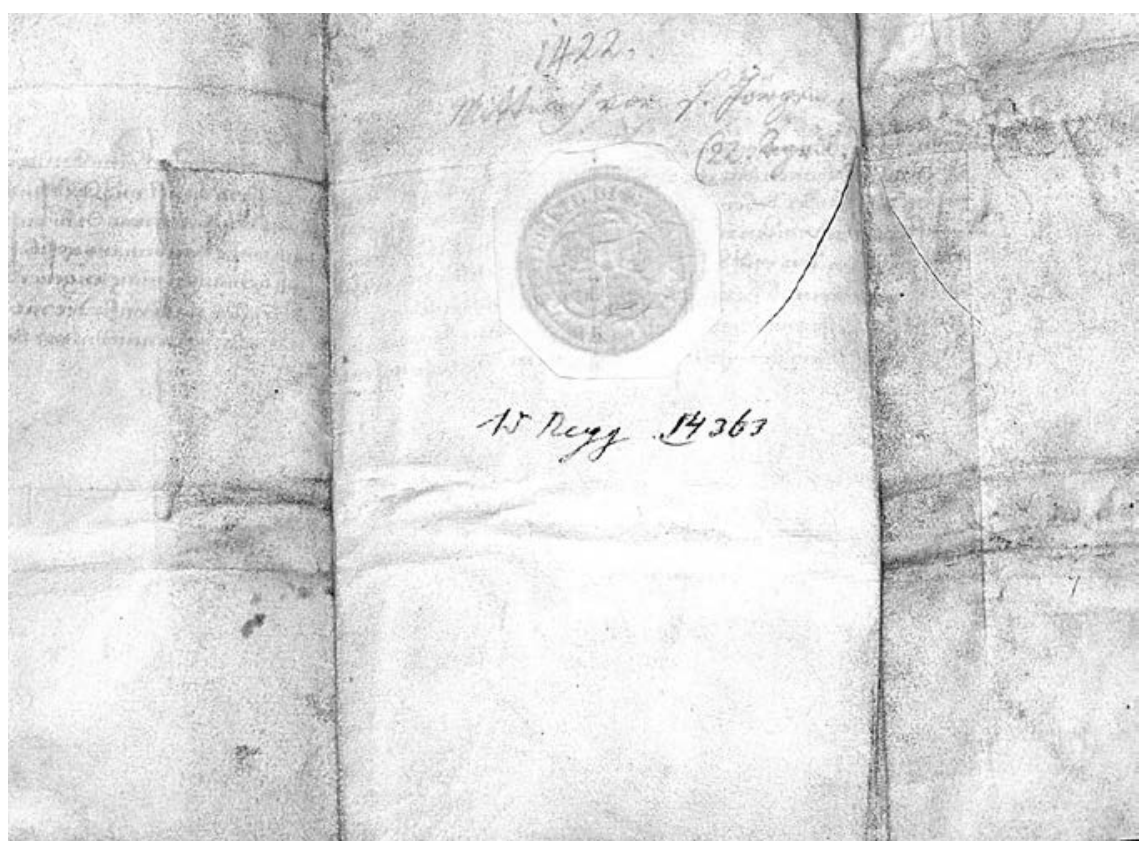

Abb. 1b 
Abb. 2 und 3: Quittungen der Hauptleute Düring von Hallwyl (8. April 1423) und Wilhelm Waldner (22. August 1423) über den Erhalt des Soldes für die in Iglau stationierten Söldner. Beide durch denselben Schreiber mundiert (HHStA Wien, AUR, 1422 IV 22).

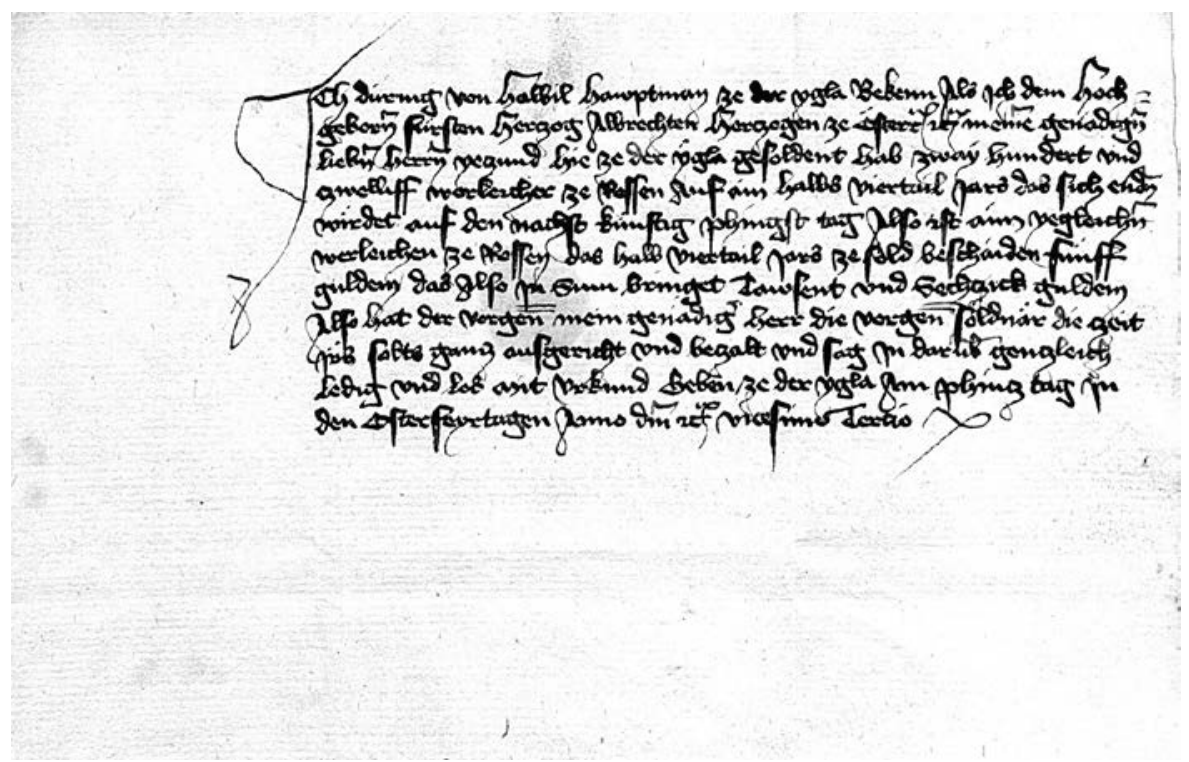

Abb. 2

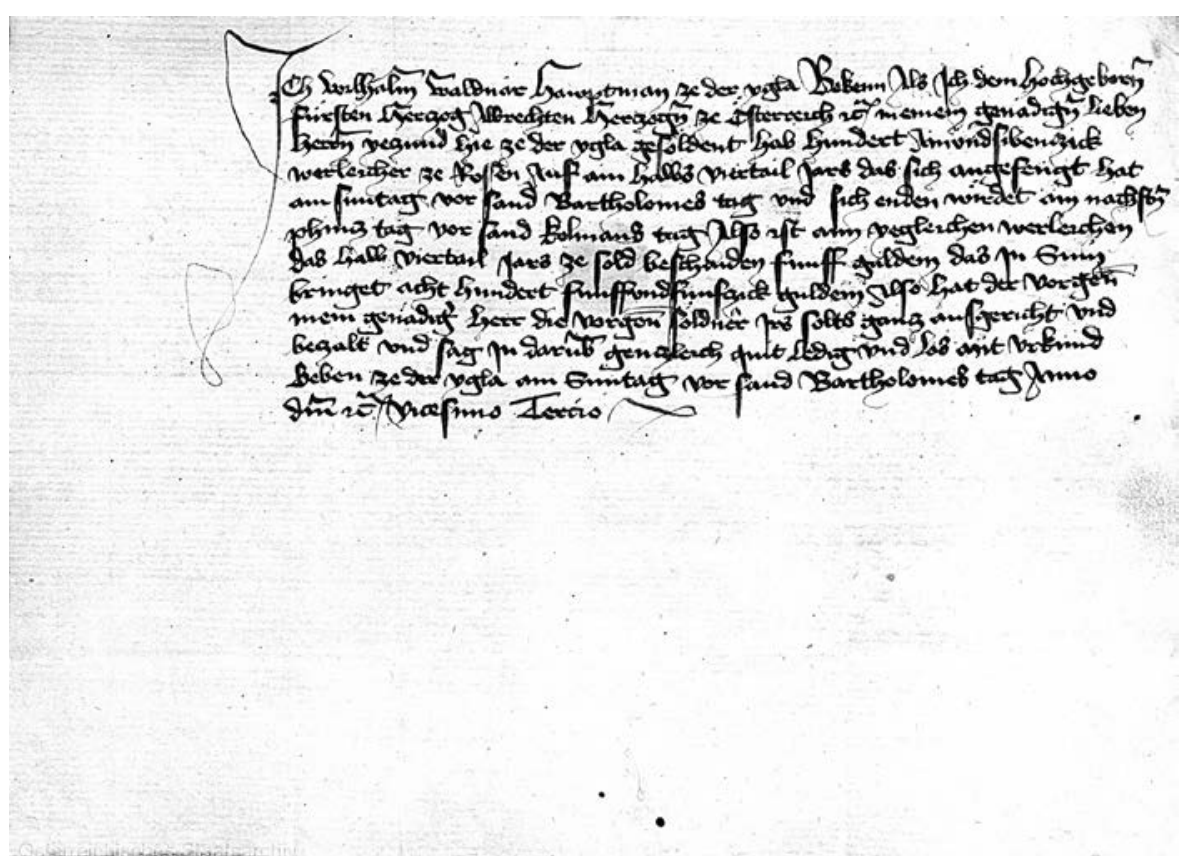

Abb. 3 


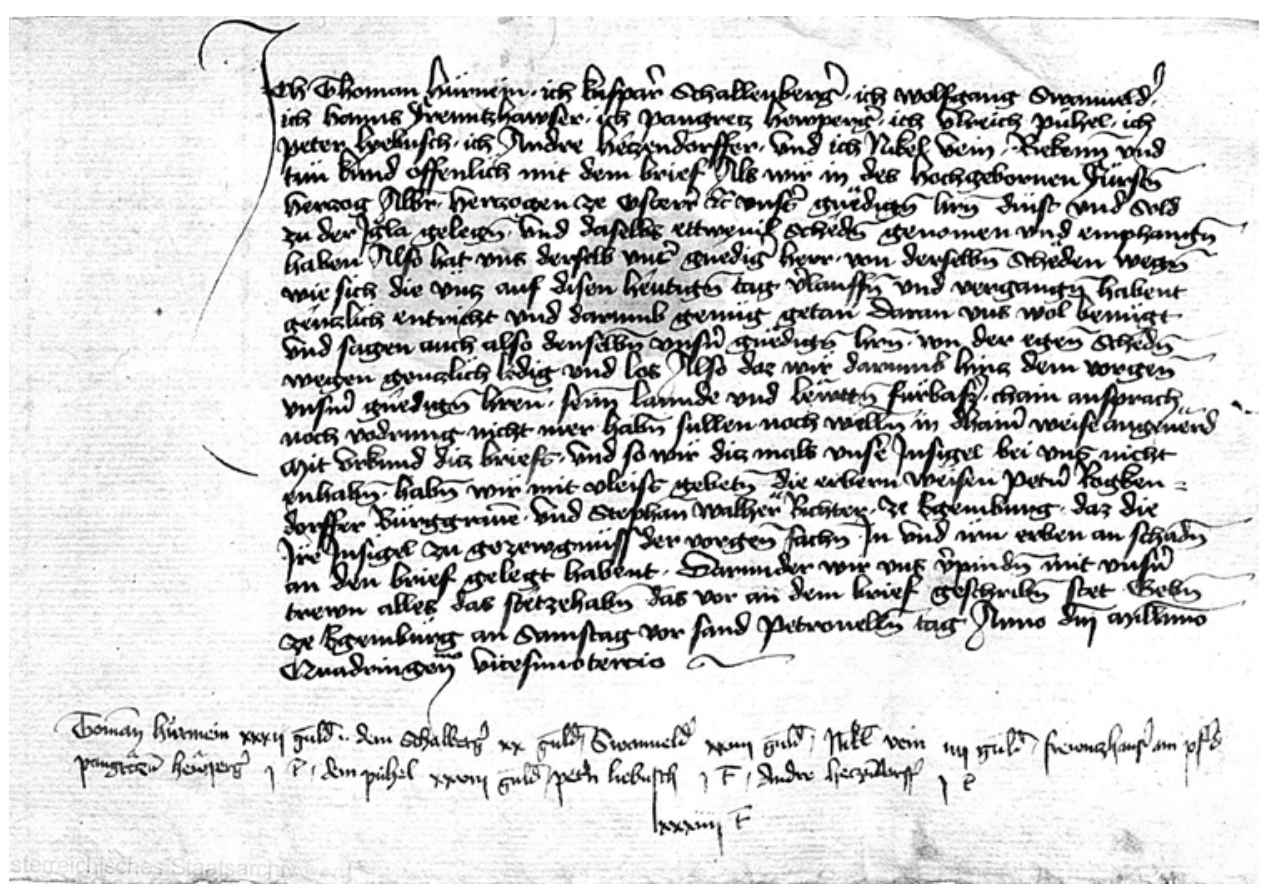

Abb. 4: Quittung Thoman Hürneins und weiterer acht in Iglau stationierter Söldner vom 29. Mai 1423 über den Ersatz aller Schäden, die sie im Dienst Herzog Albrechts in Iglau erlitten haben. Von anderer Hand unter dem Textspiegel eine Liste der Beträge, die die einzelnen Söldner jeweils erhielten (HHStA Wien, AUR, 1422 IV 22).

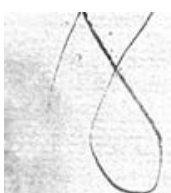

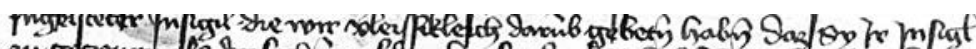

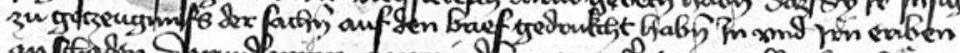

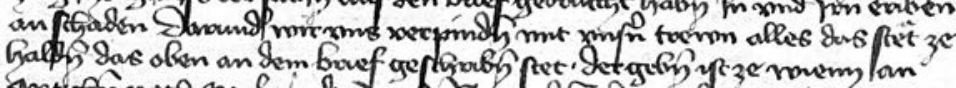

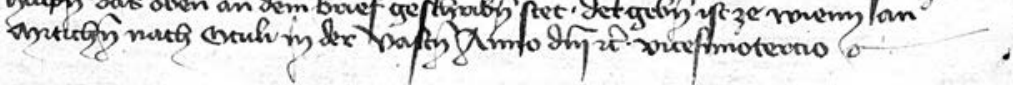

$$
\begin{aligned}
& \text { molfyrangs funcun pars ioj guls } \\
& \text { Eafpor seficyer od } 8
\end{aligned}
$$

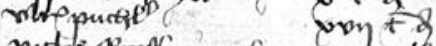

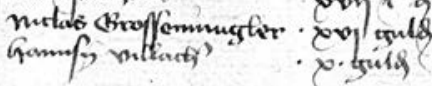

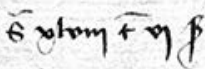

Abb. 5: Detail eines ähnlichen Nachtrags auf der Quittung Wolfgang Kurnbachs und weiterer vier Söldner vom 10. März 1423. Wie im Iglauer Material überwiegend der Fall wurde der Nachtrag hier durch den Urkundenschreiber mundiert und mittig unter dem Textspiegel platziert (HHStA Wien, AUR, 1422 IV 22). 
Thagation bot:

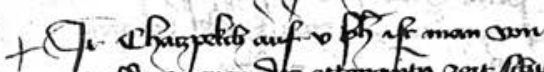

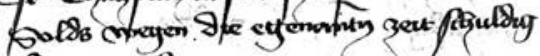
fym yulexy

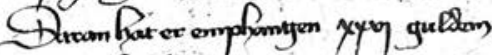

$\eta \gamma$ do

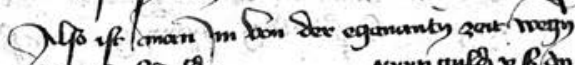

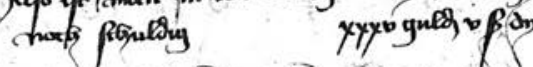

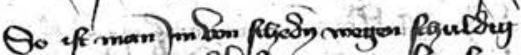

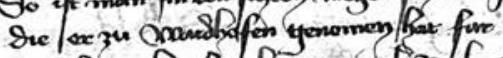

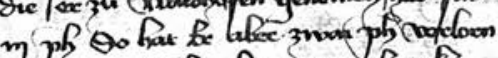

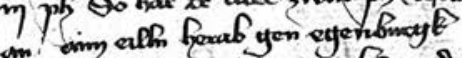
cond fure $y$ ponizine $y$ orembe condy

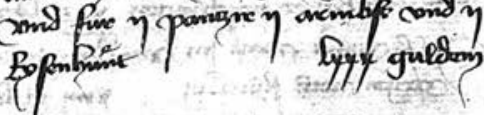

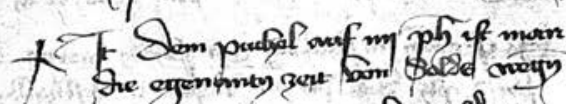
pisuleng I guelam

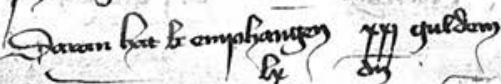
Tep const omam in fon dore extenumey

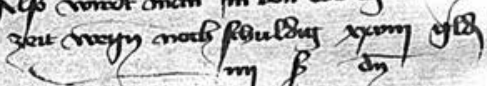

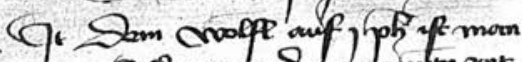

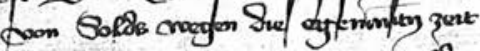

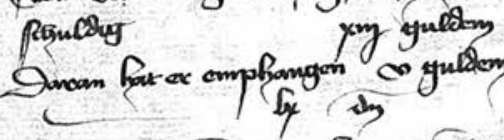

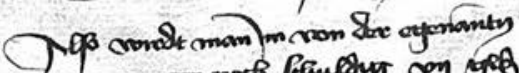

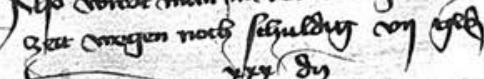
txy $8 y$

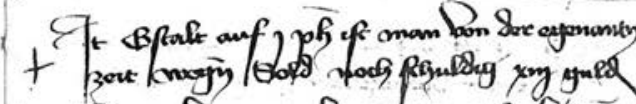

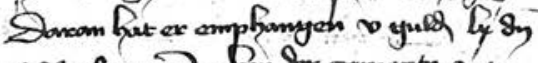

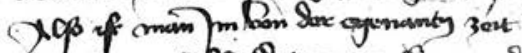

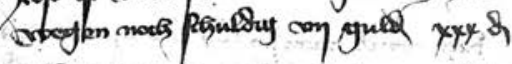

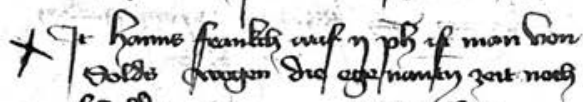
farmesy y y gueseon

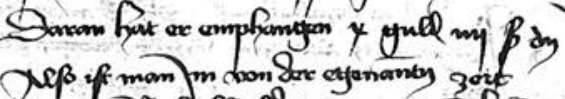

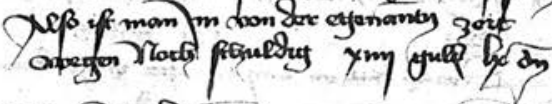

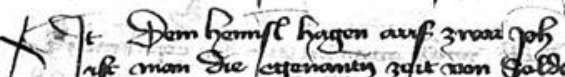

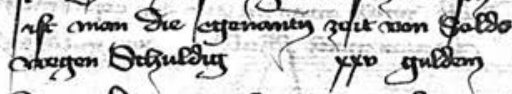

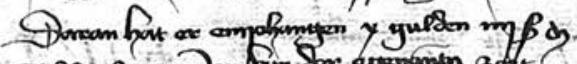

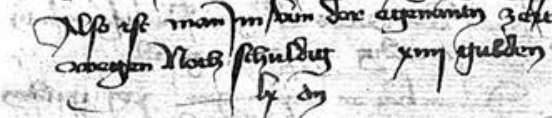

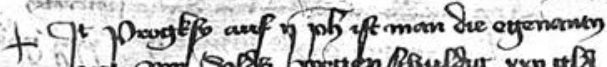

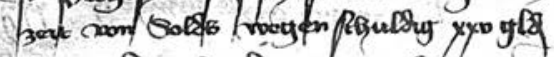

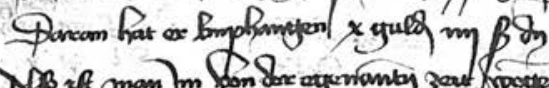

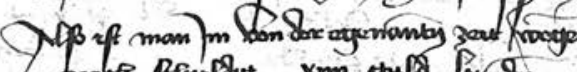

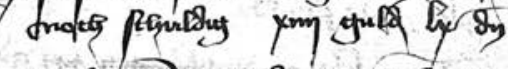

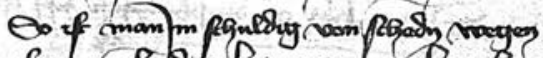

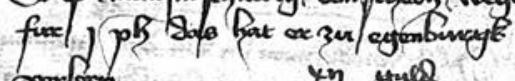
17) yull

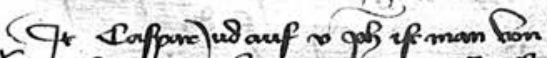

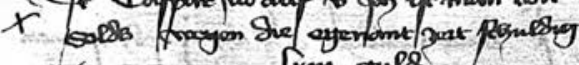
Gaveon Bat ax amp ly OUlS

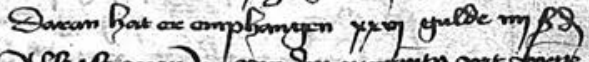

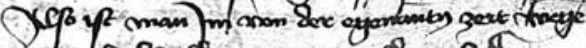

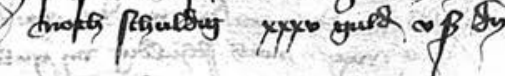

Abb. 6: Register der Schulden Herzog Albrechts seinen Söldnern in Znaim gegenüber vom 9. November 1429. Auf fol. 5v und 6r Beginn der Einträge über Chaczpekchens Rotte. Die Abbildung zeigt deutlich die einheitliche Anlage des Registers. Zu jedem Söldner gibt es mindestens drei Absätze (Gesamtsold, bereits ausbezahlter und noch ausstehender Betrag) und ggf. noch einen vierten Absatz, der erlittene Schäden verzeichnet (HHStA Wien, 


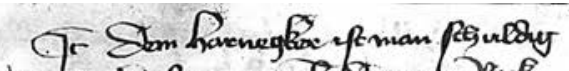

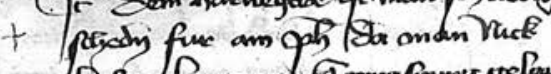

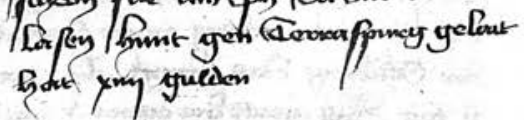

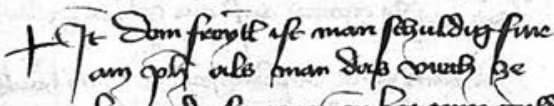

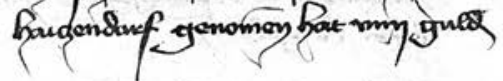

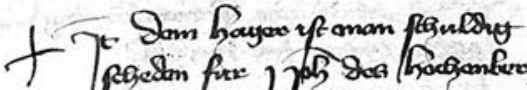

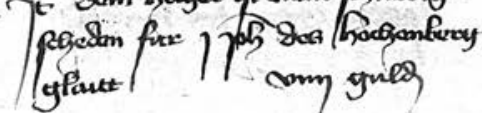

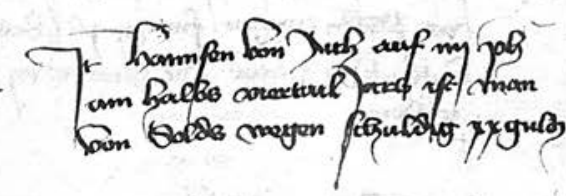

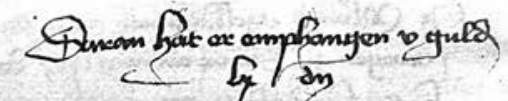
Xep conde mam morg pantesy yom guskem my of

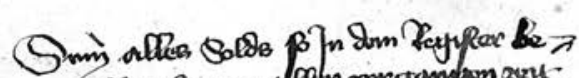

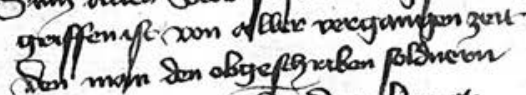

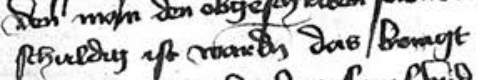

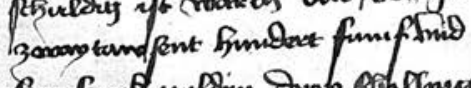

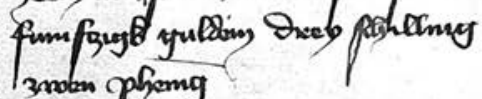

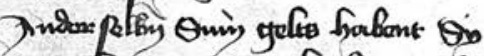

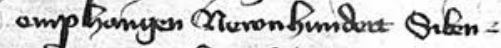

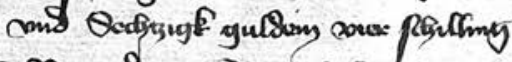

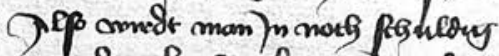

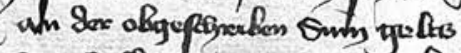

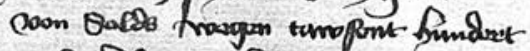

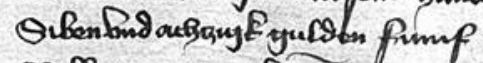
Peglling suren gofiomy ।

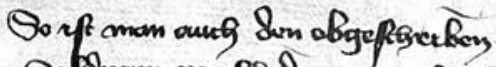

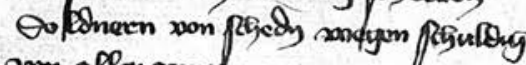

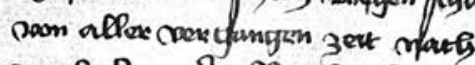

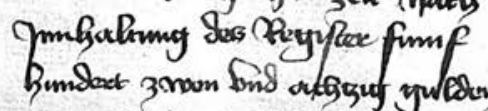

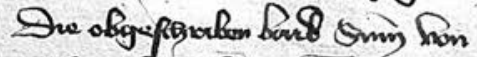

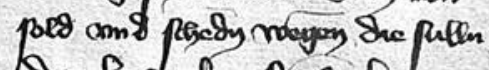
Dim Bornyaboren finc pos frekgog

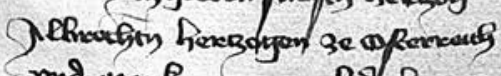

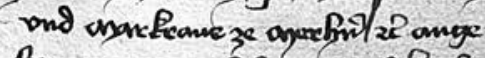

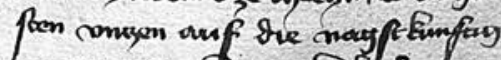

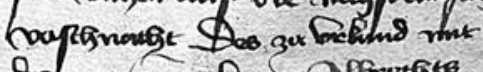
Qted eyenoming foresoy plebert.

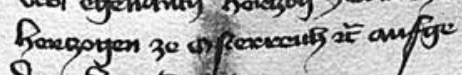
Souchem Qunte.

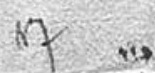

Abb. 7: Register der Schulden Herzog Albrechts seinen Söldnern in Znaim gegenüber vom

9. November 1429. Auf fol. $16 \mathrm{v}$ abschließend Einträge über Schadenersatz für einige Söldner, zu denen - im Unterschied zum Rest des Registers - kein ausstehender Sold verzeichnet wird. Auf fol. 17r folgen die Endsumme des gesamten Registers, die Verpflichtung Herzog Albrechts, die aufgeführten Schulden zu begleichen, die Corroboratio und das Signet des Ausstellers (HHStA Wien, AUR, 1429 XI 09). 


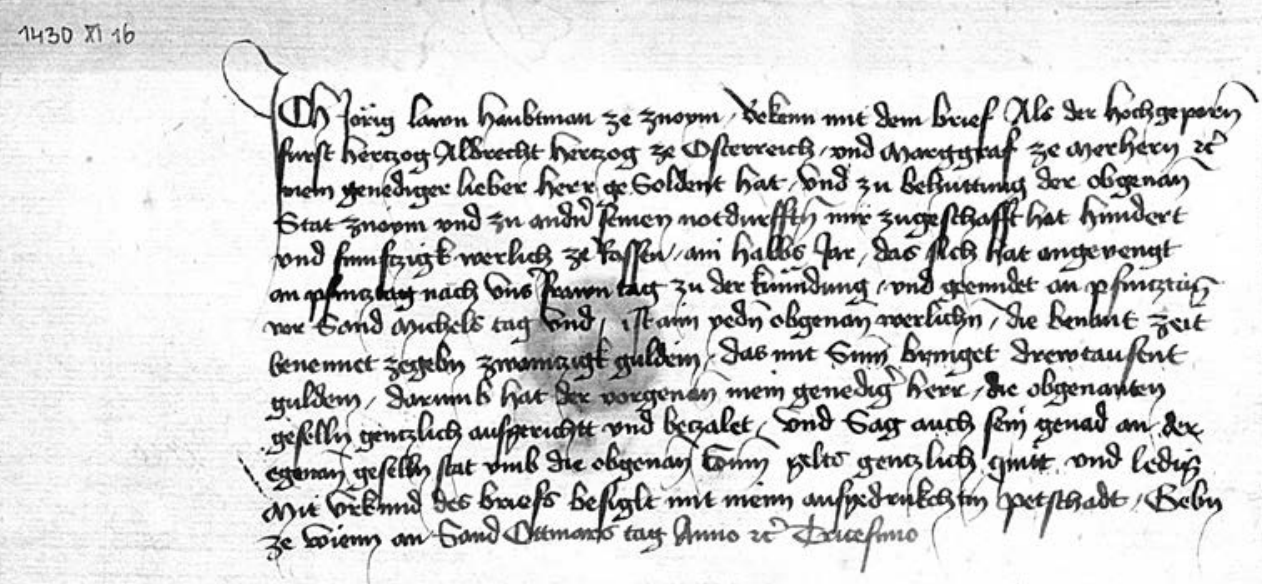

Abb. 8: Quittung des Hauptmanns Jörg Laun vom 16. November 1430 über den Erhalt des Soldes für die in Znaim stationierten Söldner (HHStA Wien, AUR, 1430 XI 16).

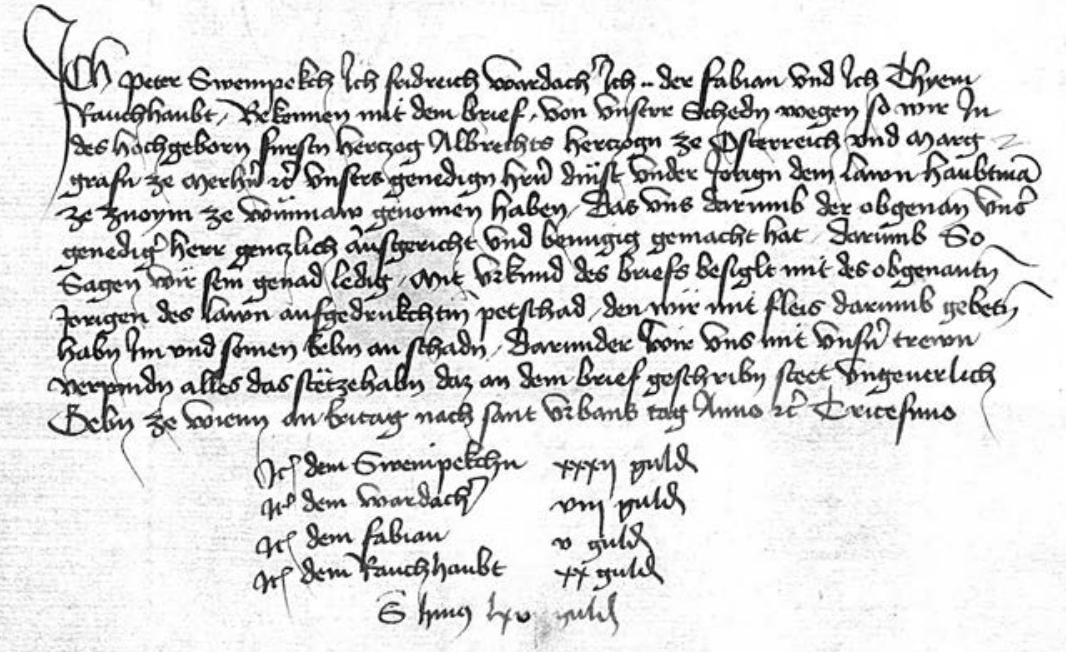

Abb. 9: Quittung Peter Sweinpekchs und weiterer drei Söldner vom 30. Mai 1430 über Ersatz aller Schäden, die sie im Dienst Herzog Albrechts in Znaim erlitten haben. Eine Liste der einzelnen Beträge mittig unter dem Textspiegel, so wie bei den Iglauer Quittungen aus dem Jahr 1423 üblich (HHStA Wien, AUR, 1430 V 30). 
Die Verschriftlichung des Kriegsalltages. Die Akten der während des Hussitenkrieges in Znaim ...

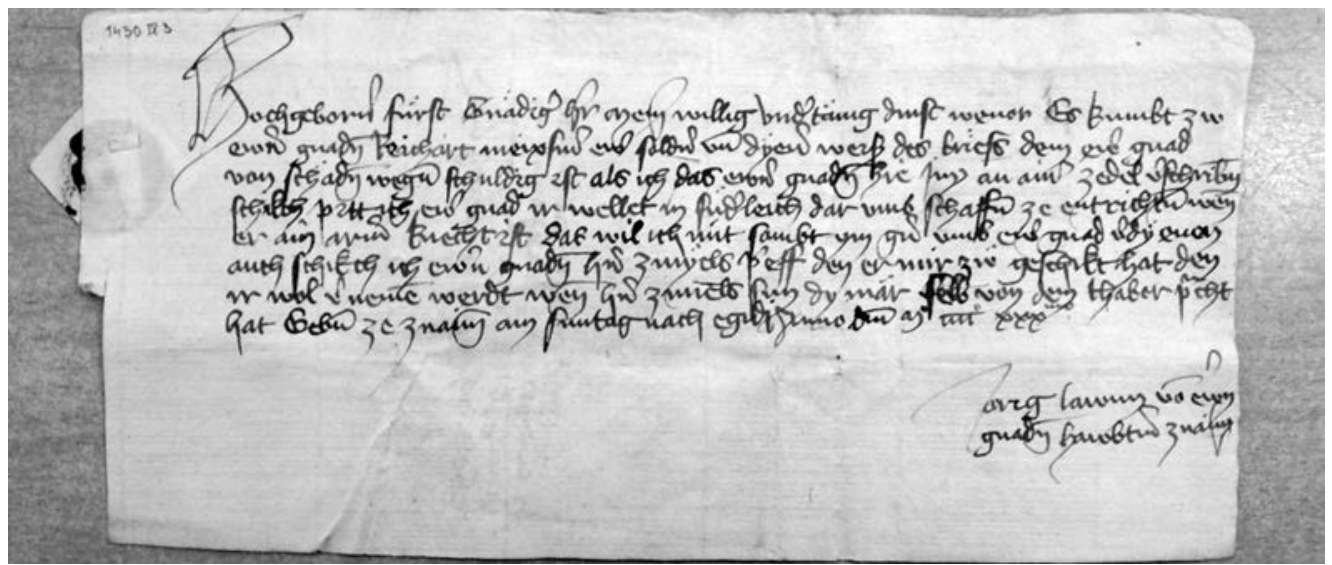

Abb. 10: Bittschrift des Hauptmanns Jörg Laun an Herzog Albrecht V. vom 3. September 1430 zugunsten Reichart Meixners. Der Herzog möge Meixner dessen Schäden, die auf dem beiliegenden Zettel näher beschrieben sind, gnädig erstatten. Der Zettel dürfte heute der Quittung Meixners (Abb. 11) beiliegen (HHStA Wien, AUR, 1430 X 18).

$1430 \pi 9$<smiles>C1CC12CC2</smiles>

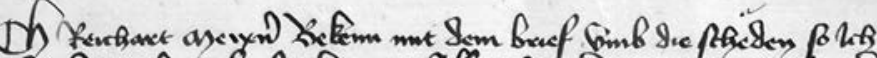

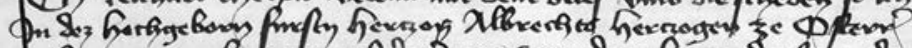

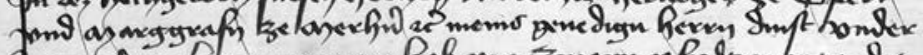

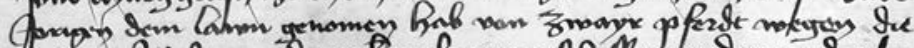

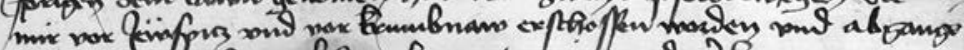

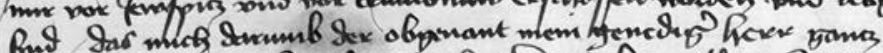

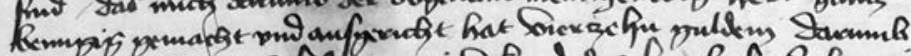

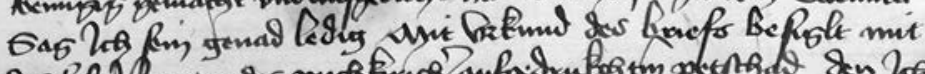

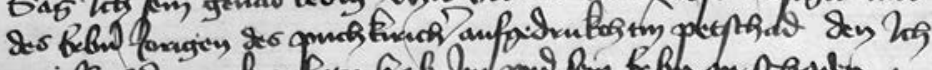

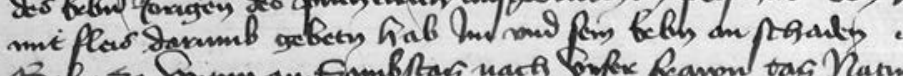

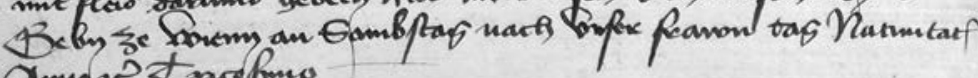
Oumane trarefure

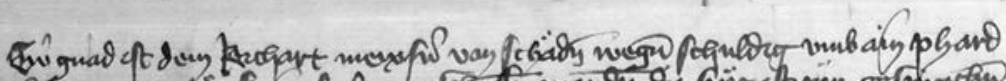

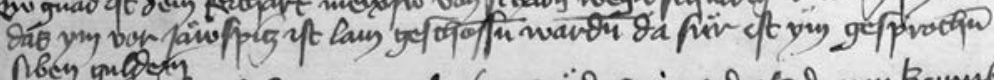

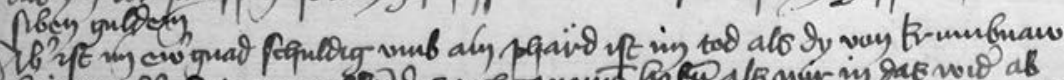

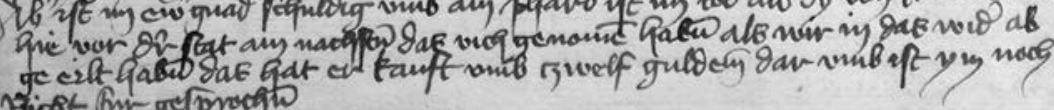
ringef pur geppropto

Abb. 11: Quittung Reichart Meixners vom 9. September 1430 über Ersatz aller Schäden, die er im Dienst Herzog Albrechts in Iglau erlitten hat. Auf die Quittung aufgeklebt der Schadenzettel, der ursprünglich der Bittschrift Jörg Launs vom 3. September 1430 (Abb. 10) beigelegt gewesen sei dürfte. Der Schadenzettel wurde durch den Schreiber der Bittschrift mundiert (HHStA Wien, AUR, $1430 \times 18$ ). 


\section{Zpísemnění válečné každodennosti. Písemnosti rakouských žoldnéřů, pưsobících ve Znojmě a Jihlavě za husitské revoluce}

Studie se zabývá písemnostmi vzniklými v prostředí pozdně středověkých žoldnéřských vojsk, a to na základě dvou pramenných sond: ucelených souborů písemností žoldnéřských posádek vévody Albrechta V. v moravských městech Jihlavě (v letech 1422/1423) a Znojmě (1429-1431) za husitské revoluce. Oba pramenné soubory jsou již dlouho známy a z větší části byly již zpř́ístupněny formou regestů, v některých př́ípadech dokonce i v plnotextové edici, ale přesto dosud nebyly soustavněji analyzovány. Studie přináší v příloze úplný soupis a stručné regesty těchto písemností včetně těch, které dosud nebyly publikovány. Vlastní jádro studie tvoří představení těchto písemností z diplomatického hlediska. Autor rozlišuje jednotlivé typy písemností a popisuje jejich formulář: záškodní listy vévody pro hejtmany žoldnéřských posádek, kvitance hejtmanů za obdržený žold a kvitance jednotlivých žoldnéřů za náhradu škody, cedule přinášející soupis utržených škod, supliky vévodovi požadující jejich náhradu, zvláštní registr dlužného žoldu a náhrady škod ze Znojma (1429). Dále se autor zamýšlí nad okolnostmi vzniku jednotlivých typů písemností, které byly vyhotoveny částečně v Jihlavě a Znojmě, částečně na vévodském dvoře ve Vídni, kde probíhala jednání o uznané výši škody. V poslední části studie se autor zaměřuje na finanční aspekty žoldnéřského vojenství a vyhodnocuje zkoumané prameny v kontextu financí vévody Albrechta V., přičemž potvrzuje extrémní finanční náročnost Albrechtovy vlády na husitské Moravě. Zcela na závěr pak autor poukazuje na některé další možnosti využití zkoumaných pramenů pro studium pozdně středověkého vojenství a pro poznání dějin husitské revoluce na Moravě. 
